CHECKLIST

\title{
A checklist of plant pathogenic fungi and Oomycota in Sri Lanka
}

\author{
N.K.B. Adikaram ${ }^{1, *}$ and D.M.D. Yakandawala ${ }^{2}$ \\ ${ }^{1}$ National Institute of Fundamental Studies, Hantana Road, Kandy 20000, Sri Lanka. \\ ${ }^{2}$ Department of Botany, University of Peradeniya, Peradeniya 20400, Sri Lanka.
}

Received: 02/06/2019; Accepted: 15/02/2020

\begin{abstract}
Sri Lanka is blessed with a rich ecosystem diversity, however, only a small fraction of the diverse flora and fauna in the country is known. Only around 3,000 species of fungi are currently known out of the estimated number of 25,000 species of native fungal flora of Sri Lanka. This includes the 2,000 species, belonging to 640 genera, recorded prior to 1950 . The fungi studied, prior to 1950 , have been well documented, as journal publications, checklists or books. In contrast, the information on Sri Lankan fungal flora, available especially after 1950, is scattered. The present 'Checklist of Plant Pathogenic Fungi in Sri Lanka' is intended to bring together all species of plant pathogenic fungi and Oomycota recorded in the country after late nineteen forties. The checklist consists of 404 species of plant pathogenic fungi and Oomycota, belonging to 110 genera and 230 species, associated with diseases of horticultural, agricultural and plantation crops and their harvested produce and forests plants in Sri Lanka.
\end{abstract}

Keywords: Fungi, Oomycota, Plant pathogenic fungi.

\section{INTRODUCTION}

Sri Lanka is an island in the Indian ocean located at the southern point of the Indian sub-continent, between $5^{\circ} 54^{\prime}$ and $9^{\circ} 52^{\prime}$ North Latitude and 79 $39^{\prime}$ and $81^{\circ}$ 53' East Longitude with a land area of $6,570,134$ ha. Topographically, the island comprises of central mountains with an elevation of up to $2500 \mathrm{~m}$, surrounded by the lowlands. The overall climate of the Island could be considered as tropical, mainly due to the differences in rainfall and elevation. A variation in the weather is observed across the island with a very distinctive dry and wet seasons. The rainfall shows a seasonal variation and country depends on the southwest and northeast monsoons and on convectional and cyclonic effects. The average temperature ranges between $28-32^{\circ} \mathrm{C}$.

Despite its small size, Sri Lanka is blessed with a rich ecosystem diversity owing to its topographic and climatic heterogeneity as well as its coastal influence. Higher plants, vertebrates and few other selected groups have been studied in detail. Most other groups remain to be explored. The native fungal flora in Sri Lanka has been conservatively estimated to be around 25,000 species (Adikaram, 2004), based on the fungus to higher plant species ratio of $6: 1$ (Hawksworth, 1991).

The total number of species known to date could be around 3,000, including those that were recorded prior to 1950 by Berkeley and Broome (1871), Petch (1906, 1910, 1923) and Petch and Bisby (1950) which amount to about 640 genera and 2,000 species. It is quite unlikely that ancient Ceylonese people lacked even an awareness, if not an understanding, of the organisms that the Western world has described as 'fungi'. It is possible that they may have used their own terminology to describe, mushrooms and toadstools for example, that would have been common in their surroundings and visible to the naked eye. However, the earliest records of fungi, by species names and drawings in Ceylon, were Peziza ceylonsche and Peziza lembosa in 1783 by Houttuyn.

The fungi studied, prior to 1950, in Ceylon have been well documented and mostly compiled in to checklists or books. In contrast, the information on Sri Lankan fungal flora, recorded after 1950, is scattered in Scientific Journals, Proceedings of Scientific Meetings and Annual Reports of Research Institutes (Karunarathna et al. 2012). A reasonable number of fungi, though known, do not appear to have been published.

Except for a few major plantation crops such as tea and rubber, understanding of the fungi infecting agricultural, horticultural, ornamental or forest plants etc. is incomplete. 'Diseases of cultivated plants - their Diagnosis and Treatment in Ceylon' by D.V.W. Abeygunawardena in 1969 was a comprehensive guide to Plant Pathology as a subject as well as to the diseases in plants cultivated in Ceylon. The book is useful even in today's context of Plant Pathology, 50 years after the book was first written. 'A handbook to the fungi parasitic on the plants of Sri Lanka' (1979) that carries morphological illustrations of numerous genera of parasitic fungi, is mainly a guide to identification of fungi causing numerous plant diseases and disease diagnosis.

The present 'Checklist of Plant Pathogenic Fungi' is intended to bring together all species of plant pathogenic fungi and Oomycota recorded in the country after late nineteen forties. Plant pathogenic fungi recorded in Sri Lanka were compiled using literature published in the country. The checklist consists of 404 entries of fungi and Oomycota, belonging to 110 genera and 230 species that have been recorded from agricultural, horticultural, plantation, forest and ornamental plants and freshly harvested produce in the country after late nineteen fifties. 
The checklist provides, for every fungal species the common and the species name of the host plant/s, the name of the disease in most cases, and the source of publication or the communication. The name of the fungus given in the checklist is the same name as it appeared in the publication. In a separate column, the current name of each species is also given.

For easy reference the names of fungi are given in alphabetical order. Oomycota, belonging to the Kingdom Chromista, are listed separately from fungi in the checklist. Some of the fungi in the checklist may have also been recorded in publications prior to 1950's.

Among the genera in the Checklist, Colletotrichum, causing anthracnose disease (Figure 1), was the most recorded plant pathogen during the period. Colletotrichum thrives under the warm and humid conditions prevailing in many parts of the country. Colletotrichum infections are most common in edible fruit species where infections usually occur in the field at early stages of fruit development. The fungus remains quiescent until the fruit undergo ripening to develop progressive anthracnose symptoms
(Adikaram et al. 1983). The genus has also undergone intense molecular revision recently increasing its species in great numbers and attention as a pathogen in a wider range of plants (Baroncellil et al. 2016). Powdery mildews are most common in many parts of the country, again due to prevailing favorable weather conditions. Botrytis cinerea infections were found only in the coldest, hilly area in the Central Province. Penicillium diseases were found under moderate temperatures.

The highest number of fungi have been recorded from vegetable diseases followed by fruit and plantation crops respectively and the total number of fungi from vegetable, fruit and plantation crops added together amounts to $69 \%$ of the total number in the checklist.

This data provided in the Checklist will be useful in the compilation of fungal biodiversity of Sri Lanka. The checklist will, not by any means, be a conclusive list and new records will continue to be added regularly in the future.
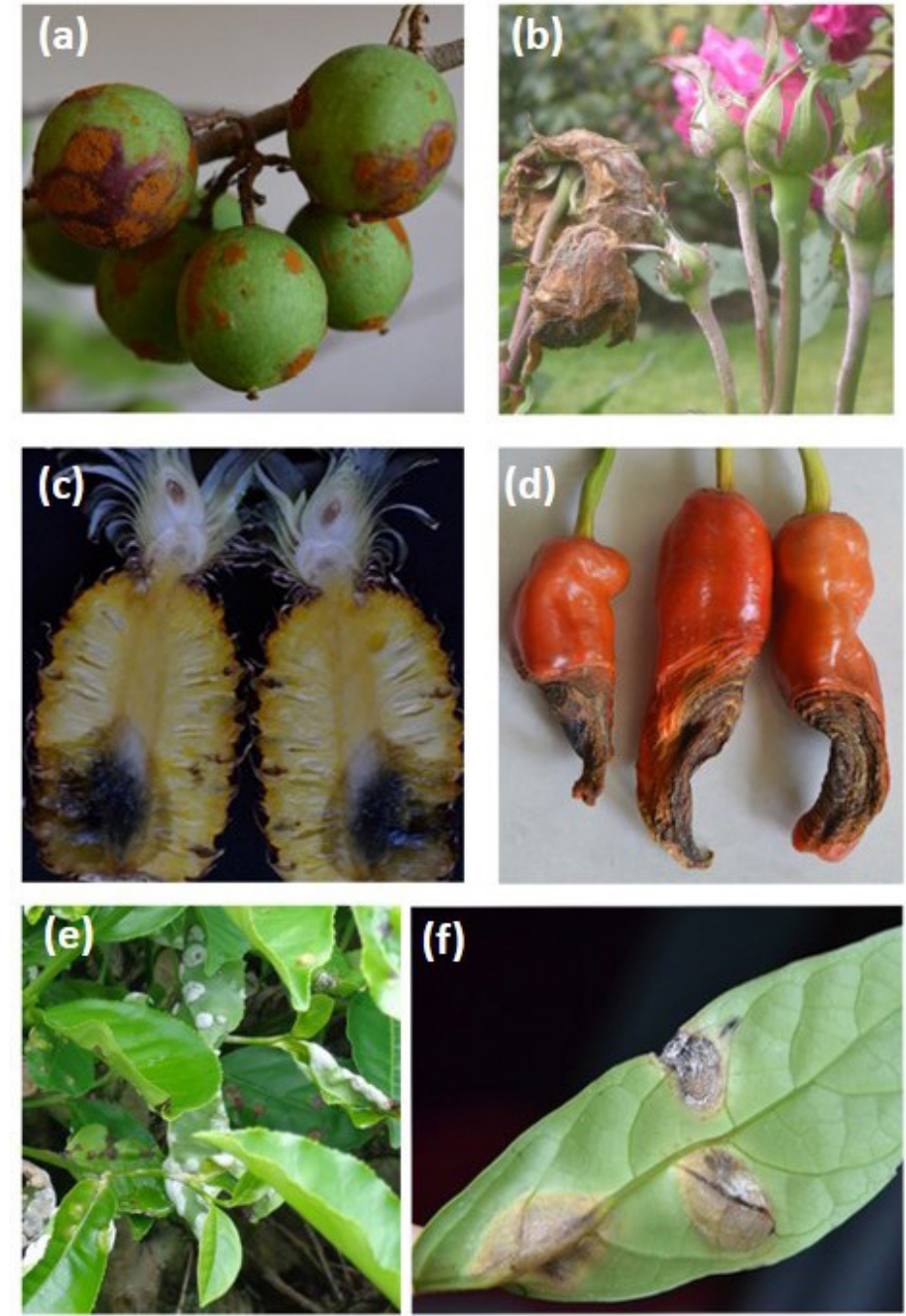

Figure 1: (a) Rust disease in Uguressa (S) (Flacourtia indica (Burm.f.) Merr.) fruit caused by Kuehneola flacourtiae (Mundk. \& Thirum.) Thirum., (b) Grey mould (Botrytis cinerea Pers.) infection (Left) of rose (Rosa chinensis var. Ramblers) and powdery mildew (Podosphaera pannosa (Wallr.) de Bary) (Right) of bud and stalk, (c) Water blister of pineapple fruit caused by Ceratocystis paradoxa (Dade) C. Moreau., (d) Anthracnose disease by Colletotrichum truncatum (Schwein.) Andrus \& W.D. Moore in Capsicum annuum L., (e) Blister blight in tea caused by Exobasidium vexans Massee, and (f) Aecia stage of leaf rust in Clerodendrum wallichii Merr. 
Table 1: Checklist of Plant Pathogenic fungi and Oomycota in Sri Lanka.

\begin{tabular}{|c|c|c|c|c|}
\hline & Species reported & Current name & Host plant and disease & Reference/s \\
\hline 1. & $\begin{array}{l}\text { Alternaria alternata } \\
\text { (Fr.) Keissl. }\end{array}$ & $\begin{array}{l}\text { Alternaria alternata (Fr.) } \\
\text { Keissl. }\end{array}$ & $\begin{array}{l}\text { Tomato (Solanum } \\
\text { lycopersicon Mill.) } \\
\text { Alternaria rot }\end{array}$ & Adikaram (1986/87) \\
\hline 2. & $\begin{array}{l}\text { Alternaria brassicae } \\
\text { (Berk.) Sacc. }\end{array}$ & $\begin{array}{l}\text { Alternaria brassicae } \\
\text { (Berk.) Sacc. }\end{array}$ & $\begin{array}{l}\text { Brassica species. } \\
\text { Alternaria spot }\end{array}$ & Bond (1947) \\
\hline 3. & $\begin{array}{l}\text { Alternaria brassicae } \\
\text { (Berk.) Sacc. }\end{array}$ & $\begin{array}{l}\text { Alternaria brassicae } \\
\text { (Berk.) Sacc. }\end{array}$ & $\begin{array}{l}\text { Raddish (Ruphanus sativa } \\
\text { L.) }\end{array}$ & $\begin{array}{l}\text { Jeyanandarajah and } \\
\text { Liyanage (1995a) }\end{array}$ \\
\hline 4. & $\begin{array}{l}\text { Alternaria brassicicola } \\
\text { (Schwein.) Wiltshire }\end{array}$ & $\begin{array}{l}\text { Alternaria brassicicola } \\
\text { (Schwein.) Wiltshire }\end{array}$ & $\begin{array}{l}\text { Cabbage (Brassica oleracea } \\
\text { var. capitata). Alternaria rot }\end{array}$ & $\begin{array}{l}\text { Habarakada and } \\
\text { Seneviratne (1987) }\end{array}$ \\
\hline 5. & $\begin{array}{l}\text { Alternaria brassicicola } \\
\text { (Schwein.) Wiltshire }\end{array}$ & $\begin{array}{l}\text { Alternaria brassicicola } \\
\text { (Schwein.) Wiltshire }\end{array}$ & $\begin{array}{l}\text { Cauliflower (Brassica } \\
\text { oleracea var. gongyloides) } \\
\text { Leaf spot }\end{array}$ & $\begin{array}{l}\text { Habarakada and } \\
\text { Seneviratne (1987) }\end{array}$ \\
\hline 6. & $\begin{array}{l}\text { Alternaria brassicicola } \\
\text { (Schwein.) Wiltshire }\end{array}$ & $\begin{array}{l}\text { Alternaria brassicicola } \\
\text { (Schwein.) Wiltshire }\end{array}$ & $\begin{array}{l}\text { Knol-khol (S) (Brassica } \\
\text { oleracea var. botrytis) Leaf } \\
\text { spot and blight }\end{array}$ & $\begin{array}{l}\text { Habarakada and } \\
\text { Seneviratne (1987) }\end{array}$ \\
\hline 7. & $\begin{array}{l}\text { Alternaria brassicicola } \\
\text { (Schwein.) Wiltshire }\end{array}$ & $\begin{array}{l}\text { Alternaria brassicicola } \\
\text { (Schwein.) Wiltshire }\end{array}$ & $\begin{array}{l}\text { Raddish (Ruphanus sativa } \\
\text { L.) } \\
\text { Alternaria leaf spot }\end{array}$ & $\begin{array}{l}\text { Jeyanandarajah and } \\
\text { Liyanage }(1995 a)\end{array}$ \\
\hline 8. & $\begin{array}{l}\text { Alternaria dauci } \\
\text { (Kühn) J.W. Groves \& } \\
\text { Skolko }\end{array}$ & $\begin{array}{l}\text { Alternaria dauci (J.G. } \\
\text { Kühn) J.W. Groves \& } \\
\text { Skolko }\end{array}$ & $\begin{array}{l}\text { Carrot (Daucus carota L.) } \\
\text { Leaf blight }\end{array}$ & $\begin{array}{l}\text { Abeygunawardhane } \\
\text { (1969) }\end{array}$ \\
\hline 9. & $\begin{array}{l}\text { Alternaria oleracea } \\
\text { Milb. }\end{array}$ & $\begin{array}{l}\text { Alternaria brassicicola } \\
\text { (Schwein.) Wiltshire. }\end{array}$ & $\begin{array}{l}\text { Cabbage (Brassica oleracea } \\
\text { L.) Leaf spot }\end{array}$ & Bond (1947) \\
\hline 10. & $\begin{array}{l}\text { Alternaria oleracea } \\
\text { Milb. }\end{array}$ & $\begin{array}{l}\text { Alternaria brassicicola } \\
\text { (Schwein.) Wiltshire. }\end{array}$ & $\begin{array}{l}\text { Kohl-rabi (Brassica } \\
\text { oleracea var. caulorapa } \\
\text { DC.). Leaf spot }\end{array}$ & Bond (1947) \\
\hline 11. & $\begin{array}{l}\text { Alternaria padwickii } \\
\text { (Ganguly) M.B. Ellis }\end{array}$ & $\begin{array}{l}\text { Alternaria padwickii } \\
\text { (Ganguly) M.B. Ellis }\end{array}$ & $\begin{array}{l}\text { Rice (Oryza sativa L.) } \\
\text { Stackburn }\end{array}$ & $\begin{array}{l}\text { Seneviratne and } \\
\text { Jeyanandarajah (2004) }\end{array}$ \\
\hline 12. & $\begin{array}{l}\text { Alternaria porri (Ellis) } \\
\text { Ciffer }\end{array}$ & $\begin{array}{l}\text { Alternaria porri (Ellis) } \\
\text { Ciffer }\end{array}$ & $\begin{array}{l}\text { Onion (small) (Allium cepa } \\
\text { var. aggregatum) G. Don } \\
\text { Purple blotch disease }\end{array}$ & $\begin{array}{l}\text { Wickramaarachchi et al. } \\
\text { (2004); Araskesasry et } \\
\text { al. (2016) }\end{array}$ \\
\hline 13. & $\begin{array}{l}\text { Alternaria porri (Ellis) } \\
\text { Ciffer }\end{array}$ & $\begin{array}{l}\text { Alternaria porri (Ellis) } \\
\text { Ciffer }\end{array}$ & $\begin{array}{l}\text { Red onion (Allium } \\
\text { ascalonicum L.) } \\
\text { Purple blotch disease }\end{array}$ & $\begin{array}{l}\text { Ravindranatha and } \\
\text { Kugathasan (1990) }\end{array}$ \\
\hline 14. & $\begin{array}{l}\text { Alternaria solani (Ellis } \\
\text { \& G. Martin) L.R. } \\
\text { Jones }\end{array}$ & Alternaria solani Sorauer & $\begin{array}{l}\text { Tomato (Solanum } \\
\text { lycopersicon Mill.) Early } \\
\text { blight }\end{array}$ & $\begin{array}{l}\text { Wickramaarachchi } \\
(2005)\end{array}$ \\
\hline 15. & Alternaria tenuis Nees & $\begin{array}{l}\text { Alternaria alternata (Fr.) } \\
\text { Keissl. }\end{array}$ & $\begin{array}{l}\text { Raddish (Ruphanus sativa } \\
\text { L.) }\end{array}$ & $\begin{array}{l}\text { Jeyanandarajah and } \\
\text { Liyanage (1995a) }\end{array}$ \\
\hline 16. & $\begin{array}{l}\text { Ampelomyces } \\
\text { quisqualis Ces. }\end{array}$ & $\begin{array}{l}\text { Ampelomyces quisqualis } \\
\text { Ces. }\end{array}$ & $\begin{array}{l}\text { Hyperparasite of Oidium } \\
\text { mangiferae on Pedilanthus } \\
\text { tithymaloides (L.) Poit. } \\
\text { Current name:Euphorbia } \\
\text { tithymaloides L. }\end{array}$ & Adikaram et al. (2002) \\
\hline 17. & $\begin{array}{l}\text { Anthostomella } \\
\text { destruens Shear }\end{array}$ & $\begin{array}{l}\text { Sordaria destruens } \\
\text { (Shear) Hawker }\end{array}$ & $\begin{array}{l}\text { Aswenna (S), (Alysicarpus } \\
\text { vaginalis (L.) DC.) }\end{array}$ & $\begin{array}{l}\text { Fernando and } \\
\text { Abeywickrama (1996) }\end{array}$ \\
\hline 18. & $\begin{array}{l}\text { Anthostomella } \\
\text { destruens Shear }\end{array}$ & $\begin{array}{l}\text { Sordaria destruens } \\
\text { (Shear) Hawker }\end{array}$ & $\begin{array}{l}\text { Neeramulliya (S) } \\
\text { (Asteracantha longifolia } \\
\text { Nees.). Current name: } \\
\text { Hygrophila auriculata } \\
\text { (Schumach.) Heine }\end{array}$ & $\begin{array}{l}\text { Fernando and } \\
\text { Abeywickrama (1996) }\end{array}$ \\
\hline
\end{tabular}




\begin{tabular}{|c|c|c|c|c|}
\hline 19. & $\begin{array}{l}\text { Armillaria fuscipes } \\
\text { Petch }\end{array}$ & Armillaria fuscipes Petch & $\begin{array}{l}\text { Tea (Camellia sinensis (L.) } \\
\text { Kuntze). General wood rot } \\
\text { Armillaria root Disease }\end{array}$ & Pegler (1986) \\
\hline 20. & $\begin{array}{l}\text { Ascochyta abelmoschi } \\
\text { Harter }\end{array}$ & $\begin{array}{l}\text { Ascochyta abelmoschi } \\
\text { Harter }\end{array}$ & $\begin{array}{l}\text { Okra (Hibiscus esculentus } \\
\text { L.). Current name: } \\
\text { Abelmoschus esculentus } \\
\text { (L.) Moench.). Pod spot }\end{array}$ & Bond (1947) \\
\hline 21. & $\begin{array}{l}\text { Ascochyta abelmoschi } \\
\text { Harter }\end{array}$ & $\begin{array}{l}\text { Ascochyta abelmoschi } \\
\text { Harter }\end{array}$ & $\begin{array}{l}\text { Shoe-flower (Hibiscus } \\
\text { rosa-sinensis L.). Leaf spot }\end{array}$ & Bond (1947) \\
\hline 22. & $\begin{array}{l}\text { Ascochyta } \\
\text { cyphomandrae Petch }\end{array}$ & $\begin{array}{l}\text { Ascochyta cyphomandrae } \\
\text { Petch }\end{array}$ & $\begin{array}{l}\text { Tree tomato } \\
\text { (Cyphomandra betacea } \\
\text { (Cav.) Sendtn.). Leaf spot }\end{array}$ & Bond (1947) \\
\hline 23. & $\begin{array}{l}\text { Ascochyta oleracea var. } \\
\text { tumida T.E.T. Bond }\end{array}$ & $\begin{array}{l}\text { Ascochyta oleracea var. } \\
\text { tumida T.E.T. Bond }\end{array}$ & $\begin{array}{l}\text { Cabbage (Brassica oleracea } \\
\text { L.). Leaf spot }\end{array}$ & Bond (1947) \\
\hline 24. & $\begin{array}{l}\text { Ascochyta passiflorae } \\
\text { Penz. \& Sacc. }\end{array}$ & $\begin{array}{l}\text { Ascochyta passiflorae } \\
\text { Penz. \& Sacc. }\end{array}$ & $\begin{array}{l}\text { Passion fruit (Passiflora } \\
\text { edulis Sims) Leaf spot }\end{array}$ & Adikaram (1986/87) \\
\hline 25 & Ascochyta pisi Lib. & $\begin{array}{l}\text { Didymella pisi Chilvers, } \\
\text { J.D. Rogers \& Peever }\end{array}$ & $\begin{array}{l}\text { Pea (Pisum sativum L.) } \\
\text { Ascochyta blight }\end{array}$ & $\begin{array}{l}\text { Abeygunawardhane } \\
(1969)\end{array}$ \\
\hline 26. & $\begin{array}{l}\text { Aspergillus aculeatus } \\
\text { Iizuka }\end{array}$ & $\begin{array}{l}\text { Aspergillus aculeatus } \\
\text { Iizuka }\end{array}$ & $\begin{array}{l}\text { Tea (Camellia sinensis (L.) } \\
\text { Kuntze). Soft rot }\end{array}$ & $\begin{array}{l}\text { Senanayake et al. } \\
(2015)\end{array}$ \\
\hline 27. & Aspergillus flavus Link. & Aspergillus flavus Link & $\begin{array}{l}\text { Stored rice (Oryza sativa } \\
\text { L.) }\end{array}$ & $\begin{array}{l}\text { Paranagama et al. } \\
(2003)\end{array}$ \\
\hline 28. & Aspergillus flavus Link. & Aspergillus flavus Link. & $\begin{array}{l}\text { Onion (Allium cepa L.) } \\
\text { Bulb rot }\end{array}$ & $\begin{array}{l}\text { Rajapakse and } \\
\text { Edirimanna (2002) }\end{array}$ \\
\hline 29. & $\begin{array}{l}\text { Aspergillus niger van } \\
\text { Tieghem }\end{array}$ & Aspergillus niger Tiegh. & $\begin{array}{l}\text { Onion (Allium cepa L.) } \\
\text { Bulb rot }\end{array}$ & $\begin{array}{l}\text { Rajapakse and } \\
\text { Edirimanna (2002) }\end{array}$ \\
\hline 30. & $\begin{array}{l}\text { Aspergillus niger van } \\
\text { Tieghem }\end{array}$ & Aspergillus niger Tiegh. & $\begin{array}{l}\text { Mango (Mangifera indica } \\
\text { L.) } \\
\text { Aspergillus rot }\end{array}$ & $\begin{array}{l}\text { Krishnapillai and } \\
\text { Wilson Wijeratnam } \\
\text { (2013) }\end{array}$ \\
\hline 31. & Aspergillus tamarii Kita & Aspergillus tamarii Kita & $\begin{array}{l}\text { Tea (Camellia sinensis (L.) } \\
\text { Kuntze). Soft rot }\end{array}$ & $\begin{array}{l}\text { Senanayake et al. } \\
(2015)\end{array}$ \\
\hline 32. & $\begin{array}{l}\text { Asperisporium caricae } \\
\text { (Speg.) Maubl. }\end{array}$ & $\begin{array}{l}\text { Asperisporium caricae } \\
\text { (Speg.) Maubl. }\end{array}$ & $\begin{array}{l}\text { Papaya (Carica papaya L.) } \\
\text { Asperisporium leaf disease }\end{array}$ & $\begin{array}{l}\text { Adikaram and Wijepala } \\
(1995)\end{array}$ \\
\hline 33. & $\begin{array}{l}\text { Bipolaris oryzae (Breda } \\
\text { de Haan) Shoemaker }\end{array}$ & $\begin{array}{l}\text { Bipolaris oryzae (Breda } \\
\text { de Haan) Shoemaker }\end{array}$ & $\begin{array}{l}\text { Rice (Oryza sativa L.) } \\
\text { Brown spot disease } \\
\text { Grain discolouration }\end{array}$ & $\begin{array}{l}\text { Mithrasena et al. } \\
(2012 \mathrm{a})\end{array}$ \\
\hline 34. & $\begin{array}{l}\text { Botryodiplodia } \\
\text { theobromae (Pat.) } \\
\text { Griffon \& Maubl. }\end{array}$ & $\begin{array}{l}\text { Lasiodiplodia theobromae } \\
\text { (Pat.) Griffon \& Maubl. }\end{array}$ & $\begin{array}{l}\text { Avocado (Persea } \\
\text { americana Mill.) Stem-end } \\
\text { rot }\end{array}$ & $\begin{array}{l}\text { Madhupani and } \\
\text { Adikaram (2017) }\end{array}$ \\
\hline 35. & $\begin{array}{l}\text { Botryodiplodia } \\
\text { theobromae (Pat.) } \\
\text { Griffon \& Maubl. }\end{array}$ & $\begin{array}{l}\text { Lasiodiplodia theobromae } \\
\text { (Pat.) Griffon \& Maubl. }\end{array}$ & $\begin{array}{l}\text { Bael fruit (Aegle marmelos } \\
\text { (L.) Corrêa) Fruit rot }\end{array}$ & $\begin{array}{l}\text { N.K.B. Adikaram, } \\
\text { Unpublished work }\end{array}$ \\
\hline 36. & $\begin{array}{l}\text { Botryodiplodia } \\
\text { theobromae (Pat.) } \\
\text { Griffon \& Maubl. }\end{array}$ & $\begin{array}{l}\text { Lasiodiplodia theobromae } \\
\text { (Pat.) Griffon \& Maubl. }\end{array}$ & $\begin{array}{l}\text { Cocoa (Theobroma cacao } \\
\text { L.) }\end{array}$ & Adikaram (1986/87) \\
\hline 37. & $\begin{array}{l}\text { Botryodiplodia } \\
\text { theobromae (Pat.) } \\
\text { Griffon \& Maubl. }\end{array}$ & $\begin{array}{l}\text { Lasiodiplodia theobromae } \\
\text { (Pat.) Griffon \& Maubl. }\end{array}$ & $\begin{array}{l}\text { Orange (Citrus sinensis (L.) } \\
\text { Osbeck) Stem-end rot }\end{array}$ & Adikaram (1986/87) \\
\hline 38. & $\begin{array}{l}\text { Botryodiplodia } \\
\text { theobromae (Pat.) } \\
\text { Griffon \& Maubl. . }\end{array}$ & $\begin{array}{l}\text { Lasiodiplodia theobromae } \\
\text { (Pat.) Griffon \& Maubl. }\end{array}$ & $\begin{array}{l}\text { Papaya (Carica papaya L.) } \\
\text { Stem-end rot }\end{array}$ & $\begin{array}{l}\text { Abeywickrama et al. } \\
(2012)\end{array}$ \\
\hline 39. & $\begin{array}{l}\text { Botryodiplodia } \\
\text { theobromae (Pat.) } \\
\text { Griffon \& Maubl. }\end{array}$ & $\begin{array}{l}\text { Lasiodiplodia theobromae } \\
\text { (Pat.) Griffon \& Maubl. }\end{array}$ & $\begin{array}{l}\text { Wood apple (Limonia } \\
\text { acidissima Groff ), Diwul } \\
\text { (S), Fruit rot }\end{array}$ & Adikaram et al. (1989) \\
\hline
\end{tabular}




\begin{tabular}{|c|c|c|c|c|}
\hline 40. & $\begin{array}{l}\text { Botryodiplodia } \\
\text { theobromae (Pat.) } \\
\text { Griffon \& Maubl. }\end{array}$ & $\begin{array}{l}\text { Lasiodiplodia theobromae } \\
\text { (Pat.) Griffon \& Maubl. }\end{array}$ & $\begin{array}{l}\text { Banana (Musa acuminata } \\
\text { Colla) } \\
\text { Crown rot }\end{array}$ & $\begin{array}{l}\text { Indrakeerthi and } \\
\text { Adikaram (2011) }\end{array}$ \\
\hline 41. & $\begin{array}{l}\text { Botryodiplodia } \\
\text { theobromae (Pat.) } \\
\text { Griffon \& Maubl. }\end{array}$ & $\begin{array}{l}\text { Lasiodiplodia theobromae } \\
\text { (Pat.) Griffon \& Maubl. }\end{array}$ & $\begin{array}{l}\text { Guava (Psidium guava } \\
\text { Griseb.) } \\
\text { Soft rot }\end{array}$ & Alahakoon et al. (2008) \\
\hline 42. & $\begin{array}{l}\text { Botryosphaeria Ces. \& } \\
\text { De Not }\end{array}$ & $\begin{array}{l}\text { Botryosphaeria Ces. \& } \\
\text { De Not }\end{array}$ & $\begin{array}{l}\text { Bo (S) (Ficus religiosa L.) } \\
\text { Leaf blotch }\end{array}$ & $\begin{array}{l}\text { Maharachchikumbura } \\
\text { and Adikaram (2009) }\end{array}$ \\
\hline 43. & Botrytis cinerea Pers. & Botrytis cinerea Pers. & $\begin{array}{l}\text { Raddish (Ruphanus sativa } \\
\text { L.) }\end{array}$ & $\begin{array}{l}\text { Jeyanandarajah and } \\
\text { Liyanage (1995a) }\end{array}$ \\
\hline 44. & Botrytis cinerea Pers. & Botrytis cinerea Pers. & $\begin{array}{l}\text { Rose (Rosa chinensis var. } \\
\text { Ramblers). Flower blight }\end{array}$ & $\begin{array}{l}\text { N.K.B. Adikaram. } \\
\text { Unpublished work }\end{array}$ \\
\hline 45. & Calonectria theae Loos & $\begin{array}{l}\text { Calonectria indusiata } \\
\text { Boedijn \& Reitsma }\end{array}$ & $\begin{array}{l}\text { Tea (Camellia sinensis (L.) } \\
\text { Kuntze) Cercosporella Leaf } \\
\text { disease }\end{array}$ & Loos (1951) \\
\hline 46. & $\begin{array}{l}\text { Catenulopsora } \\
\text { flacourtiae Mundk \& } \\
\text { Thirum }\end{array}$ & $\begin{array}{l}\text { Kuehneola flacourtiae } \\
\text { (Mundk. \& Thirum.) }\end{array}$ & $\begin{array}{l}\text { Uguressa (S) (Flacourtia } \\
\text { ramontchi L'Hérit.) } \\
\text { Current name: Flacourtia } \\
\text { indica (Burm.f.) Merr. Rust } \\
\text { disease }\end{array}$ & $\begin{array}{l}\text { N.K.B. Adikaram. } \\
\text { Unpublished work }\end{array}$ \\
\hline 47. & $\begin{array}{l}\text { Ceratocystis paradoxa } \\
\text { (De Seynes) Sacc. }\end{array}$ & $\begin{array}{l}\text { Thielaviopsis paradoxa } \\
\text { (De Seynes) Höhn. }\end{array}$ & $\begin{array}{l}\text { Coconut } \\
\text { (Cocos nucifera L.) } \\
\text { Stem bleeding disease }\end{array}$ & Gunawardena (1955) \\
\hline 48. & $\begin{array}{l}\text { Ceratophorum setosum } \\
\text { O. Kirch. }\end{array}$ & $\begin{array}{l}\text { Pleiochaeta setosa } \\
\text { (Kirchn.) }\end{array}$ & $\begin{array}{l}\text { Crotalaria anagyroides } \\
\text { Kunth }\end{array}$ & $\begin{array}{l}\text { P. Sivanathan, } \\
\text { Unpublished work }\end{array}$ \\
\hline 49. & $\begin{array}{l}\text { Cercospora beticola } \\
\text { Chidd. }\end{array}$ & $\begin{array}{l}\text { Cercospora beticola } \\
\text { Chidd. }\end{array}$ & $\begin{array}{l}\text { Beet (Beta vulgaris L.) } \\
\text { Cercospora leaf spot }\end{array}$ & $\begin{array}{l}\text { Abeygunawardhane } \\
\text { (1969) }\end{array}$ \\
\hline 50. & $\begin{array}{l}\text { Cercospora } \\
\text { brassicicola } \text { P. Henn. }\end{array}$ & $\begin{array}{l}\text { Cercospora brassicicola } \\
\text { P. Henn. }\end{array}$ & $\begin{array}{l}\text { Chinese Mustard (Brassica } \\
\text { juncea (L.) Czern.). Leaf } \\
\text { spot }\end{array}$ & $\begin{array}{l}\text { P. Sivanathan, } \\
\text { Unpublished work }\end{array}$ \\
\hline 51. & $\begin{array}{l}\text { Cercospora capsici } \\
\text { Unamuno }\end{array}$ & $\begin{array}{l}\text { Passalora capsicicola } \\
\text { (Vassiljevsky) U. Braun \& } \\
\text { F.O. Freire }\end{array}$ & $\begin{array}{l}\text { Chilli (Capsicum annuum } \\
\text { L.). } \\
\text { Leaf spot }\end{array}$ & $\begin{array}{l}\text { Abeygunawardhane } \\
\text { (1969) }\end{array}$ \\
\hline 52. & $\begin{array}{l}\text { Cercospora carotae } \\
\text { (Pass.) Solheim }\end{array}$ & $\begin{array}{l}\text { Cercospora carotae } \\
\text { (Pass.) Kazn. \& } \\
\text { Siemaszko }\end{array}$ & $\begin{array}{l}\text { Carrot (Daucus carota L.) } \\
\text { Leaf blight }\end{array}$ & $\begin{array}{l}\text { Abeygunawardhane } \\
\text { (1969) }\end{array}$ \\
\hline 53. & $\begin{array}{l}\text { Cercospora janseana } \\
\text { (Racib.) Constant. }\end{array}$ & $\begin{array}{l}\text { Passalora janseana } \\
\text { (Racib.) U. Braun }\end{array}$ & $\begin{array}{l}\text { Rice (Oryza sativa L.) } \\
\text { Narrow brown leaf spot }\end{array}$ & $\begin{array}{l}\text { Dissanayake and } \\
\text { Wickramasinghe (1999) }\end{array}$ \\
\hline 54. & $\begin{array}{l}\text { Cercospora } \\
\text { melongenae Welles }\end{array}$ & $\begin{array}{l}\text { Cercospora physalidis } \\
\text { Ellis }\end{array}$ & $\begin{array}{l}\text { Brinjal (Solanum } \\
\text { melongena L.). Leaf spot }\end{array}$ & $\begin{array}{l}\text { Abeygunawardhane } \\
\text { (1969) }\end{array}$ \\
\hline 55. & $\begin{array}{l}\text { Cercospora nicotianae } \\
\text { Ellis \& Everh. }\end{array}$ & $\begin{array}{l}\text { Cercospora physalidis } \\
\text { Ellis, }\end{array}$ & $\begin{array}{l}\text { Tobacco (Nicotiana } \\
\text { tabacum L.). Frog eye }\end{array}$ & $\begin{array}{l}\text { Park and Chandraratne } \\
(1940)\end{array}$ \\
\hline 56. & $\begin{array}{l}\text { Cercospora oryzae I. } \\
\text { Miyake }\end{array}$ & Sphaerulina oryzina Hara & $\begin{array}{l}\text { Rice (Oryza sativa L.) } \\
\text { Leaf spot }\end{array}$ & Seneviratne (1978) \\
\hline 57. & $\begin{array}{l}\text { Cercospora personata } \\
\text { (Berk. \& M.A. Curtis) } \\
\text { Ellis \& Everh. }\end{array}$ & $\begin{array}{l}\text { Nothopassalora personata } \\
\text { (Berk. \& M.A. Curtis) U. } \\
\text { Braun }\end{array}$ & $\begin{array}{l}\text { Ground nut (Arachis } \\
\text { hypogaea L.). Leaf spot }\end{array}$ & $\begin{array}{l}\text { Abeygunawardhane } \\
\text { (1969) }\end{array}$ \\
\hline 58. & $\begin{array}{l}\text { Cercospora piaropi } \\
\text { Tharp }\end{array}$ & Cercospora piaropi Tharp & $\begin{array}{l}\text { Water hyacinth (Eichhornia } \\
\text { crassipes Mart. Solms) } \\
\text { Leaf spot }\end{array}$ & $\begin{array}{l}\text { Hettiarachchi et al. } \\
\text { (1983) }\end{array}$ \\
\hline 59. & $\begin{array}{l}\text { Cercospora rodmanii } \\
\text { Conway }\end{array}$ & $\begin{array}{l}\text { Cercospora rodmanii } \\
\text { Conway }\end{array}$ & $\begin{array}{l}\text { Water hyacinth (Eichhornia } \\
\text { crassipes (Mart.) Solms) } \\
\text { Leaf spot }\end{array}$ & $\begin{array}{l}\text { Cheanieha Queen et al. } \\
\text { (2016) }\end{array}$ \\
\hline 60. & $\begin{array}{l}\text { Cercospora solani } \\
\text { Thüm }\end{array}$ & Cercospora solani Thüm & $\begin{array}{l}\text { Solanum nigrum L. } \\
\text { Current name: } \\
\text { Solanum americanum Mill. } \\
\text { Leaf yellowing }\end{array}$ & Bond (1947) \\
\hline
\end{tabular}




\begin{tabular}{|c|c|c|c|c|}
\hline 61. & $\begin{array}{l}\text { Cercospora zinniae } \\
\text { Ellis \& G. Martin }\end{array}$ & $\begin{array}{l}\text { Cercospora zinniae Ellis } \\
\text { \& G. Martin }\end{array}$ & $\begin{array}{l}\text { Zinnia (Zinnia elegans L.) } \\
\text { Leaf spot }\end{array}$ & $\begin{array}{l}\text { G.M. Nilmini Kumari, } \\
\text { Unpublished work }\end{array}$ \\
\hline 62. & $\begin{array}{l}\text { Cercosporella brassicae } \\
\text { (Fautr. \& Roum) v. } \\
\text { Hoehn }\end{array}$ & $\begin{array}{l}\text { Neopseudocercosporella } \\
\text { capsellae (Ellis \& Everh.) } \\
\text { Videira \& Crous }\end{array}$ & $\begin{array}{l}\text { Turnips (Brassica } \\
\text { campestris L.). Current } \\
\text { name: Brassica rapa L. } \\
\text { White spot }\end{array}$ & Bond (1947) \\
\hline 63. & $\begin{array}{l}\text { Ceriporiopsis } \\
\text { hypolateritius (Berk. ex } \\
\text { Cooke) Ryvarden }\end{array}$ & $\begin{array}{l}\text { Ceriporiopsis } \\
\text { hypolateritia (Berk. ex } \\
\text { Cooke) Ryvarden }\end{array}$ & $\begin{array}{l}\text { Tea (Camellia sinensis (L.) } \\
\text { Kuntze). Red Root rot }\end{array}$ & Arulpragasam (1988) \\
\hline 64. & $\begin{array}{l}\text { Chalara paradoxa (De } \\
\text { Seynes) Sacc. }\end{array}$ & $\begin{array}{l}\text { Ceratocystis paradoxa } \\
\text { (Dade) C. Moreau }\end{array}$ & $\begin{array}{l}\text { Pineapple (Ananas comosus } \\
\text { (L.) Merril). Water blister }\end{array}$ & $\begin{array}{l}\text { Damunupola and } \\
\text { Adikaram (2000) }\end{array}$ \\
\hline 65. & $\begin{array}{l}\text { Chalara paradoxa }(\mathrm{De} \\
\text { Seynes) Sacc. }\end{array}$ & $\begin{array}{l}\text { Ceratocystis paradoxa } \\
\text { (Dade) C. Moreau }\end{array}$ & $\begin{array}{l}\text { Pineapple (Ananas comosus } \\
\text { (L.) Merril.) Stem-end rot }\end{array}$ & Adikaram et al. (2019) \\
\hline 66. & $\begin{array}{l}\text { Chalara paradoxa }(\mathrm{De} \\
\text { Seynes) Sacc. }\end{array}$ & $\begin{array}{l}\text { Ceratocystis paradoxa } \\
\text { (Dade) C. Moreau }\end{array}$ & $\begin{array}{l}\text { Pineapple (Ananas comosus } \\
\text { (L.) Merril) Crown bud rot }\end{array}$ & Adikaram et al. (2019) \\
\hline 67. & $\begin{array}{l}\text { Choanephora } \\
\text { cucurbitarum (Berk. \& } \\
\text { Rav.) Thaxter }\end{array}$ & $\begin{array}{l}\text { Choanephora } \\
\text { infundibulifera f. } \\
\text { cucurbitarum (Berk. \& } \\
\text { Ravenel) Schipper }\end{array}$ & $\begin{array}{l}\text { Winged bean } \\
\text { (Psophocarpus } \\
\text { tetragonolobus (L.) DC.) } \\
\text { Choanephora blight }\end{array}$ & $\begin{array}{l}\text { Gunasekera et al. } \\
(1985)\end{array}$ \\
\hline 68. & $\begin{array}{l}\text { Choanephora } \\
\text { cucurbitarum (Berk. \& } \\
\text { Rav.) Thaxter }\end{array}$ & $\begin{array}{l}\text { Choanephora } \\
\text { infundibulifera f. } \\
\text { cucurbitarum (Berk. \& } \\
\text { Ravenel) Schipper }\end{array}$ & $\begin{array}{l}\text { Psophocarpus scandens } \\
\text { (Endl.) Verdc. (Endl.) Verdc } \\
\text { Choanephora blight }\end{array}$ & $\begin{array}{l}\text { Gunasekera et al. } \\
\text { (1990) }\end{array}$ \\
\hline 69. & $\begin{array}{l}\text { Cladosporium fulvum } \\
\text { Cooke }\end{array}$ & Fulvia fulva (Cooke) Cif. & $\begin{array}{l}\text { Tomato (Solanum } \\
\text { lycopersicon Mill.) Leaf } \\
\text { mould }\end{array}$ & $\begin{array}{l}\text { Abeygunawardhane } \\
\text { (1969) }\end{array}$ \\
\hline 70. & $\begin{array}{l}\text { Cladosporium } \\
\text { versicolor T.E.T. Bond }\end{array}$ & $\begin{array}{l}\text { Passalora perfoliati (Ellis } \\
\text { \& Everh.) U. Braun \& } \\
\text { Crous }\end{array}$ & $\begin{array}{l}\text { Hulan-tala (S) (Ageratum } \\
\text { conyzoides (L.) L.) } \\
\text { Leaf spot/blotch }\end{array}$ & Bond (1947) \\
\hline 71. & $\begin{array}{l}\text { Cladosporium } \\
\text { cladosporioides } \\
\text { (Fresen.) G.A. de Vries }\end{array}$ & $\begin{array}{l}\text { Cladosporium } \\
\text { cladosporioides (Fresen.) } \\
\text { G.A. de Vries }\end{array}$ & $\begin{array}{l}\text { Tomato (Solanum } \\
\text { lycopersicon Mill.) }\end{array}$ & $\begin{array}{l}\text { Abayasekara et al. } \\
(2013)\end{array}$ \\
\hline 72. & Cladosporium sp. & Cladosporium sp. & $\begin{array}{l}\text { Mango (Mangifera indica } \\
\text { L.). Inflorescence blight }\end{array}$ & Sinniah et al. (2012) \\
\hline 73. & $\begin{array}{l}\text { Cochliobolus } \\
\text { miyabeanus (S. Ito \& } \\
\text { Kurib.) Drechsler ex } \\
\text { Dastur } \\
\end{array}$ & $\begin{array}{l}\text { Bipolaris oryzae (Breda } \\
\text { de Haan) Shoemaker }\end{array}$ & $\begin{array}{l}\text { Rice (Oryza sativa L.) } \\
\text { Brown spot disease }\end{array}$ & Fernando et al. (2016) \\
\hline 74. & $\begin{array}{l}\text { Coleosporium } \\
\text { plumeriae Pat. }\end{array}$ & $\begin{array}{l}\text { Coleosporium plumeriae } \\
\text { Pat. }\end{array}$ & $\begin{array}{l}\text { Temple tree (Plumeria sp.). } \\
\text { Plumeria rust }\end{array}$ & $\begin{array}{l}\text { Adikaram and } \\
\text { Weeraratne (2006) }\end{array}$ \\
\hline 75. & $\begin{array}{l}\text { Colletotrichum } \\
\text { acutatum J.H. } \\
\text { Simmonds }\end{array}$ & $\begin{array}{l}\text { Colletotrichum acutatum } \\
\text { J.H. Simmonds }\end{array}$ & $\begin{array}{l}\text { Red onion (Allium cepa L.). } \\
\text { Leaf twister Disease }\end{array}$ & $\begin{array}{l}\text { Vengadaramana and } \\
\text { Costa }(2015)\end{array}$ \\
\hline 76. & $\begin{array}{l}\text { Colletotrichum } \\
\text { acutatum J.H. } \\
\text { Simmonds }\end{array}$ & $\begin{array}{l}\text { Colletotrichum acutatum } \\
\text { J.H. Simmonds }\end{array}$ & $\begin{array}{l}\text { Chilli (Capsicum annuum } \\
\text { L.) fruit. Anthracnose }\end{array}$ & $\begin{array}{l}\text { Mahendranathan et al. } \\
\text { (2011) }\end{array}$ \\
\hline 77. & $\begin{array}{l}\text { Colletotrichum } \\
\text { acutatum J.H. } \\
\text { Simmonds }\end{array}$ & $\begin{array}{l}\text { Colletotrichum acutatum } \\
\text { J.H. Simmonds }\end{array}$ & $\begin{array}{l}\text { Uguressa (S) (Flacourtia } \\
\text { ramontchi L'Hérit.) } \\
\text { Current name: } \\
\text { Flacourtia indica (Burm.f.) } \\
\text { Merr. Anthracnose }\end{array}$ & $\begin{array}{l}\text { Jayasinghe and } \\
\text { Fernando (2004) }\end{array}$ \\
\hline 78. & $\begin{array}{l}\text { Colletotrichum } \\
\text { acutatum J.H. } \\
\text { Simmonds }\end{array}$ & $\begin{array}{l}\text { Colletotrichum acutatum } \\
\text { J.H. Simmonds }\end{array}$ & $\begin{array}{l}\text { Rubber (Hevea brasiliensis } \\
\text { (Willd. ex A. Juss.) Müll. } \\
\text { Arg.) Colletotrichum leaf } \\
\text { disease }\end{array}$ & $\begin{array}{l}\text { Thambugala and } \\
\text { Deshappriya (2009) }\end{array}$ \\
\hline 79. & $\begin{array}{l}\text { Colletotrichum } \\
\text { acutatum J.H. } \\
\text { Simmonds }\end{array}$ & $\begin{array}{l}\text { Colletotrichum acutatum } \\
\text { J.H. Simmonds }\end{array}$ & $\begin{array}{l}\text { Mango (Mangifera indica } \\
\text { L.). } \\
\text { Anthracnose }\end{array}$ & $\begin{array}{l}\text { Jayasinghe and } \\
\text { Fernando (2009) }\end{array}$ \\
\hline
\end{tabular}




\begin{tabular}{|c|c|c|c|c|}
\hline 80. & $\begin{array}{l}\text { Colletotrichum asianum } \\
\text { Prihastuti, L. Cai \& } \\
\text { K.D. Hyde }\end{array}$ & $\begin{array}{l}\text { Colletotrichum asianum } \\
\text { Prihastuti, L. Cai \& K.D. } \\
\text { Hyde }\end{array}$ & $\begin{array}{l}\text { Mango (Mangifera indica } \\
\text { L.). } \\
\text { Anthracnose }\end{array}$ & Vithanage et al. (2014). \\
\hline 81. & $\begin{array}{l}\text { Colletotrichum } \\
\text { camelliae Massee }\end{array}$ & $\begin{array}{l}\text { Colletotrichum camelliae } \\
\text { Massee }\end{array}$ & $\begin{array}{l}\text { Tea (Camellia sinensis (L.) } \\
\text { Kuntze). Brown blight \& } \\
\text { anthracnose }\end{array}$ & Webster (1952) \\
\hline 82. & $\begin{array}{l}\text { Colletotrichum capsici } \\
\text { (Syd. \& P. Syd.) E.J. } \\
\text { Butler \& Bisby }\end{array}$ & $\begin{array}{l}\text { Colletotrichum truncatum } \\
\text { (Schwein.) Andrus \& } \\
\text { W.D. Moore }\end{array}$ & $\begin{array}{l}\text { Aubergine (Solanum } \\
\text { melongena L.) Anthracnose }\end{array}$ & $\begin{array}{l}\text { Mahendranadan et al. } \\
(2010)\end{array}$ \\
\hline 83. & $\begin{array}{l}\text { Colletotrichum capsici } \\
\text { (Syd. \& P. Syd.) E.J. } \\
\text { Butler \& Bisby }\end{array}$ & $\begin{array}{l}\text { Colletotrichum truncatum } \\
\text { (Schwein.) Andrus \& } \\
\text { W.D. Moore }\end{array}$ & $\begin{array}{l}\text { Chilli (Capsicum annuum } \\
\text { L.) Antharcnose }\end{array}$ & Adikaram (1986/87) \\
\hline 84. & $\begin{array}{l}\text { Colletotrichum capsici } \\
\text { (Syd. \& P. Syd.) E.J. } \\
\text { Butler \& Bisby. }\end{array}$ & $\begin{array}{l}\text { Colletotrichum truncatum } \\
\text { (Schwein.) Andrus \& } \\
\text { W.D. Moore }\end{array}$ & $\begin{array}{l}\text { Papaya (Carica papaya L.) } \\
\text { Anthracnose }\end{array}$ & Dharmasiri (1988) \\
\hline 85. & $\begin{array}{l}\text { Colletotrichum capsici } \\
\text { (Syd. \& P. Syd.) E.J. } \\
\text { Butler \& Bisby }\end{array}$ & $\begin{array}{l}\text { Colletotrichum truncatum } \\
\text { (Schwein.) Andrus \& } \\
\text { W.D. Moore }\end{array}$ & $\begin{array}{l}\text { Wood apple (Limonia } \\
\text { acidissima Groff) Fruit rot }\end{array}$ & Adikaram et al. (1989) \\
\hline 86. & $\begin{array}{l}\text { Colletotrichum } \\
\text { coccodes (Wallr.) S. } \\
\text { Hughes }\end{array}$ & $\begin{array}{l}\text { Colletotrichum coccodes } \\
\text { (Wallr.) S. Hughes }\end{array}$ & $\begin{array}{l}\text { Tomato (Solanum } \\
\text { lycopersicon Mill.). } \\
\text { Anthracnose }\end{array}$ & $\begin{array}{l}\text { Wanasinghe and } \\
\text { Damunupola }(2019) \\
\text { Adikaram (1986/87) }\end{array}$ \\
\hline 87. & $\begin{array}{l}\text { Colletotrichum } \\
\text { endophytica } \\
\text { Manamgoda, } \\
\text { Udayanga, L. Cai \& } \\
\text { K.D. Hyde }\end{array}$ & $\begin{array}{l}\text { Colletotrichum } \\
\text { endophytica Manamgoda, } \\
\text { Udayanga, L. Cai \& K.D. } \\
\text { Hyde }\end{array}$ & $\begin{array}{l}\text { Avocado fruit (Persea } \\
\text { americana Mill.) } \\
\text { Anthracnose }\end{array}$ & $\begin{array}{l}\text { Dissanayaake et al. } \\
(2016)\end{array}$ \\
\hline 88. & $\begin{array}{l}\text { Colletotrichum } \\
\text { fructicola Prihastuti, L. } \\
\text { Cai \& K.D. Hyde }\end{array}$ & $\begin{array}{l}\text { Colletotrichum fructicola } \\
\text { Prihastuti, L. Cai \& } \\
\text { K.D. Hyde }\end{array}$ & $\begin{array}{l}\text { Anthurium (Anthurium } \\
\text { andraeanum Andre) } \\
\text { Anthracnose \& black nose }\end{array}$ & $\begin{array}{l}\text { S. Komala Vithanage, } \\
\text { D.M.D. Yakandawala, } \\
\text { L.N. Manawadu and } \\
\text { N.K.B. Adikaram, } \\
\text { Unpublished work }\end{array}$ \\
\hline 89. & $\begin{array}{l}\text { Colletotrichum } \\
\text { fructicola Prihastuti, L. } \\
\text { Cai \& K.D. Hyde }\end{array}$ & $\begin{array}{l}\text { Colletotrichum fructicola } \\
\text { Prihastuti, L. Cai \& } \\
\text { K.D. Hyde }\end{array}$ & $\begin{array}{l}\text { Mango (Mangifera indica } \\
\text { L.). } \\
\text { Anthracnose }\end{array}$ & Vithanage et al. (2014). \\
\hline 90. & $\begin{array}{l}\text { Colletotrichum } \\
\text { gigasporum Rakotonir. } \\
\text { \& Munaut }\end{array}$ & $\begin{array}{l}\text { Colletotrichum } \\
\text { gigasporum Rakotonir. \& } \\
\text { Munaut }\end{array}$ & $\begin{array}{l}\text { Avocado (Persea } \\
\text { americana Mill.). } \\
\text { Anthracnose }\end{array}$ & $\begin{array}{l}\text { Hunupolagama et al. } \\
(2015)\end{array}$ \\
\hline 91. & $\begin{array}{l}\text { Colletotrichum } \\
\text { gloeosporioides PENZ. }\end{array}$ & $\begin{array}{l}\text { Colletotrichum } \\
\text { gloeosporioides PENZ. }\end{array}$ & $\begin{array}{l}\text { Mango (Mangifera indica } \\
\text { L.) } \\
\text { Anthracnose }\end{array}$ & $\begin{array}{l}\text { Karunanayake et al. } \\
(2014)\end{array}$ \\
\hline 92. & $\begin{array}{l}\text { Colletotrichum } \\
\text { gloeosporioides PENZ. }\end{array}$ & $\begin{array}{l}\text { Colletotrichum } \\
\text { gloeosporioides PENZ. }\end{array}$ & $\begin{array}{l}\text { Avocado (Persea } \\
\text { americana Mill.). } \\
\text { Anthracnose }\end{array}$ & $\begin{array}{l}\text { Sivanathan and } \\
\text { Adikaram (1989) }\end{array}$ \\
\hline 93. & $\begin{array}{l}\text { Colletotrichum } \\
\text { gloeosporioides PENZ. }\end{array}$ & $\begin{array}{l}\text { Colletotrichum } \\
\text { gloeosporioides PENZ. }\end{array}$ & $\begin{array}{l}\text { Shallot onion ( Allium cepa } \\
\text { var. aggregatum G.Don) }\end{array}$ & $\begin{array}{l}\text { Wijesinghe and } \\
\text { Rajapakse (1997) }\end{array}$ \\
\hline 94. & $\begin{array}{l}\text { Colletotrichum } \\
\text { gloeosporioides PENZ. }\end{array}$ & $\begin{array}{l}\text { Colletotrichum } \\
\text { gloeosporioides PENZ. }\end{array}$ & $\begin{array}{l}\text { Guava (Psidium guava } \\
\text { Griseb.). Current name: } \\
\text { Psidium guajava L.) } \\
\text { Anthracnose }\end{array}$ & Alahakoon et al. (2008) \\
\hline 95. & $\begin{array}{l}\text { Colletotrichum } \\
\text { gloeosporioides PENZ. }\end{array}$ & $\begin{array}{l}\text { Colletotrichum } \\
\text { gloeosporioides PENZ. }\end{array}$ & $\begin{array}{l}\text { Chilli (Capsicum annuum } \\
\text { L.) } \\
\text { Antharacnose }\end{array}$ & Adikaram (1986/87) \\
\hline 96. & $\begin{array}{l}\text { Colletotrichum } \\
\text { gloeosporioides PENZ. }\end{array}$ & $\begin{array}{l}\text { Colletotrichum } \\
\text { gloeosporioides PENZ. }\end{array}$ & $\begin{array}{l}\text { Dioscorea alata L. } \\
\text { Anthracnose }\end{array}$ & Weeraratne et al. (2016) \\
\hline 97. & $\begin{array}{l}\text { Colletotrichum } \\
\text { gloeosporioides PENZ. }\end{array}$ & $\begin{array}{l}\text { Colletotrichum } \\
\text { gloeosporioides PENZ. }\end{array}$ & $\begin{array}{l}\text { Aerial yam (Dioscorea } \\
\text { bulbifera L.). Anthracnose }\end{array}$ & Weeraratne et al. (2016) \\
\hline
\end{tabular}




\begin{tabular}{|c|c|c|c|c|}
\hline 98. & $\begin{array}{l}\text { Colletotrichum } \\
\text { gloeosporioides PENZ. }\end{array}$ & $\begin{array}{l}\text { Colletotrichum } \\
\text { gloeosporioides PENZ. }\end{array}$ & $\begin{array}{l}\text { Dioscorea pentaphylla L. } \\
\text { Anthracnose }\end{array}$ & Weeraratne et al. (2016) \\
\hline 99. & $\begin{array}{l}\text { Colletotrichum } \\
\text { gloeosporioides PENZ. }\end{array}$ & $\begin{array}{l}\text { Colletotrichum } \\
\text { gloeosporioides PENZ. }\end{array}$ & $\begin{array}{l}\text { Dioscorea rotundata L. } \\
\text { Anthracnose }\end{array}$ & Weeraratne et al. (2016) \\
\hline 100. & $\begin{array}{l}\text { Colletotrichum } \\
\text { gloeosporioides PENZ. }\end{array}$ & $\begin{array}{l}\text { Colletotrichum } \\
\text { gloeosporioides PENZ. }\end{array}$ & $\begin{array}{l}\text { 'Kukulala' (S), Asiatic } \\
\text { yam. (Dioscorea } \\
\text { esculenta (Lour.) Burkill). } \\
\text { Anthracnose }\end{array}$ & Weeraratne et al. (2016) \\
\hline 101. & $\begin{array}{l}\text { Colletotrichum } \\
\text { gloeosporioides PENZ }\end{array}$ & $\begin{array}{l}\text { Colletotrichum } \\
\text { gloeosporioides PENZ. }\end{array}$ & $\begin{array}{l}\text { Uguressa (S) (Flacourtia } \\
\text { ramontchi L'Hérit.).Current } \\
\text { name. Flacourtia } \\
\text { indica (Burm.f.) Merr. } \\
\text { Anthracnose }\end{array}$ & $\begin{array}{l}\text { Jayasinghe and } \\
\text { Fernando (2004) }\end{array}$ \\
\hline 102. & $\begin{array}{l}\text { Colletotrichum } \\
\text { gloeosporiodes PENZ. }\end{array}$ & $\begin{array}{l}\text { Colletotrichum } \\
\text { gloeosporioides PENZ. }\end{array}$ & $\begin{array}{l}\text { Cluster onion (Allium cepa } \\
\text { L.). Anthracnose }\end{array}$ & $\begin{array}{l}\text { Araskesasry et al. } \\
(2016)\end{array}$ \\
\hline 103. & $\begin{array}{l}\text { Colletotrichum } \\
\text { gloeosporioides PENZ. }\end{array}$ & $\begin{array}{l}\text { Colletotrichum } \\
\text { gloeosporioides PENZ. }\end{array}$ & $\begin{array}{l}\text { Red onion (Allium cepa L.). } \\
\text { Leaf Twister Disease }\end{array}$ & $\begin{array}{l}\text { Vengadaramana and } \\
\text { Costa }(2015)\end{array}$ \\
\hline 104. & $\begin{array}{l}\text { Colletotrichum } \\
\text { gloeosporioides PENZ. }\end{array}$ & $\begin{array}{l}\text { Colletotrichum } \\
\text { gloeosporioides PENZ. }\end{array}$ & $\begin{array}{l}\text { Rubber (Hevea brasiliensis } \\
\text { (Willd. ex A.Juss.) Müll. } \\
\text { Arg.). Colletotrichum leaf } \\
\text { disease }\end{array}$ & $\begin{array}{l}\text { Thambugala and } \\
\text { Deshappriya (2009) }\end{array}$ \\
\hline 105. & $\begin{array}{l}\text { Colletotrichum } \\
\text { gloeosporioides PENZ. }\end{array}$ & $\begin{array}{l}\text { Colletotrichum } \\
\text { gloeosporioides PENZ. }\end{array}$ & $\begin{array}{l}\text { Pomegranate (Punica } \\
\text { granatum L.). Anthracnose }\end{array}$ & Adikaram (1986/87) \\
\hline 106. & $\begin{array}{l}\text { Colletotrichum } \\
\text { gloeosporioides PENZ. }\end{array}$ & $\begin{array}{l}\text { Colletotrichum } \\
\text { gloeosporioides PENZ. }\end{array}$ & $\begin{array}{l}\text { Orange (Citrus sinensis (L.) } \\
\text { Osbeck). Anthracnose }\end{array}$ & Adikaram (1986/87) \\
\hline
\end{tabular}

107. Colletotrichum Colletotrichum Colletotrichum B.C. Stone) Current name: gloeosporioides PENZ. gloeosporioides PENZ. Citrus decumana var.

Adikaram (1986/87) racemosa $\mathrm{M}$. Roem Anthracnose

\begin{tabular}{|c|c|c|c|c|}
\hline 108. & $\begin{array}{l}\text { Colletotrichum } \\
\text { gloeosporioides PENZ. }\end{array}$ & $\begin{array}{l}\text { Colletotrichum } \\
\text { gloeosporioides PENZ. }\end{array}$ & $\begin{array}{l}\text { Banana (Musa acuminata } \\
\text { Colla). } \\
\text { Crown rot }\end{array}$ & $\begin{array}{l}\text { Indrakeerthi and } \\
\text { Adikaram (2011) }\end{array}$ \\
\hline 109. & $\begin{array}{l}\text { Colletotrichum } \\
\text { higginsianum Sacc. }\end{array}$ & $\begin{array}{l}\text { Colletotrichum } \\
\text { higginsianum Sacc. }\end{array}$ & $\begin{array}{l}\text { Raddish (Ruphanus sativa } \\
\text { L.) }\end{array}$ & $\begin{array}{l}\text { Jeyanandarajah and } \\
\text { Liyanage (1995a) }\end{array}$ \\
\hline 110. & $\begin{array}{l}\text { Colletotrichum } \\
\text { laticiphilum Damm, } \\
\text { P.F. Cannon \& Crous }\end{array}$ & $\begin{array}{l}\text { Colletotrichum } \\
\text { laticiphilum Damm, P.F. } \\
\text { Cannon \& Crous }\end{array}$ & $\begin{array}{l}\text { Rubber (Hevea brasiliensis } \\
\text { (Willd. ex A.Juss.) Müll. } \\
\text { Arg.) }\end{array}$ & $\begin{array}{l}\text { Hunupolagama et al. } \\
(2017)\end{array}$ \\
\hline 111. & $\begin{array}{l}\text { Colletotrichum } \\
\text { lindemuthianum (Sacc. } \\
\text { \& Magnus) Briosi \& } \\
\text { Cavara }\end{array}$ & $\begin{array}{l}\text { Colletotrichum } \\
\text { lindemuthianum (Sacc. \& } \\
\text { Magnus) Briosi \& Cavara }\end{array}$ & $\begin{array}{l}\text { Bean pods \& seedlings } \\
\text { (Phaseolus vulgaris L.) } \\
\text { Anthracnose }\end{array}$ & Adikaram (1986/87) \\
\hline 112. & $\begin{array}{l}\text { Colletotrichum musae } \\
\text { (Berk. \& M.A. Curtis) } \\
\text { Arx }\end{array}$ & $\begin{array}{l}\text { Colletotrichum musae } \\
\text { (Berk. \& M.A. Curtis) } \\
\text { Arx }\end{array}$ & $\begin{array}{l}\text { Banana (Musa acuminata) } \\
\text { Crown rot }\end{array}$ & $\begin{array}{l}\text { Indrakeerthi and } \\
\text { Adikaram (2011) }\end{array}$ \\
\hline 113. & $\begin{array}{l}\text { Colletotrichum musae } \\
\text { (Berk. \& M.A. Curtis) } \\
\text { Arx }\end{array}$ & $\begin{array}{l}\text { Colletotrichum musae } \\
\text { (Berk. \& M.A. Curtis) } \\
\text { Arx }\end{array}$ & $\begin{array}{l}\text { Banana (Musa acuminata } \\
\text { Colla). } \\
\text { Anthracnose }\end{array}$ & $\begin{array}{l}\text { Wanigasekara et al. } \\
(2014)\end{array}$ \\
\hline 114. & $\begin{array}{l}\text { Colletotrichum } \\
\text { nymphaeae (Pass.) Aa }\end{array}$ & $\begin{array}{l}\text { Colletotrichum } \\
\text { nymphaeae (Pass.) Aa }\end{array}$ & $\begin{array}{l}\text { Rubber (Hevea brasiliensis } \\
\text { (Willd. ex A.Juss.) Müll. } \\
\text { Arg.) }\end{array}$ & $\begin{array}{l}\text { Hunupolagama et al. } \\
(2017)\end{array}$ \\
\hline 115. & $\begin{array}{l}\text { Colletotrichum } \\
\text { phomoides (Sacc.) } \\
\text { Chester }\end{array}$ & $\begin{array}{l}\text { Colletotrichum coccodes } \\
\text { (Wallr.) S. Hughes }\end{array}$ & $\begin{array}{l}\text { Tomato (Solanum } \\
\text { lycopersicon Mill.). } \\
\text { Anthracnose }\end{array}$ & $\begin{array}{l}\text { Abeygunawardhane } \\
(1969)\end{array}$ \\
\hline
\end{tabular}




\begin{tabular}{|c|c|c|c|c|}
\hline 116. & $\begin{array}{l}\text { Colletotrichum piperis } \\
\text { F. Stevens }\end{array}$ & $\begin{array}{l}\text { Colletotrichum piperis } \mathrm{F} \text {. } \\
\text { Stevens }\end{array}$ & $\begin{array}{l}\text { Pepper (Piper nigrum L.) } \\
\text { Leaf spot }\end{array}$ & $\begin{array}{l}\text { P. Sivanathan, } \\
\text { Unpublshed work }\end{array}$ \\
\hline 117. & $\begin{array}{l}\text { Colletotrichum } \\
\text { siamense Prihast., L. } \\
\text { Cai \& K.D. Hyde }\end{array}$ & $\begin{array}{l}\text { Colletotrichum siamense } \\
\text { Prihast., L. Cai \& K.D. } \\
\text { Hyde }\end{array}$ & $\begin{array}{l}\text { Anthurium (Anthurium } \\
\text { andraeanum Linden) } \\
\text { Spathe rot }\end{array}$ & $\begin{array}{l}\text { S.K. Vithanage, } \\
\text { N.K.B. Adikaram, } \\
\text { D.M.D. Yakandawala } \\
\text { and L.N. Manawadu, } \\
\text { Unpublished work }\end{array}$ \\
\hline 118. & $\begin{array}{l}\text { Colletotrichum } \\
\text { siamense Prihast., L. } \\
\text { Cai \& K.D. Hyde }\end{array}$ & $\begin{array}{l}\text { Colletotrichum siamense } \\
\text { Prihast., L. Cai \& K.D. } \\
\text { Hyde }\end{array}$ & $\begin{array}{l}\text { Avocado (Persea } \\
\text { americana Mill.). } \\
\text { Anthracnose }\end{array}$ & $\begin{array}{l}\text { Dissanayake et al. } \\
(2016)\end{array}$ \\
\hline 119. & $\begin{array}{l}\text { Colletotrichum } \\
\text { siamense Prihast., L. } \\
\text { Cai \& K.D. Hyde }\end{array}$ & $\begin{array}{l}\text { Colletotrichum siamense } \\
\text { Prihast., L. Cai \& K.D. } \\
\text { Hyde }\end{array}$ & $\begin{array}{l}\text { Begonia spp. foliage } \\
\text { Anthracnose }\end{array}$ & $\begin{array}{l}\text { Wickramasinghe, } \\
\text { Yakandawala and } \\
\text { Adikaram (2019) }\end{array}$ \\
\hline 120. & $\begin{array}{l}\text { Colletotrichum } \\
\text { siamense Prihast., L. } \\
\text { Cai \& K.D. Hyde }\end{array}$ & $\begin{array}{l}\text { Colletotrichum siamense } \\
\text { Prihast., L. Cai \& K.D. } \\
\text { Hyde }\end{array}$ & $\begin{array}{l}\text { Cashew (Anacardium } \\
\text { occidentale L.) Anthracnose }\end{array}$ & $\begin{array}{l}\text { N.K.B. Adikaram, } \\
\text { D.M.D. Yakandawala } \\
\text { and D.S. Madhupani, } \\
\text { Unpublished work }\end{array}$ \\
\hline 121. & $\begin{array}{l}\text { Colletotrichum } \\
\text { siamense Prihast., L. } \\
\text { Cai \& K.D. Hyde }\end{array}$ & $\begin{array}{l}\text { Colletotrichum siamense } \\
\text { Prihast., L. Cai \& K.D. } \\
\text { Hyde }\end{array}$ & $\begin{array}{l}\text { Mango (Mangifera indica } \\
\text { L.). } \\
\text { Anthracnose }\end{array}$ & Vithanage et al. (2014). \\
\hline 122. & $\begin{array}{l}\text { Colletotrichum } \\
\text { siamense Prihast., L. } \\
\text { Cai \& K.D. Hyde }\end{array}$ & $\begin{array}{l}\text { Colletotrichum siamense } \\
\text { Prihast., L. Cai \& K.D. } \\
\text { Hyde }\end{array}$ & $\begin{array}{l}\text { Papaya (Carica papaya L.) } \\
\text { Anthracnose }\end{array}$ & $\begin{array}{l}\text { N.K.B. Adikaram, } \\
\text { D.M.D. Yakandawala } \\
\text { and D.S. Madhupani, } \\
\text { Unpublished work }\end{array}$ \\
\hline 123. & $\begin{array}{l}\text { Colletotrichum } \\
\text { siamense Prihast., L. } \\
\text { Cai \& K.D. Hyde }\end{array}$ & $\begin{array}{l}\text { Colletotrichum siamense } \\
\text { Prihast., L. Cai \& K.D. } \\
\text { Hyde }\end{array}$ & $\begin{array}{l}\text { Rubber (Hevea brasiliensis) } \\
\text { Leaf disease }\end{array}$ & Herath et al. (2019) \\
\hline 124. & $\begin{array}{l}\text { Colletotrichum } \\
\text { truncatum (Schwein.) } \\
\text { Andrus \& W.D. Moore }\end{array}$ & $\begin{array}{l}\text { Colletotrichum truncatum } \\
\text { (Schwein.) Andrus \& } \\
\text { W.D. Moore }\end{array}$ & $\begin{array}{l}\text { Begonia (Begonia sp.) } \\
\text { Anthracnose }\end{array}$ & $\begin{array}{l}\text { Wicramasinghe, } \\
\text { Yakandawala and } \\
\text { Adikaram (2019) }\end{array}$ \\
\hline 125. & $\begin{array}{l}\text { Colletotrichum } \\
\text { truncatum (Schwein.) } \\
\text { Andrus \& W.D. Moore }\end{array}$ & $\begin{array}{l}\text { Colletotrichum truncatum } \\
\text { (Schwein.) Andrus \& } \\
\text { W.D. Moore }\end{array}$ & $\begin{array}{l}\text { Papaya (Carica papaya L.) } \\
\text { Anthracnose }\end{array}$ & $\begin{array}{l}\text { N.K.B. Adikaram, } \\
\text { D.M.D. Yakandawala } \\
\text { and D.S. Madhupani, } \\
\text { Unpublished work }\end{array}$ \\
\hline 126. & $\begin{array}{l}\text { Colletotrichum } \\
\text { truncatum (Schwein.) } \\
\text { Andrus \& W.D. Moore }\end{array}$ & $\begin{array}{l}\text { Colletotrichum truncatum } \\
\text { (Schwein.) Andrus \& } \\
\text { W.D. Moore }\end{array}$ & $\begin{array}{l}\text { Termeric (Curcuma longa } \\
\text { L.). } \\
\text { Leaf blight }\end{array}$ & $\begin{array}{l}\text { Abeygunawardhane } \\
\text { (1969) }\end{array}$ \\
\hline 127. & $\begin{array}{l}\text { Cordana musae Preuss } \\
\text { ex. Sacc. }\end{array}$ & $\begin{array}{l}\text { Neocordana musae } \\
\text { (Zimm.) Hern.-Restr. \& } \\
\text { Crous }\end{array}$ & $\begin{array}{l}\text { Banana (Musa acuminata } \\
\text { Colla). Cordana leaf spot }\end{array}$ & Perera et al. (2013) \\
\hline 128. & $\begin{array}{l}\text { Corticium salmonicolor } \\
\text { Berk. \& Broome }\end{array}$ & $\begin{array}{l}\text { Erythricium salmonicolor } \\
\text { (Berk. \& Broome) Burds }\end{array}$ & $\begin{array}{l}\text { Calophyllum walkeri Wight } \\
\text { Pink disease }\end{array}$ & Adikaram et al. (2007) \\
\hline 129. & $\begin{array}{l}\text { Corticium salmonicolor } \\
\text { Berk. \& Broome }\end{array}$ & $\begin{array}{l}\text { Erythricium salmonicolor } \\
\text { (Berk. \& Broome) Burds }\end{array}$ & $\begin{array}{l}\text { Symplocos cochinchinensis } \\
\text { (Lour.) S. Moore } \\
\text { Pink disease }\end{array}$ & Adikaram et al. (2007) \\
\hline 130. & $\begin{array}{l}\text { Corticium salmonicolor } \\
\text { Berk \& Broome }\end{array}$ & $\begin{array}{l}\text { Erythricium salmonicolor } \\
\text { (Berk. \& Broome) Burds }\end{array}$ & $\begin{array}{l}\text { Symplocos elegans } \\
\text { Thwaites } \\
\text { Pink disease }\end{array}$ & Adikaram et al. (2007) \\
\hline 131. & $\begin{array}{l}\text { Corticium salmonicolor } \\
\text { Berk \& Broome }\end{array}$ & $\begin{array}{l}\text { Erythricium salmonicolor } \\
\text { (Berk. \& Broome) Burds }\end{array}$ & $\begin{array}{l}\text { Symplocos obtusa Wall. ex } \\
\text { G.Don Pink disease }\end{array}$ & Adikaram et al. (2007) \\
\hline 132. & $\begin{array}{l}\text { Corticium salmonicolor } \\
\text { Berk \& Broome }\end{array}$ & $\begin{array}{l}\text { Erythricium salmonicolor } \\
\text { (Berk. \& Broome) Burds }\end{array}$ & $\begin{array}{l}\text { Coffee (Coffea arabica L.). } \\
\text { Pink disease }\end{array}$ & $\begin{array}{l}\text { P. Sivanathan, } \\
\text { Unpublished work }\end{array}$ \\
\hline 133. & $\begin{array}{l}\text { Corticium salmonicolor } \\
\text { Berk \& Broome }\end{array}$ & $\begin{array}{l}\text { Erythricium salmonicolor } \\
\text { (Berk. \& Broome) Burds }\end{array}$ & $\begin{array}{l}\text { Cinnamon (Cinnamomum } \\
\text { verum Presl. } \\
\text { Syn. Cinnamomum } \\
\text { zeylanicum Blume) Pink } \\
\text { disease }\end{array}$ & $\begin{array}{l}\text { Rajapakse and } \\
\text { Wasantha Kumara, } \\
(2007)\end{array}$ \\
\hline
\end{tabular}




\begin{tabular}{|c|c|c|c|c|}
\hline 134. & $\begin{array}{l}\text { Corticium solani (Prill. } \\
\text { \& Delacr.) Bourdot \& } \\
\text { Galzin }\end{array}$ & $\begin{array}{l}\text { Rhizoctonia solani J.G. } \\
\text { Kühn }\end{array}$ & $\begin{array}{l}\text { Potato (Solanum tuberosum } \\
\text { L.) Black scurf disease }\end{array}$ & $\begin{array}{l}\text { Gunawardana and } \\
\text { Bandara (1993) }\end{array}$ \\
\hline 135. & $\begin{array}{l}\text { Corynespora cassiicola } \\
\text { (Burk. \& Curtis) Wei }\end{array}$ & $\begin{array}{l}\text { Corynespora cassiicola } \\
\text { (Burk. \& Curtis) Wei }\end{array}$ & $\begin{array}{l}\text { Aubergine } \\
\text { (Solanum melongena L.) }\end{array}$ & Adikaram (1986/87) \\
\hline 136. & $\begin{array}{l}\text { Corynespora } \\
\text { cassiicola (Burk. \& } \\
\text { Curtis) Wei }\end{array}$ & $\begin{array}{l}\text { Corynespora cassiicola } \\
\text { (Burk. \& Curtis) Wei }\end{array}$ & $\begin{array}{l}\text { Croton (Codiaeum } \\
\text { variegatum (L.) Rumph. ex } \\
\text { A.Juss.). Leaf disease }\end{array}$ & $\begin{array}{l}\text { Jayasuriya and } \\
\text { Thennakoon (2009) }\end{array}$ \\
\hline 137. & $\begin{array}{l}\text { Corynespora cassiicola } \\
\text { (Burk. \& Curtis) Wei }\end{array}$ & $\begin{array}{l}\text { Corynespora cassiicola } \\
\text { (Burk. \& Curtis) Wei }\end{array}$ & $\begin{array}{l}\text { Rubber (Hevea brasiliensis } \\
\text { (Willd. ex A.Juss.) Müll. } \\
\text { Arg.). Corynespora leaf } \\
\text { spot }\end{array}$ & Liyanage et al. (1986) \\
\hline 138. & $\begin{array}{l}\text { Corynespora cassiicola } \\
\text { (Burk. \& Curtis) Wei }\end{array}$ & $\begin{array}{l}\text { Corynespora cassiicola } \\
\text { (Burk. \& Curtis) Wei }\end{array}$ & $\begin{array}{l}\text { Tomato (Solanum } \\
\text { lycopersicon Mill.) Target } \\
\text { spot }\end{array}$ & $\begin{array}{l}\text { Adikaram }(1986 / 87) \\
\text { Weeraratne et al. }(2019)\end{array}$ \\
\hline 139. & $\begin{array}{l}\text { Curvularia lunata } \\
\text { (Wakker) Boedijn }\end{array}$ & $\begin{array}{l}\text { Curvularia lunata } \\
\text { (Wakker) Boedijn }\end{array}$ & $\begin{array}{l}\text { Rice (Oryza sativa L.) } \\
\text { Grain discoloration }\end{array}$ & Nasla et al. (2019) \\
\hline 140. & $\begin{array}{l}\text { Curvularia pallescens } \\
\text { Boedijn }\end{array}$ & $\begin{array}{l}\text { Curvularia pallescens } \\
\text { Boedijn }\end{array}$ & $\begin{array}{l}\text { Neeramulliya (S) } \\
\text { (Asteracantha longifolia } \\
\text { Nees.) }\end{array}$ & $\begin{array}{l}\text { Fernando and } \\
\text { Abeywickrama (1996) }\end{array}$ \\
\hline 141. & $\begin{array}{l}\text { Curvularia pallescence } \\
\text { Boedijn }\end{array}$ & $\begin{array}{l}\text { Curvularia pallescens } \\
\text { Boedijn }\end{array}$ & $\begin{array}{l}\text { Rice (Oryza sativa L.) } \\
\text { Grain discoloration }\end{array}$ & Nasla et al. (2019) \\
\hline 142. & $\begin{array}{l}\text { Curvularia } \\
\text { senegalensis (Speg.) } \\
\text { Subram. }\end{array}$ & $\begin{array}{l}\text { Curvularia senegalensis } \\
\text { (Speg.) Subram. }\end{array}$ & $\begin{array}{l}\text { Rubber (Hevea brasiliensis) } \\
\text { Leaf disease }\end{array}$ & Herath et al. (2019) \\
\hline 143. & $\begin{array}{l}\text { Curvularia tuberculata } \\
\text { B.L. Jain }\end{array}$ & $\begin{array}{l}\text { Curvularia tuberculata } \\
\text { B.L. Jain }\end{array}$ & $\begin{array}{l}\text { Water hyacinth (Eichhornia } \\
\text { crassipes Mart. Solms.) } \\
\text { Leaf spot }\end{array}$ & $\begin{array}{l}\text { Hettiarachchi et al. } \\
\text { (1983) }\end{array}$ \\
\hline 144. & $\begin{array}{l}\text { Cylindrocladium } \\
\text { quinqueseptatum } \\
\text { Boedijn \& Reitsma }\end{array}$ & $\begin{array}{l}\text { Calonectria } \\
\text { quinqueseptata } \\
\text { Figueiredo \& Namek }\end{array}$ & $\begin{array}{l}\text { Clove (Syzygium } \\
\text { aromaticum (L.) Merr. } \\
\text { \& Perry) (Syn. Eugenia } \\
\text { caryophyllata Thunb.). } \\
\text { Leaf spot }\end{array}$ & $\begin{array}{l}\text { Jayasinghe and } \\
\text { Wijesundera (1995) }\end{array}$ \\
\hline 145. & $\begin{array}{l}\text { Cylindrocladium } \\
\text { uinqueseptatum } \\
\text { Boedijn \& Reitsma }\end{array}$ & $\begin{array}{l}\text { Calonectria } \\
\text { quinqueseptata } \\
\text { Figueiredo \& Namek }\end{array}$ & $\begin{array}{l}\text { Rubber (Hevea brasiliensis } \\
\text { (Willd. ex A.Juss.) Müll. } \\
\text { Arg.). Leaf spot }\end{array}$ & Jayasinghe et al. (2009) \\
\hline 146. & Denticulria mangiferae & Denticulria mangiferae & $\begin{array}{l}\text { Mango (Mangifera indica } \\
\text { L.). Mango scab }\end{array}$ & $\begin{array}{l}\text { N.K.B. Adikaram, } \\
\text { Unpublished work }\end{array}$ \\
\hline 147. & $\begin{array}{l}\text { Diplocarpon rosea } \\
\text { Wolf. }\end{array}$ & Diplocarpon rosea Wolf. & $\begin{array}{l}\text { Rose (Rosa indica L.) } \\
\text { Black spot disease. }\end{array}$ & $\begin{array}{l}\text { P. Sivanathan, } \\
\text { Unpublished work. }\end{array}$ \\
\hline 148. & $\begin{array}{l}\text { Dreshlera graminea } \\
\text { S. Ito \& Kurib. }\end{array}$ & $\begin{array}{l}\text { Pyrenophora graminea S. } \\
\text { Ito \& Kurib. }\end{array}$ & $\begin{array}{l}\text { Raddish (Ruphanus sativa } \\
\text { L.) }\end{array}$ & $\begin{array}{l}\text { Jeyanandarajah and } \\
\text { Liyanage }(1995 a)\end{array}$ \\
\hline 149. & $\begin{array}{l}\text { Drechslera rostrata } \\
\text { (Drechsler) M.J. } \\
\text { Richardson \& E.M. } \\
\text { Fraser }\end{array}$ & $\begin{array}{l}\text { Exserohilum rostratum } \\
\text { (Drechsler) K.J. Leonard } \\
\text { \& Suggs }\end{array}$ & $\begin{array}{l}\text { Livistona chinensis (Jacq.) } \\
\text { R.Br. ex Mart. Leaf spot }\end{array}$ & Hewage et al. (2007) \\
\hline 150. & Erysiphe sp. & Erysiphe sp. & $\begin{array}{l}\text { Momordica charantia } L . \\
\text { Powdery mildew }\end{array}$ & $\begin{array}{l}\text { Ratnayake et al. } \\
(2016 \mathrm{~b})\end{array}$ \\
\hline 151. & $\begin{array}{l}\text { Erysiphe } \\
\text { cichoracearum DC. }\end{array}$ & $\begin{array}{l}\text { Golovinomyces } \\
\text { cichoracearum (DC.) V.P. } \\
\text { Heluta }\end{array}$ & $\begin{array}{l}\text { Okra (Hibiscus esculentus } \\
\text { L.). Powdery Mildew }\end{array}$ & $\begin{array}{l}\text { Samarajeewa and } \\
\text { Rathnayake (2004) }\end{array}$ \\
\hline 152. & $\begin{array}{l}\text { Erysiphe } \\
\text { cichoracearum DC. }\end{array}$ & $\begin{array}{l}\text { Golovinomyces } \\
\text { cichoracearum (DC.) V.P. } \\
\text { Heluta }\end{array}$ & $\begin{array}{l}\text { Zinnia (Zinnia elegans L.) } \\
\text { Powdery mildew }\end{array}$ & $\begin{array}{l}\text { Adikaram, unpublished } \\
\text { work }\end{array}$ \\
\hline
\end{tabular}


153. Erysiphe polygoni DC. Erysiphe polygoni DC

\begin{tabular}{cll}
\hline 154. & $\begin{array}{l}\text { Erysiphe quercicola } \\
\text { S. Takam \& U. Braun }\end{array}$ & $\begin{array}{l}\text { Erysiphe quercicola } \\
\text { S. Takam. \& U. Braun }\end{array}$ \\
\hline 155. & $\begin{array}{l}\text { Exobasidium vexans } \\
\text { Massee }\end{array}$ & $\begin{array}{l}\text { Exobasidium vexans } \\
\text { Massee }\end{array}$ \\
\hline 156. & $\begin{array}{l}\text { Fomes applanatus } \\
\text { (Pers.) Gillet }\end{array}$ & $\begin{array}{l}\text { Ganoderma applanatum } \\
\text { (Pers.) Pat. }\end{array}$ \\
\hline 157. & $\begin{array}{l}\text { Fomes lignosus } \\
\text { (Klotzsch) Bres. }\end{array}$ & $\begin{array}{l}\text { Rigidoporus microporus } \\
\text { (Sw.) Overeem }\end{array}$
\end{tabular}

\begin{tabular}{|c|c|c|c|c|}
\hline 158. & $\begin{array}{l}\text { Fomes lucidus (Curtis) } \\
\text { Cooke }\end{array}$ & $\begin{array}{l}\text { Ganoderma lucidum } \\
\text { (Curtis) P. Karst. }\end{array}$ & $\begin{array}{l}\text { Tea (Camellia sinensis (L.) } \\
\text { Kuntze). General wood rot }\end{array}$ & Balasuriya (2008) \\
\hline 159. & Fomes noxius Corner & $\begin{array}{l}\text { Pyrrhoderma noxium } \\
\text { (Corner) L.W. Zhou \& } \\
\text { Y.C. Dai }\end{array}$ & $\begin{array}{l}\text { Cinnomon (Cinnamomum } \\
\text { verum Presl.) } \\
\text { Syn. Cinnamomum } \\
\text { zeylanicum Blume) White } \\
\text { root disease }\end{array}$ & $\begin{array}{l}\text { Jayasimghe } \text { et al. } \\
\text { (2017) }\end{array}$ \\
\hline 160. & Fomes noxius Corner & $\begin{array}{l}\text { Pyrrhoderma noxium } \\
\text { (Corner) L.W. Zhou \& } \\
\text { Y.C. Dai }\end{array}$ & $\begin{array}{l}\text { Coffee (Coffea arabica L.). } \\
\text { Brown root disease }\end{array}$ & $\begin{array}{l}\text { P. Sivanathan, } \\
\text { Unpublished worfk }\end{array}$ \\
\hline 161. & $\begin{array}{l}\text { Fusarium acuminatum } \\
\text { Wollenw. }\end{array}$ & $\begin{array}{l}\text { Fusarium acuminatum } \\
\text { Wollenw. }\end{array}$ & $\begin{array}{l}\text { Gokatu (Tribulus terrestris } \\
\text { L.) }\end{array}$ & $\begin{array}{l}\text { Abeywickrama et al. } \\
\text { (1992) }\end{array}$ \\
\hline 162. & $\begin{array}{l}\text { Fusarium avenaceum } \\
\text { (Fr.) Sacc. }\end{array}$ & $\begin{array}{l}\text { Fusarium avenaceum (Fr.) } \\
\text { Sacc. }\end{array}$ & $\begin{array}{l}\text { Carnation (Dianthus } \\
\text { caryophyllus L.) }\end{array}$ & de Silva et al. (2005) \\
\hline 163. & $\begin{array}{l}\text { Fusarium culmorum } \\
\text { (W.G. Sm.) Sacc. }\end{array}$ & $\begin{array}{l}\text { Fusarium culmorum } \\
\text { (W.G. Sm.) Sacc. }\end{array}$ & $\begin{array}{l}\text { Gokatu (Tribulus terrestris } \\
\text { L.) }\end{array}$ & $\begin{array}{l}\text { Abeywickrama et al. } \\
\text { (1992) }\end{array}$ \\
\hline 164. & $\begin{array}{l}\text { Fusarium } \\
\text { decemcellulare Brick }\end{array}$ & $\begin{array}{l}\text { Albonectria } \\
\text { rigidiuscula } \text { (Berk. \& } \\
\text { Broome) Rossman \& } \\
\text { Samuels }\end{array}$ & $\begin{array}{l}\text { Cocoa (Theobroma cacao } \\
\text { L.) } \\
\text { Pod rot }\end{array}$ & Adikaram (1986/87) \\
\hline 165. & $\begin{array}{l}\text { Fusarium epithele } \\
\text { McAlpine }\end{array}$ & $\begin{array}{l}\text { Fusarium epithele } \\
\text { McAlpine }\end{array}$ & $\begin{array}{l}\text { Orange (Citrus sinensis (L.) } \\
\text { Osbeck) }\end{array}$ & Adikaram (1986/87) \\
\hline 166. & $\begin{array}{l}\text { Fusarium graminearum } \\
\text { Schwabe }\end{array}$ & $\begin{array}{l}\text { Fusarium graminearum } \\
\text { Schwabe }\end{array}$ & $\begin{array}{l}\text { Gokatu (Tribulus terrestris } \\
\text { L.) }\end{array}$ & $\begin{array}{l}\text { Abeywickrama et al. } \\
\text { (1992) }\end{array}$ \\
\hline 167. & $\begin{array}{l}\text { Fusarium mangiferae } \\
\text { Britz, M.J. Wingf. \& } \\
\text { Marasas }\end{array}$ & $\begin{array}{l}\text { Fusarium mangiferae } \\
\text { Britz, M.J. Wingf. \& } \\
\text { Marasas }\end{array}$ & $\begin{array}{l}\text { Mango (Mangifera indica } \\
\text { L.). } \\
\text { Floral malformation }\end{array}$ & Sinniah et al. (2013) \\
\hline 168. & $\begin{array}{l}\text { Fusarium mangiferae } \\
\text { Britz, M.J. Wingf. \& } \\
\text { Marasas }\end{array}$ & $\begin{array}{l}\text { Fusarium mangiferae } \\
\text { Britz, M.J. Wingf. \& } \\
\text { Marasas }\end{array}$ & $\begin{array}{l}\text { Mango (Mangifera indica } \\
\text { L.). } \\
\text { Stem-end browning }\end{array}$ & $\begin{array}{l}\text { D.M.S. Dissanayake, } \\
\text { N.K.B. Adikaram and } \\
\text { D.M.D.Yakandawala, } \\
\text { Unpublished work }\end{array}$ \\
\hline 169. & $\begin{array}{l}\text { Fusarium moniliforme } \\
\text { Sheldon }\end{array}$ & $\begin{array}{l}\text { Fusarium fujikuroi } \\
\text { Nirenberg }\end{array}$ & $\begin{array}{l}\text { Dracena godseffiana Leaf } \\
\text { spot }\end{array}$ & $\begin{array}{l}\text { Jeyanandarajah and } \\
\text { Wijesooriya (1997) }\end{array}$ \\
\hline 170. & $\begin{array}{l}\text { Fusarium moniliforme } \\
\text { Sheldon }\end{array}$ & $\begin{array}{l}\text { Fusarium fujikuroi } \\
\text { Nirenberg }\end{array}$ & $\begin{array}{l}\text { Maize (Zea mays L.) } \\
\text { Red ear rot disease }\end{array}$ & Priyantha et al. (2015) \\
\hline 171. & $\begin{array}{l}\text { Fusarium oxysporum } \\
\text { Schltdl }\end{array}$ & $\begin{array}{l}\text { Fusarium oxysporum } \\
\text { Schltdl }\end{array}$ & $\begin{array}{l}\text { Cucumber (Cucumis sativus } \\
\text { L.). } \\
\text { Fusarium rot }\end{array}$ & $\begin{array}{l}\text { Bogamuwa and } \\
\text { Karunaratne (1985) }\end{array}$ \\
\hline 172. & Fusarium oxysporum & $\begin{array}{l}\text { Fusarium oxysporum } \\
\text { Schltdl. }\end{array}$ & $\begin{array}{l}\text { Jack tree (Artocarpus } \\
\text { heterophyllus Lam.) Root } \\
\text { rot }\end{array}$ & Kuruppu et al. (2019) \\
\hline
\end{tabular}
Ganoderma lucidum
(Curtis) P. Karst.

Pea (Pisum sativum L.) Powdery mildew

Atteria (S), Jasmine orange

(E), (Murraya paniculata

(L.) Jack). Powdery mildew

Tea (Camellia sinensis (L.) Kuntze) Blister blight

Tea (Camellia sinensis (L.) Kuntze). General wood rot

Rubber (Hevea brasiliensis

(Willd. ex A.Juss.) Müll.

Arg.). White root disease

Peries et al. (1959)

Abeygunawardhane (1969)

N.K.B. Adikaram and D.M.D. Yakandawala, Unpublished work

Loos (1949)

Balasuriya (2008)

Balasuriya (2008)

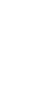

Cinnomon (Cinnamomum

Syn Cinnamomum Jayasimghe et al.

zeylanicum Blume) White (2017) root disease

Coffee (Coffea arabica L.). P. Sivanathan, Brown root disease Unpublished worfk

\begin{tabular}{|c|c|c|c|c|}
\hline 161. & $\begin{array}{l}\text { Fusarium acuminatum } \\
\text { Wollenw. }\end{array}$ & $\begin{array}{l}\text { Fusarium acuminatum } \\
\text { Wollenw. }\end{array}$ & $\begin{array}{l}\text { Gokatu (Tribulus terrestris } \\
\text { L.) }\end{array}$ & $\begin{array}{l}\text { Abeywickrama et al. } \\
(1992)\end{array}$ \\
\hline 162. & $\begin{array}{l}\text { Fusarium avenaceum } \\
\text { (Fr.) Sacc. }\end{array}$ & $\begin{array}{l}\text { Fusarium avenaceum (Fr.) } \\
\text { Sacc. }\end{array}$ & $\begin{array}{l}\text { Carnation (Dianthus } \\
\text { caryophyllus L.) }\end{array}$ & de Silva et al. (2005) \\
\hline 163. & $\begin{array}{l}\text { Fusarium culmorum } \\
\text { (W.G. Sm.) Sacc. }\end{array}$ & $\begin{array}{l}\text { Fusarium culmorum } \\
\text { (W.G. Sm.) Sacc. }\end{array}$ & $\begin{array}{l}\text { Gokatu (Tribulus terrestris } \\
\text { L.) }\end{array}$ & $\begin{array}{l}\text { Abeywickrama et al. } \\
\text { (1992) }\end{array}$ \\
\hline 164. & $\begin{array}{l}\text { Fusarium } \\
\text { decemcellulare Brick }\end{array}$ & $\begin{array}{l}\text { Albonectria } \\
\text { rigidiuscula (Berk. \& } \\
\text { Broome) Rossman \& } \\
\text { Samuels }\end{array}$ & $\begin{array}{l}\text { Cocoa (Theobroma cacao } \\
\text { L.) } \\
\text { Pod rot }\end{array}$ & Adikaram (1986/87) \\
\hline 165. & $\begin{array}{l}\text { Fusarium epithele } \\
\text { McAlpine }\end{array}$ & $\begin{array}{l}\text { Fusarium epithele } \\
\text { McAlpine }\end{array}$ & $\begin{array}{l}\text { Orange (Citrus sinensis (L.) } \\
\text { Osbeck) }\end{array}$ & Adikaram (1986/87) \\
\hline 166. & $\begin{array}{l}\text { Fusarium graminearum } \\
\text { Schwabe }\end{array}$ & $\begin{array}{l}\text { Fusarium graminearum } \\
\text { Schwabe }\end{array}$ & $\begin{array}{l}\text { Gokatu (Tribulus terrestris } \\
\text { L.) }\end{array}$ & $\begin{array}{l}\text { Abeywickrama et al. } \\
\text { (1992) }\end{array}$ \\
\hline 167. & $\begin{array}{l}\text { Fusarium mangiferae } \\
\text { Britz, M.J. Wingf. \& } \\
\text { Marasas }\end{array}$ & $\begin{array}{l}\text { Fusarium mangiferae } \\
\text { Britz, M.J. Wingf. \& } \\
\text { Marasas }\end{array}$ & $\begin{array}{l}\text { Mango (Mangifera indica } \\
\text { L.). } \\
\text { Floral malformation }\end{array}$ & Sinniah et al. (2013) \\
\hline 168. & $\begin{array}{l}\text { Fusarium mangiferae } \\
\text { Britz, M.J. Wingf. \& } \\
\text { Marasas }\end{array}$ & $\begin{array}{l}\text { Fusarium mangiferae } \\
\text { Britz, M.J. Wingf. \& } \\
\text { Marasas }\end{array}$ & $\begin{array}{l}\text { Mango (Mangifera indica } \\
\text { L.). } \\
\text { Stem-end browning }\end{array}$ & $\begin{array}{l}\text { D.M.S. Dissanayake, } \\
\text { N.K.B. Adikaram and } \\
\text { D.M.D.Yakandawala, } \\
\text { Unpublished work }\end{array}$ \\
\hline 169. & $\begin{array}{l}\text { Fusarium moniliforme } \\
\text { Sheldon }\end{array}$ & $\begin{array}{l}\text { Fusarium fujikuroi } \\
\text { Nirenberg }\end{array}$ & $\begin{array}{l}\text { Dracena godseffiana Leaf } \\
\text { spot }\end{array}$ & $\begin{array}{l}\text { Jeyanandarajah and } \\
\text { Wijesooriya (1997) }\end{array}$ \\
\hline 170. & $\begin{array}{l}\text { Fusarium moniliforme } \\
\text { Sheldon }\end{array}$ & $\begin{array}{l}\text { Fusarium fujikuroi } \\
\text { Nirenberg }\end{array}$ & $\begin{array}{l}\text { Maize (Zea mays L.) } \\
\text { Red ear rot disease }\end{array}$ & Priyantha et al. (2015) \\
\hline 171. & $\begin{array}{l}\text { Fusarium oxysporum } \\
\text { Schltdl }\end{array}$ & $\begin{array}{l}\text { Fusarium oxysporum } \\
\text { Schltdl }\end{array}$ & $\begin{array}{l}\text { Cucumber (Cucumis sativus } \\
\text { L.). } \\
\text { Fusarium rot }\end{array}$ & $\begin{array}{l}\text { Bogamuwa and } \\
\text { Karunaratne (1985) }\end{array}$ \\
\hline 172. & Fusarium oxysporum & $\begin{array}{l}\text { Fusarium oxysporum } \\
\text { Schltdl. }\end{array}$ & $\begin{array}{l}\text { Jack tree (Artocarpus } \\
\text { heterophyllus Lam.) Root } \\
\text { rot }\end{array}$ & Kuruppu et al. (2019) \\
\hline
\end{tabular}


Shallot onion (Allium cepa Wijesinghe and var. aggregatum G.Don) Rajapakse (1997)
Fusarium oxysporum f. Fusarium oxysporum $\mathrm{f}$.

173. sp. Cepae W.C. Snyder sp. Cepae W.C. Snyder \& \& H.N. Hansen

Fusarium oxysporum f. Fusarium oxysporum f.sp.

174. sp. Cubenase (Foc.) 175. Fusarium oxysporum
pv. dianthi

Fusarium oxysporum

(Johnson) W.C. Snyder

\& H.N. Hansen

Fusarium oxysporum $\mathrm{f}$.

177. sp. Niveum

Fusarium oxysporum $\mathrm{f}$
sp. Lycopersici race 1

179. sp. Lycopersici race 1

Fusarium oxysporum $\mathrm{f}$.

180. sp. radicis-lycopersici

Jarvis \& Shoemaker

Fusarium

181. pallidoroseum (Cooke) sacc.

Fusarium incarnatum

(Roberge) Sacc. nicotianae (Johnson) W.C. Snyder \& H.N. Hansen
Cubense (E.F. Sm.) W.C. Snyder \& H.N. Hansen

Fusarium oxysporum Schltdl.
Fusarium oxysporum f.sp. Niveum (E.F. Sm.) W.C.

Fusarium oxysporium Schltdl

Fusarium oxysporum $\mathrm{f}$ sp. Lycopersici race 1

Fusarium oxysporum f.sp. radicis-lycopersici Jarvis \& Shoemaker
176. f. sp. Nicotianae

178. Fusarium oxysporium Schltdl

Fusarium oxysporum f.sp.

Banana (Musa acuminata

Colla). Fusarium wilt

Carnation (Dianthus

caryophyllus L.) Vascular wilt

Tobacco (Nicotiana tabacum L.). Damping-off

Sumith and Bandara (2002).

Rajapakse et al. (2005)

Ferdinandez et al.

(2019)

de Silva et al. (2005) Snyder \& H.N. Hansen

Water melon (Citrullus lanatus). Vascular wilt

Sapumohotti (1995)

Fusarium

182. pallidoroseum (Matsush.) Nirenberg

Fusarium incarnatum (Roberge) Sacc.

Fusarium proliferatum

(Matsush.) Nirenberg ex Gerlach \& Nirenberg

183. Fusarium proliferatum
(Matsush.) Nirenberg

Fusarium incarnatum

184. Fusarium semitectum Berk. \& Ravenel

(Desm.) Sacc.

Neocosmospora solani

185. Fusarium solani (Mart.) Appel \& Wollenw

(Mart.) L. Lombard \& Crous

186. Fusarium solani (Mart.) Neocosmospora solani (Mart.) L. Lombard \& Crous

Appel \& Wollenw

Neocosmospora solani (Mart.) L. Lombard \& Crous

187. Fusarium solani (Mart.) Appel \& Wollenw

Fusarium solani (Mart.) Neocosmospora solani

188. Appel \& Wollenw (Mart.) L. Lombard \& Crous

189. Fusarium solani (Mart.) Neocosmospora solani Appel \& Wollenw (Mart.) L. Lombard \& Crous

Neocosmospora solani

190. Fusarium solani (Mart.) Appel \& Wollenw
(Mart.) L. Lombard \& Crous
Tea (Camellia sinensis (L.) Senanayake et al. Kuntze). Soft rot

(2015)

Tomato (Solanum

lycopersicon Mill.)

Vascular wilt

Weeraratne and de

Costa (2018)

Brinjal (Solanum

melongena L.). Vascular wilt

Weeraratne and de

Costa (2018)

Polyscias balfouriana

(André) L.H.Bailey, $P$.

filicifolia (C.Moore ex

E.Fourn.) L.H.Bailey

Stem rot, Root rot

Dracaena godseffiana Jeyanandarajah and

Sander ex Mast. Leaf spot Wijesooriya (1997)

Banana (Musa acuminata

Colla). Fruit rot

Anthony et al. (2004).

Banana (Musa acuminata

Colla).

Indrakeerthi and

Crown rot

Adikaram (2011)

Onion (Allium cepa L.)

Bulb rot

Anparasy (1994)

Jack tree (Artocarpus

heterophyllus Lam.)

Kuruppu et al. (2019)

Collar rot

Rubber (Hevea brasiliensis

(Willd. ex A.Juss.) Müll.

Liyanage and

Arg.). Fusarium wilt

Dantanarayana (1983)

Brinjal (Solanum melongena L.). Fruit rot

Rajapakse and Fonseka (2005)

Jojoba plant (Simmondsia chinensis (Link) Wilt disease

Rabeendran and

Raveendranath (1990)

Pepper (Piper nigrum)

Slow decline

Gunawardena et al.

(2019) 


\begin{tabular}{|c|c|c|c|c|}
\hline 191. & $\begin{array}{l}\text { Fusarium solani (Mart.) } \\
\text { Appel \& Wollenw }\end{array}$ & $\begin{array}{l}\text { Neocosmospora solani } \\
\text { (Mart.) L. Lombard \& } \\
\text { Crous }\end{array}$ & $\begin{array}{l}\text { Seed potato (Solanum } \\
\text { tuberosum L.). Dry rot }\end{array}$ & Rajapakse et al. (2006) \\
\hline 192. & $\begin{array}{l}\text { Fusarium solani (Mart.) } \\
\text { Appel \& Wollenw }\end{array}$ & $\begin{array}{l}\text { Neocosmospora solani } \\
\text { (Mart.) L. Lombard \& } \\
\text { Crous }\end{array}$ & $\begin{array}{l}\text { Avocado (Persea } \\
\text { americana Mill.). Fruit rot }\end{array}$ & Adikaram (1986/87) \\
\hline 193. & $\begin{array}{l}\text { Fusarium solani (Mart.) } \\
\text { Appel \& Wollenw }\end{array}$ & $\begin{array}{l}\text { Neocosmospora solani } \\
\text { (Mart.) L. Lombard \& } \\
\text { Crous }\end{array}$ & $\begin{array}{l}\text { Tea (Camellia sinensis (L.) } \\
\text { Kuntze). Soft rot }\end{array}$ & $\begin{array}{l}\text { Senanayake et al. } \\
(2015)\end{array}$ \\
\hline 194. & $\begin{array}{l}\text { Fusarium verticillioides } \\
\text { (Sacc.) Nirenberg }\end{array}$ & $\begin{array}{l}\text { Fusarium fujikuroi } \\
\text { Nirenberg }\end{array}$ & $\begin{array}{l}\text { Maize (Zea mays L.) } \\
\text { Kernal infection }\end{array}$ & $\begin{array}{l}\text { Senevirathna and } \\
\text { Takayuki (2009) }\end{array}$ \\
\hline 195. & $\begin{array}{l}\text { Ganoderma boninense } \\
\text { Pat. }\end{array}$ & $\begin{array}{l}\text { Ganoderma orbiforme } \\
\text { (Fr.) Ryvarden }\end{array}$ & $\begin{array}{l}\text { Coconut (Cocos nucifera } \\
\text { L.) Basal stem rot }\end{array}$ & Peries (1974) \\
\hline 196. & $\begin{array}{l}\text { Ganoderma boninense } \\
\text { Pat. }\end{array}$ & $\begin{array}{l}\text { Ganoderma orbiforme } \\
\text { (Fr.) Ryvarden }\end{array}$ & $\begin{array}{l}\text { Coconut (C. nucifera L.). } \\
\text { Coconut root and bole rot }\end{array}$ & Wijesekera et al. (1996) \\
\hline 197. & $\begin{array}{l}\text { Ganoderma lucidum } \\
\text { (Curtis) P. Karst }\end{array}$ & $\begin{array}{l}\text { Ganoderma lucidum } \\
\text { (Curtis) P. Karst }\end{array}$ & $\begin{array}{l}\text { Cassia nodosa Roxb. } \\
\text { Current name: Cassia } \\
\text { javanica subsp. nodosa } \\
\text { (Roxb.) K. Larsen \& S.S. } \\
\text { Larsen } \\
\text { Ganoderma root and butt rot }\end{array}$ & Fernando (2008) \\
\hline 198. & $\begin{array}{l}\text { Ganoderma lucidum } \\
\text { (Curtis) P. Karst }\end{array}$ & $\begin{array}{l}\text { Ganoderma lucidum } \\
\text { (Curtis) P. Karst }\end{array}$ & $\begin{array}{l}\text { Cassia fistula } \mathrm{L} . \\
\text { Ganoderma root and butt rot }\end{array}$ & Fernando (2008) \\
\hline 199. & $\begin{array}{l}\text { Ganoderma lucidum } \\
\text { (Curtis) P. Karst }\end{array}$ & $\begin{array}{l}\text { Ganoderma lucidum } \\
\text { (Curtis) P. Karst }\end{array}$ & $\begin{array}{l}\text { Delonix regia (Hook.) Raf. } \\
\text { Ganoderma root and butt rot }\end{array}$ & Fernando (2008) \\
\hline 200. & $\begin{array}{l}\text { Geotrichum candidum } \\
\text { Link. }\end{array}$ & $\begin{array}{l}\text { Dipodascus geotrichum } \\
\text { (E.E. Butler \& L.J. } \\
\text { Petersen) Arx }\end{array}$ & $\begin{array}{l}\text { Avocado (Persea } \\
\text { americana Mill.) Sour Rot }\end{array}$ & $\begin{array}{l}\text { Adikaram and } \\
\text { Theivendirarajah (1981) }\end{array}$ \\
\hline
\end{tabular}

$\begin{array}{ll}\text { 201. Geotrichum candidum } & \begin{array}{l}\text { Dipodascus geotrichum } \\ \text { Link. }\end{array} \\ & \text { Petersen) Arx }\end{array}$

202. Gliocladium roseum
Bainier

Clonostachys rosea (Link) Schroers, Samuels, Seifert \& W. Gams
Potato (Solanum tuberosum L.). Rubbery rot

Rajapakse et al. (2006)

Avocado (Persea americana Mill.)
Adikaram and

Theivendirarajah (1981)

\begin{tabular}{|c|c|c|c|c|}
\hline 203. & $\begin{array}{l}\text { Gerlachia oryzae } \\
\text { Hashioka \& Yokoqi) W. } \\
\text { Gams }\end{array}$ & $\begin{array}{l}\text { Microdochium albescens } \\
\text { (Thüm.) Hern.-Restr. \& } \\
\text { Crous, in Hernández- } \\
\text { Restrepo, Groenewald \& } \\
\text { Crous }\end{array}$ & $\begin{array}{l}\text { Rice (Oryza sativa L.) } \\
\text { Leaf scald }\end{array}$ & $\begin{array}{l}\text { Seneviratne and } \\
\text { Jeyanandarajah (2004) }\end{array}$ \\
\hline 204. & $\begin{array}{l}\text { Gibberella fujikuroi } \\
\text { (Sawada) Wollenw }\end{array}$ & $\begin{array}{l}\text { Gibberella fujikuroi } \\
\text { (Sawada) Wollenw. }\end{array}$ & $\begin{array}{l}\text { Rice (Oryza sativa L.) } \\
\text { Bakanae disease }\end{array}$ & $\begin{array}{l}\text { Seneviratne and } \\
\text { Jeyanandarajah (2004) }\end{array}$ \\
\hline 205. & $\begin{array}{l}\text { Gloeosporium } \\
\text { mangiferae Henn. }\end{array}$ & $\begin{array}{l}\text { Colletotrichum coccodes } \\
\text { (Wallr.) S. Hughes }\end{array}$ & $\begin{array}{l}\text { Mango (Mangifera indica } \\
\text { L.) Anthracnose }\end{array}$ & $\begin{array}{l}\text { Kanakaratne and } \\
\text { Adikaram (1985) }\end{array}$ \\
\hline 206. & $\begin{array}{l}\text { Gliocephalotrichum } \\
\text { microchlamydosporum } \\
\text { J.A. Mey, B.J. Willey \& } \\
\text { F.G. Simmons }\end{array}$ & $\begin{array}{l}\text { Gliocephalotrichum } \\
\text { microchlamydosporum } \\
\text { (J.A. Mey.) B.J. Wiley \& } \\
\text { E.G. Simmons }\end{array}$ & $\begin{array}{l}\text { Rambutan (Nephelium } \\
\text { lappaceum L.) } \\
\text { Brown spot }\end{array}$ & Sivakumar et al. (1997) \\
\hline 207. & $\begin{array}{l}\text { Glomerella cingulata } \\
\text { (Stoneman) Spauld. \& } \\
\text { H. Schrenk. }\end{array}$ & $\begin{array}{l}\text { Colletotrichum } \\
\text { gloeosporioides (Penz.) } \\
\text { Penz. \& Sacc. }\end{array}$ & $\begin{array}{l}\text { Anthurium (Anthurium } \\
\text { andraeanum Linden ex } \\
\text { André). Anthracnose }\end{array}$ & $\begin{array}{l}\text { Abeygunawardhane } \\
(1969)\end{array}$ \\
\hline 208. & $\begin{array}{l}\text { Glomerella cingulata } \\
\text { (Stoneman) Spauld. \& } \\
\text { H. Schrenk. }\end{array}$ & $\begin{array}{l}\text { Colletotrichum } \\
\text { gloeosporioides (Penz.) } \\
\text { Penz. \& Sacc. }\end{array}$ & $\begin{array}{l}\text { Ficus religiosa L. } \\
\text { Leaf spot }\end{array}$ & $\begin{array}{l}\text { Mahaarachchikumbura } \\
\text { and Adikaram (2009) }\end{array}$ \\
\hline
\end{tabular}




\begin{tabular}{|c|c|c|c|c|}
\hline 209. & $\begin{array}{l}\text { Glomerella cingulata } \\
\text { (Stoneman) Spauld. \& } \\
\text { H. Schrenk. }\end{array}$ & $\begin{array}{l}\text { Colletotrichum } \\
\text { gloeosporioides (Penz.) } \\
\text { Penz. \& Sacc. }\end{array}$ & $\begin{array}{l}\text { Mangifera indica L. } \\
\text { Anthracnose }\end{array}$ & $\begin{array}{l}\text { N.K.B. Adikaram, } \\
\text { Unpublished work }\end{array}$ \\
\hline 210. & $\begin{array}{l}\text { Glomerella cingulata } \\
\text { (Stoneman) Spauld. \& } \\
\text { H. Schrenk. }\end{array}$ & $\begin{array}{l}\text { Colletotrichum } \\
\text { gloeosporioides (Penz.) } \\
\text { Penz. \& Sacc. }\end{array}$ & $\begin{array}{l}\text { Green pepper (Capsicum } \\
\text { annuum L.). Anthracnose }\end{array}$ & $\begin{array}{l}\text { N.K.B. Adikaram, } \\
\text { Unpublished work }\end{array}$ \\
\hline 211. & $\begin{array}{l}\text { Goplana dioscoreae } \\
\text { (Berk. \& Broome) } \\
\text { Cummins }\end{array}$ & $\begin{array}{l}\text { Goplana dioscoreae } \\
\text { (Berk. \& Broome) } \\
\text { Cummins }\end{array}$ & $\begin{array}{l}\text { Dioscorea alata } \mathrm{L} . \\
\text { Rust disease }\end{array}$ & Weeraratne et al. (2016) \\
\hline 212. & $\begin{array}{l}\text { Goplana dioscoreae } \\
\text { (Berk. \& Broome) } \\
\text { Cummins }\end{array}$ & $\begin{array}{l}\text { Goplana dioscoreae } \\
\text { (Berk. \& Broome) } \\
\text { Cummins }\end{array}$ & $\begin{array}{l}\text { Aerial yam (Dioscorea } \\
\text { bulbifera L.). Rust disease }\end{array}$ & Weeraratne et al. (2016) \\
\hline 213. & $\begin{array}{l}\text { Goplana dioscoreae } \\
\text { Cummins }\end{array}$ & $\begin{array}{l}\text { Goplana dioscoreae } \\
\text { (Berk. \& Broome) } \\
\text { Cummins }\end{array}$ & $\begin{array}{l}\text { Dioscorea pentaphylla L. } \\
\text { Rust disease }\end{array}$ & Weeraratne et al. (2016) \\
\hline 214. & $\begin{array}{l}\text { Goplana dioscoreae } \\
\text { (Berk. \& Broome) } \\
\text { Cummins }\end{array}$ & $\begin{array}{l}\text { Goplana dioscoreae } \\
\text { (Berk. \& Broome) } \\
\text { Cummins }\end{array}$ & $\begin{array}{l}\text { Dioscorea rotundata } \mathrm{L} . \\
\text { Rust disease }\end{array}$ & Weeraratne et al. (2016) \\
\hline 215. & $\begin{array}{l}\text { Goplana dioscoreae } \\
\text { (Berk. \& Broome) } \\
\text { Cummins }\end{array}$ & $\begin{array}{l}\text { Goplana dioscoreae } \\
\text { (Berk. \& Broome) } \\
\text { Cummins }\end{array}$ & $\begin{array}{l}\text { Dioscorea esculenta (Lour.) } \\
\text { Burkill Rust disease }\end{array}$ & Weeraratne et al. (2016) \\
\hline 216. & $\begin{array}{l}\text { Guignardia heveae Syd. } \\
\& \text { P. Syd. }\end{array}$ & $\begin{array}{l}\text { Guignardia heveae Syd. } \\
\& \text { P. Syd. }\end{array}$ & $\begin{array}{l}\text { Rubber (Hevea brasiliensis } \\
\text { (Willd. ex A.Juss.) Müll. } \\
\text { Arg.). Leaf disease }\end{array}$ & IMI 345803 \\
\hline 217. & $\begin{array}{l}\text { Guignardia musae } \\
\text { Racib. }\end{array}$ & Guignardia musae Racib. & $\begin{array}{l}\text { Banana (Musa acuminata } \\
\text { Colla). Freckle disease }\end{array}$ & $\begin{array}{l}\text { Abayasekara et al. } \\
(2013)\end{array}$ \\
\hline 218. & $\begin{array}{l}\text { Helminthosporium } \\
\text { incurvatum C. Bernard, } \\
\text { Bull }\end{array}$ & $\begin{array}{l}\text { Bipolaris incurvata }(\mathrm{C} . \\
\text { Bernard) Alcorn }\end{array}$ & $\begin{array}{l}\text { Coconut palm (Cocos } \\
\text { nucifera L.). Brown spot }\end{array}$ & Mahindapala (1978) \\
\hline 219. & $\begin{array}{l}\text { Helminthosporium } \\
\text { sacchari E.J. Butler }\end{array}$ & $\begin{array}{l}\text { Bipolaris sacchari (E.J. } \\
\text { Butler) Shoemaker }\end{array}$ & $\begin{array}{l}\text { Sugarcane (Saccharum } \\
\text { officinarum) L. } \\
\text { Eye spot disease }\end{array}$ & Comstock (2000) \\
\hline 220. & $\begin{array}{l}\text { Helminthosporium } \\
\text { solani McAlpine }\end{array}$ & $\begin{array}{l}\text { Helminthosporium solani } \\
\text { McAlpine }\end{array}$ & $\begin{array}{l}\text { Potato (Solanum tuberosum } \\
\text { L.). Silver scurf disease }\end{array}$ & $\begin{array}{l}\text { Gunawardana. and } \\
\text { Bandara (1993) }\end{array}$ \\
\hline 221. & $\begin{array}{l}\text { Hemiliea vastatrix } \\
\text { Berk. \& Broome }\end{array}$ & $\begin{array}{l}\text { Hemiliea vastatrix Berk. } \\
\text { \& Broome }\end{array}$ & $\begin{array}{l}\text { Coffee (Coffea arabica L.). } \\
\text { Coffee rust }\end{array}$ & Kularatne (1997) \\
\hline 222. & $\begin{array}{l}\text { Heterosporium } \\
\text { tropaeoli T.E.T. Bond }\end{array}$ & $\begin{array}{l}\text { Acroconidiella tropaeoli } \\
\text { (T.E.T. Bond) J.C. Lindq. } \\
\text { \& Alippi }\end{array}$ & $\begin{array}{l}\text { Tropaeolum majus L. Leaf } \\
\text { spot }\end{array}$ & Bond (1947) \\
\hline 223. & Irpex destruens Petch & Irpex destruens Petch & $\begin{array}{l}\text { Tea (Camellia sinensis L.) } \\
\text { Kuntze). General wood rot }\end{array}$ & Norris (1930) \\
\hline 224. & $\begin{array}{l}\text { Irpex subvinosus (Berk. } \\
\text { \& Broome) Stapers. }\end{array}$ & $\begin{array}{l}\text { Radulodon subvinosus } \\
\text { (Berk. \& Broome) } \\
\text { Stalpers }\end{array}$ & $\begin{array}{l}\text { Tea (Camellia sinensis (L.) } \\
\text { Kuntze). General wood rot }\end{array}$ & Gadd (1936) \\
\hline 225. & $\begin{array}{l}\text { Isariopsis griseola } \\
\text { Sacc. }\end{array}$ & $\begin{array}{l}\text { Pseudocercospora } \\
\text { griseola (Sacc.) Crous \& } \\
\text { U. Braun }\end{array}$ & $\begin{array}{l}\text { Bean (Phaseolus vulgaris } \\
\text { L.). } \\
\text { Angular leaf spot }\end{array}$ & Jayasekara et al. (2016) \\
\hline 226. & $\begin{array}{l}\text { Laetisaria fuciformis } \\
\text { (Berk.) Burds. }\end{array}$ & $\begin{array}{l}\text { Laetisaria fuciformis } \\
\text { (Berk.) Burds. }\end{array}$ & $\begin{array}{l}\text { Grass (Pennisetum } \\
\text { clandestinum Hochst. ex } \\
\text { Chiov.).Red thread disease }\end{array}$ & Adikaram et al. (2001) \\
\hline 227. & $\begin{array}{l}\text { Laetisaria fuciformis } \\
\text { (Berk.) Burds. }\end{array}$ & $\begin{array}{l}\text { Laetisaria fuciformis } \\
\text { (Berk.) Burds. }\end{array}$ & $\begin{array}{l}\text { Grass (Pennisetum glabrum } \\
\text { Steud.). Current name: } \\
\text { Pennisetum thunbergii } \\
\text { Kunth. Red thread disease }\end{array}$ & Adikaram et al. (2001) \\
\hline
\end{tabular}




\begin{tabular}{|c|c|c|c|c|}
\hline 228. & $\begin{array}{l}\text { Lasiodiplodia } \\
\text { crassispora T.I. } \\
\text { Burgess \& P.A. Barber }\end{array}$ & $\begin{array}{l}\text { Lasiodiplodia crassispora } \\
\text { T.I. Burgess \& P.A. } \\
\text { Barber }\end{array}$ & $\begin{array}{l}\text { Cinnamon (Cinnamomum } \\
\text { varum Presl.) Syn. } \\
\text { Cinnamomum zeylanicum } \\
\text { Blume)Rough bark disease }\end{array}$ & Tharangani et al. (2019) \\
\hline 229. & $\begin{array}{l}\text { Lasiodiplodia } \\
\text { crassispora T.I. } \\
\text { Burgess \& P.A. Barber }\end{array}$ & $\begin{array}{l}\text { Lasiodiplodia crassispora } \\
\text { T.I. Burgess \& P.A. } \\
\text { Barber }\end{array}$ & $\begin{array}{l}\text { Dry zone forest trees } \\
\text { Die-back }\end{array}$ & $\begin{array}{l}\text { Bandara and Attanayake } \\
(2016)\end{array}$ \\
\hline 230. & $\begin{array}{l}\text { Lasiodiplodia } \\
\text { theobromae (Pat.) } \\
\text { Griffon \& Maubl }\end{array}$ & $\begin{array}{l}\text { Lasiodiplodia theobromae } \\
\text { (Pat.) Griffon \& Maubl }\end{array}$ & $\begin{array}{l}\text { Dry zone forest trees } \\
\text { Die-back }\end{array}$ & $\begin{array}{l}\text { Bandara and Attanayake } \\
(2016)\end{array}$ \\
\hline 231. & $\begin{array}{l}\text { Lasiodiplodia } \\
\text { theobromae (Pat.) } \\
\text { Griffon \& Maubl. }\end{array}$ & $\begin{array}{l}\text { Lasiodiplodia theobromae } \\
\text { (Pat.) Griffon \& Maubl }\end{array}$ & $\begin{array}{l}\text { Jak (Artocarpus } \\
\text { heterophyllus Lam.) } \\
\text { Lasidiplodia rot }\end{array}$ & $\begin{array}{l}\text { N.K.B. Adikaram, } \\
\text { unpublished work }\end{array}$ \\
\hline 232. & $\begin{array}{l}\text { Lasiodiplodia } \\
\text { theobromae (Pat.) } \\
\text { Griffon \& Maubl. }\end{array}$ & $\begin{array}{l}\text { Lasiodiplodia theobromae } \\
\text { (Pat.) Griffon \& Maubl }\end{array}$ & Dry zone forest trees & $\begin{array}{l}\text { Bandara and Attanayake } \\
(2016)\end{array}$ \\
\hline 233. & $\begin{array}{l}\text { Lasiodiplodia } \\
\text { theobromae (Pat.) } \\
\text { Griffon \& Maubl. }\end{array}$ & $\begin{array}{l}\text { Lasiodiplodia theobromae } \\
\text { (Pat.) Griffon \& Maubl }\end{array}$ & $\begin{array}{l}\text { Rambutan (Nephelium } \\
\text { lappaceum Linn.) } \\
\text { Stem-end rot }\end{array}$ & Sivakumar et al. (1997) \\
\hline 234. & $\begin{array}{l}\text { Lasiodiplodia } \\
\text { theobromae (Pat.) } \\
\text { Griffon \& Maubl. }\end{array}$ & $\begin{array}{l}\text { Lasiodiplodia theobromae } \\
\text { (Pat.) Griffon \& Maubl }\end{array}$ & $\begin{array}{l}\text { Banana (Musa acuminata } \\
\text { Colla). Finger rot }\end{array}$ & Adikaram et al. (2019) \\
\hline 235. & $\begin{array}{l}\text { Lasiodiplodia } \\
\text { theobromae (Pat.) } \\
\text { Griffon \& Maubl. }\end{array}$ & $\begin{array}{l}\text { Lasiodiplodia theobromae } \\
\text { (Pat.) Griffon \& Maubl }\end{array}$ & $\begin{array}{l}\text { Mango (Mangifera indica } \\
\text { L.) } \\
\text { Stem-end rot }\end{array}$ & $\begin{array}{l}\text { Karunanayake et al. } \\
(2015)\end{array}$ \\
\hline 236. & $\begin{array}{l}\text { Lasiodiplodia } \\
\text { theobromae (Pat.) } \\
\text { Griffon \& Maubl. }\end{array}$ & $\begin{array}{l}\text { Lasiodiplodia theobromae } \\
\text { (Pat.) Griffon \& Maubl }\end{array}$ & $\begin{array}{l}\text { Papaya (Carica papaya L.) } \\
\text { fruit Stem-end rot }\end{array}$ & $\begin{array}{l}\text { Abeywickrama et al. } \\
(2012)\end{array}$ \\
\hline 237. & $\begin{array}{l}\text { Lasiodiplodia } \\
\text { theobromae (Pat.) } \\
\text { Griffon \& Maubl. }\end{array}$ & $\begin{array}{l}\text { Lasiodiplodia theobromae } \\
\text { (Pat.) Griffon \& Maubl }\end{array}$ & $\begin{array}{l}\text { Avocado (Persea } \\
\text { americana Mill.) Stem-end } \\
\text { rot }\end{array}$ & $\begin{array}{l}\text { Madhupani and } \\
\text { Adikaram (2017) }\end{array}$ \\
\hline 238. & $\begin{array}{l}\text { Macrophoma musae } \\
\text { (Sacc.) Berl. \& Voglino }\end{array}$ & $\begin{array}{l}\text { Phyllosticta musarum } \\
\text { (Cooke) Aa }\end{array}$ & $\begin{array}{l}\text { Banana (Musa sapientum } \\
\text { L.) } \\
\text { Freckle disease }\end{array}$ & Adikaram (1986/87) \\
\hline 239. & $\begin{array}{l}\text { Macrophoma theicola } \\
\text { Petch }\end{array}$ & $\begin{array}{l}\text { Macrophoma theicola } \\
\text { Petch }\end{array}$ & $\begin{array}{l}\text { Tea (Camellia sinensis (L.) } \\
\text { Kuntze). Stem and branch } \\
\text { canker. }\end{array}$ & $\begin{array}{l}\text { Sabanayagam et al. } \\
\text { (1974) }\end{array}$ \\
\hline 240. & $\begin{array}{l}\text { Macrophoma theicola } \\
\text { Petch }\end{array}$ & $\begin{array}{l}\text { Macrophoma theicola } \\
\text { Petch }\end{array}$ & $\begin{array}{l}\text { Tea (Camellia sinensis (L.) } \\
\text { Kuntze). Ring barking }\end{array}$ & Arulphragasm (1984) \\
\hline 241. & $\begin{array}{l}\text { Macrophomina } \\
\text { phaseolina (Tassi) } \\
\text { Goid. }\end{array}$ & $\begin{array}{l}\text { Macrophomina } \\
\text { phaseolina (Tassi) Goid }\end{array}$ & $\begin{array}{l}\text { Bean (Phaseolus vulgaris } \\
\text { L.). } \\
\text { Charcoal rot }\end{array}$ & $\begin{array}{l}\text { Sivanathan and } \\
\text { Adikaram (1985) }\end{array}$ \\
\hline 242. & $\begin{array}{l}\text { Macrophomina } \\
\text { phaseolina (Tassi) } \\
\text { Goid. }\end{array}$ & $\begin{array}{l}\text { Macrophomina } \\
\text { phaseolina (Tassi) Goid }\end{array}$ & $\begin{array}{l}\text { Brinjal (Solanum } \\
\text { melongena L.). Seed } \\
\text { infection }\end{array}$ & Jeyanandarajah (1990) \\
\hline 243. & $\begin{array}{l}\text { Macrophomina } \\
\text { phaseolina (Tassi) } \\
\text { Goid. }\end{array}$ & $\begin{array}{l}\text { Macrophomina } \\
\text { phaseolina (Tassi) Goid }\end{array}$ & $\begin{array}{l}\text { Sesame (Sesamum indicum } \\
\text { L.). Charcoal rot }\end{array}$ & Kariyawasam (1996) \\
\hline 244. & $\begin{array}{l}\text { Macrophomina } \\
\text { phaseolina (Tassi) } \\
\text { Goid. }\end{array}$ & $\begin{array}{l}\text { Macrophomina } \\
\text { phaseolina (Tassi) Goid }\end{array}$ & $\begin{array}{l}\text { Cowpea (Vigna unguiculata } \\
\text { (L.) Walp.). Seed infection }\end{array}$ & Jeyanandarajah (1990) \\
\hline 245. & $\begin{array}{l}\text { Macrophomina } \\
\text { phaseolina (Tassi) } \\
\text { Goid. }\end{array}$ & $\begin{array}{l}\text { Macrophomina } \\
\text { phaseolina (Tassi) Goid }\end{array}$ & $\begin{array}{l}\text { Lettuce (Lactuca sativa L.) } \\
\text { Seed infection }\end{array}$ & Jeyanandarajah (1990) \\
\hline 246. & $\begin{array}{l}\text { Macrophomina } \\
\text { phaseolina (Tassi) } \\
\text { Goid. }\end{array}$ & $\begin{array}{l}\text { Macrophomina } \\
\text { phaseolina (Tassi) Goid }\end{array}$ & $\begin{array}{l}\text { Rice (Oryzae sativum L.) } \\
\text { Seed infection }\end{array}$ & Jeyanandarajah (1990) \\
\hline
\end{tabular}




\begin{tabular}{|c|c|c|c|c|}
\hline 247. & $\begin{array}{l}\text { Macrophomina } \\
\text { phaseolina (Tassi) } \\
\text { Goid. }\end{array}$ & $\begin{array}{l}\text { Macrophomina } \\
\text { phaseolina (Tassi) Goid }\end{array}$ & $\begin{array}{l}\text { Soy bean (Glycine max } \\
\text { (L.) Merr.). Seed infection }\end{array}$ & Jeyanandarajah (1990) \\
\hline 248. & $\begin{array}{l}\text { Macrophomina } \\
\text { phaseolina (Tassi) } \\
\text { Goid. }\end{array}$ & $\begin{array}{l}\text { Macrophomina } \\
\text { phaseolina (Tassi) Goid }\end{array}$ & $\begin{array}{l}\text { Snake gourd (Trichosanthes } \\
\text { cucumerina subsp. } \\
\text { anguina\} Seed infection }\end{array}$ & Jeyanandarajah (1990) \\
\hline 249. & $\begin{array}{l}\text { Macrosporium carotae } \\
\text { (Ellis. \& Langl.) J.A. } \\
\text { Stev. \& Wellman }\end{array}$ & $\begin{array}{l}\text { Alternaria dauci (J.G. } \\
\text { Kühn) J.W. Groves \& } \\
\text { Skolko }\end{array}$ & $\begin{array}{l}\text { Carrot (Daucus carota L.) } \\
\text { Leaf blight }\end{array}$ & Bond (1947) \\
\hline 250. & $\begin{array}{l}\text { Magnaporthe grisea } \\
\text { (T.T. Hebert) M.E. Barr }\end{array}$ & $\begin{array}{l}\text { Pyricularia grisea Cooke } \\
\text { ex Sacc. }\end{array}$ & $\begin{array}{l}\text { Rice (Oryza sativa L.) } \\
\text { Blast disease }\end{array}$ & $\begin{array}{l}\text { Jayawardana et al. } \\
(2015)\end{array}$ \\
\hline 251. & $\begin{array}{l}\text { Magnaporthe } \\
\text { oryzae B.C. Couch. }\end{array}$ & Pyricularia oryzae Cavara & $\begin{array}{l}\text { Rice (Oryza sativa L.) } \\
\text { Rice blast disease }\end{array}$ & $\begin{array}{l}\text { Seneviratne and Jeya- } \\
\text { nandarajah (2004); } \\
\text { Mithrasena et al. } \\
(2012 \text { b) }\end{array}$ \\
\hline 252. & $\begin{array}{l}\text { Magnaporthe salvinii } \\
\text { (Catt.) R.A. Krause \& } \\
\text { R.K. Webster }\end{array}$ & $\begin{array}{l}\text { Nakataea oryzae (Catt.) J. } \\
\text { Luo \& N. Zhang }\end{array}$ & $\begin{array}{l}\text { Rice (Oryza sativa L.) } \\
\text { Stem rot }\end{array}$ & $\begin{array}{l}\text { Seneviratne and } \\
\text { Jeyanandarajah (2004) }\end{array}$ \\
\hline 253. & $\begin{array}{l}\text { Marasmius equicrinis } \\
\text { Muell. Ex Berk }\end{array}$ & $\begin{array}{l}\text { Marasmius crinis-equi F. } \\
\text { Muell. ex Kalchbr. }\end{array}$ & $\begin{array}{l}\text { Tea (Camellia sinensis (L.) } \\
\text { Kuntze). Horse hair blight }\end{array}$ & Arulpragasam (1989) \\
\hline 254. & $\begin{array}{l}\text { Marasmius crinis-equi } \\
\text { F. Muell. ex Kalchbr. }\end{array}$ & $\begin{array}{l}\text { Marasmius crinis-equi F. } \\
\text { Muell. ex Kalchbr. }\end{array}$ & $\begin{array}{l}\text { Tea (Camellia sinensis (L.) } \\
\text { Kuntze). Horse hair blight }\end{array}$ & Arulpragasam (1989) \\
\hline 255. & $\begin{array}{l}\text { Monilinia fructicola (G. } \\
\text { Winter) Honey }\end{array}$ & $\begin{array}{l}\text { Monilinia fructicola (G. } \\
\text { Winter) Honey }\end{array}$ & $\begin{array}{l}\text { Cocoa (Theobroma cacao } \\
\text { L.). } \\
\text { Pod rot. }\end{array}$ & Adikaram (1986/87) \\
\hline 256. & $\begin{array}{l}\text { Monilochaetes } \\
\text { infuscans } \\
\text { Halst. ex Harter }\end{array}$ & $\begin{array}{l}\text { Monilochaetes infuscans } \\
\text { Harter }\end{array}$ & $\begin{array}{l}\text { Sweet potato (Ipomoea } \\
\text { batatas (L.) Lam.) Scurf } \\
\text { disease }\end{array}$ & $\begin{array}{l}\text { Jeyanandarajah and } \\
\text { Liyanage }(1995 b)\end{array}$ \\
\hline 257. & $\begin{array}{l}\text { Monochaetia kansensis } \\
\text { (Ellis \& Barthol.) Sacc. } \\
\text { \& D. Sacc. }\end{array}$ & $\begin{array}{l}\text { Monochaetia kansensis } \\
\text { (Ellis \& Barthol.) Sacc. \& } \\
\text { D. Sacc. }\end{array}$ & $\begin{array}{l}\text { Cinnomum (Cinnamomum } \\
\text { verum Presl.) Syn. } \\
\text { Cinnamomum zeylanicum } \\
\text { Blume) Rough bark } \\
\text { disease }\end{array}$ & Tharangani et al. (2019) \\
\hline 258. & $\begin{array}{l}\text { Mycosphaerella } \\
\text { eumusae Crous \& } \\
\text { Mour. }\end{array}$ & $\begin{array}{l}\text { Mycosphaerella eumusae } \\
\text { Carlier, M.-F. Zapater, } \\
\text { Lapeyre, D.R. Jones \& } \\
\text { Mour. }\end{array}$ & $\begin{array}{l}\text { Banana (Musa acuminata } \\
\text { Colla). } \\
\text { Septoria leaf spot }\end{array}$ & Udugama (2002) \\
\hline 259. & $\begin{array}{l}\text { Mycosphaerella } \\
\text { henningsii Sivan. }\end{array}$ & $\begin{array}{l}\text { Mycosphaerella } \\
\text { henningsii Sivan. }\end{array}$ & $\begin{array}{l}\text { Manioc (Manihot } \\
\text { esculenta Crantz) Leaf spot }\end{array}$ & $\begin{array}{l}\text { (Adikaram, } \\
\text { Unpublished work) }\end{array}$ \\
\hline 260. & $\begin{array}{l}\text { Mycosphaerella } \\
\text { fijiensis Morelett }\end{array}$ & $\begin{array}{l}\text { Pseudocercospora } \\
\text { fijiensis (M. Morelet) } \\
\text { Deighton }\end{array}$ & $\begin{array}{l}\text { Banana (Musa acuminata } \\
\text { Colla). } \\
\text { Black sigotaka }\end{array}$ & Udugama (2002) \\
\hline 261. & $\begin{array}{l}\text { Mycosphaerella } \\
\text { musicola Leach }\end{array}$ & $\begin{array}{l}\text { Mycosphaerella musicola } \\
\text { Leach }\end{array}$ & $\begin{array}{l}\text { Banana (Musa acuminata } \\
\text { Colla). Yellow Sigotaka }\end{array}$ & Udugama (2002) \\
\hline 262. & $\begin{array}{l}\text { Myrothecium roridum } \\
\text { Tode }\end{array}$ & $\begin{array}{l}\text { Paramyrothecium roridum } \\
\text { (Tode) L. Lombard \& } \\
\text { Crous }\end{array}$ & $\begin{array}{l}\text { Cucumber (Cucumis sativus } \\
\text { L.) }\end{array}$ & Adikaram (1986/87) \\
\hline 263. & $\begin{array}{l}\text { Myrothecium roridum } \\
\text { Tode }\end{array}$ & $\begin{array}{l}\text { Paramyrothecium roridum } \\
\text { (Tode) L. Lombard \& } \\
\text { Crous }\end{array}$ & $\begin{array}{l}\text { Aubergine (Solanum } \\
\text { melongena L.) }\end{array}$ & Adikaram (1986/87) \\
\hline 264. & $\begin{array}{l}\text { Myrothecium roridum } \\
\text { Tode }\end{array}$ & $\begin{array}{l}\text { Paramyrothecium roridum } \\
\text { (Tode) L. Lombard \& } \\
\text { Crous }\end{array}$ & $\begin{array}{l}\text { Water hyacinth (Eichhornia } \\
\text { crassipes Mart. Solms.). } \\
\text { Leaf spot }\end{array}$ & $\begin{array}{l}\text { Hettiarachchi et al. } \\
\text { (1983) }\end{array}$ \\
\hline 265. & $\begin{array}{l}\text { Nattrassia mangiferae } \\
\text { (Syd. \& P. Syd.) B. } \\
\text { Sutton \& Dyko }\end{array}$ & $\begin{array}{l}\text { Neofusicoccum } \\
\text { mangiferae (Syd. \& P. } \\
\text { Syd.) Crous, Slippers \& } \\
\text { A.J.L. Phillips }\end{array}$ & $\begin{array}{l}\text { Rubber (Hevea brasiliensis } \\
\text { (Willd. ex A.Juss.) Müll. } \\
\text { Arg.) Foot canker and } \\
\text { sudden wilt }\end{array}$ & $\begin{array}{l}\text { Jayasinghe and Silva } \\
\text { (1994) }\end{array}$ \\
\hline
\end{tabular}




\begin{tabular}{|c|c|c|c|c|}
\hline 266. & $\begin{array}{l}\text { Nemania diffusa } \\
\text { (Sowerby) Gray }\end{array}$ & $\begin{array}{l}\text { Nemania diffusa } \\
\text { (Sowerby) Gray }\end{array}$ & $\begin{array}{l}\text { Tea (Camellia sinensis (L.) } \\
\text { Kuntze) Hypoxylon wood } \\
\text { rot }\end{array}$ & $\begin{array}{l}\text { Balasuriya and } \\
\text { Adikaram (2009; 2002) }\end{array}$ \\
\hline 267. & $\begin{array}{l}\text { Neocosmospora } \\
\text { vasinfecta } \text { E.F. Smith }\end{array}$ & $\begin{array}{l}\text { Fusarium } \\
\text { neocosmosporiellum } \\
\text { O’Donnell \& Geiser }\end{array}$ & $\begin{array}{l}\text { Aswenna (S) (Alysicarpus } \\
\text { vaginalis (L). DC.) }\end{array}$ & $\begin{array}{l}\text { Fernando and } \\
\text { Abeywickrama (1996) }\end{array}$ \\
\hline 268. & $\begin{array}{l}\text { Neofusicoccum } \\
\text { brasiliense M.W. } \\
\text { Marques, A.J.L. Phillips } \\
\text { \& Camara }\end{array}$ & $\begin{array}{l}\text { Neofusicoccum } \\
\text { brasiliense M.W. } \\
\text { Marques, A.J.L. Phillips } \\
\text { \& Camara }\end{array}$ & $\begin{array}{l}\text { Mango (Mangifera indica } \\
\text { L.). } \\
\text { Stem-end browning }\end{array}$ & $\begin{array}{l}\text { Dissanayake, Yakanda } \\
\text {-wala \& Adikaram } \\
\text { (Unpublished work) }\end{array}$ \\
\hline 269. & $\begin{array}{l}\text { Neofusicoccum } \\
\text { parvum (Pennycook } \\
\text { \& Samuels) Crous, } \\
\text { Slippers \& A.J.L. } \\
\text { Phillips) }\end{array}$ & $\begin{array}{l}\text { Neofusicoccum parvum } \\
\text { (Pennycook \& Samuels) } \\
\text { Crous, Slippers \& A.J.L. } \\
\text { Phillips) }\end{array}$ & $\begin{array}{l}\text { Cinnomum (Cinnamomum } \\
\text { verum Presl.) Syn. } \\
\text { Cinnamomum zeylanicum } \\
\text { Blume) Rough bark disease }\end{array}$ & $\begin{array}{l}\text { Tharangani et al. } \\
(2019)\end{array}$ \\
\hline 270. & $\begin{array}{l}\text { Neofusicoccum ribis } \\
\text { (Slippers, Crous \& M.J. } \\
\text { Wingf.) Crous, Slippers } \\
\text { \& A.J.L. Phillips) }\end{array}$ & $\begin{array}{l}\text { Neofusicoccum ribis } \\
\text { (Slippers, Crous \& M.J. } \\
\text { Wingf.) Crous, Slippers \& } \\
\text { A.J.L. Phillips) }\end{array}$ & $\begin{array}{l}\text { Cinnomum (Cinnamomum } \\
\text { verum Presl. Syn. } \\
\text { Cinnamomum zeylanicum } \\
\text { Blume) Rough bark disease }\end{array}$ & $\begin{array}{l}\text { Tharangani et al. } \\
(2019)\end{array}$ \\
\hline 271. & Nigrospora Zimm. & Nigrospora Zimm. & $\begin{array}{l}\text { Kurakkan (Eleusine } \\
\text { coracana (L.) Gaertn) } \\
\text { Panicle browning } \\
\end{array}$ & Rajapakse et al. (2003) \\
\hline 272. & $\begin{array}{l}\text { Oidiopsis taurica } \text { Lév. } \\
\text { E.S. Salmon }\end{array}$ & $\begin{array}{l}\text { Leveillula taurica (Lév.) } \\
\text { G. Arnaud }\end{array}$ & $\begin{array}{l}\text { Pigeon pea (Cajanus cajan } \\
\text { (L.) Millsp.). Powdery } \\
\text { mildew }\end{array}$ & $\begin{array}{l}\text { Abeygunawardhane } \\
\text { (1969) }\end{array}$ \\
\hline 273. & $\begin{array}{l}\text { Oidium heveae B.A. } \\
\text { Steinm }\end{array}$ & $\begin{array}{l}\text { Oidium heveae B.A. } \\
\text { Steinm. }\end{array}$ & $\begin{array}{l}\text { Rubber (Hevea brasiliensis } \\
\text { (Willd. ex A.Juss.) Müll. } \\
\text { Arg.) Powdery Mildew }\end{array}$ & Jayasinghe (1999a,b) \\
\hline 274. & $\begin{array}{l}\text { Oidium mangiferae } \\
\text { Berthet Bolm. }\end{array}$ & $\begin{array}{l}\text { Oidium mangiferae } \\
\text { Berthet Bolm }\end{array}$ & $\begin{array}{l}\text { Mango (Mangifera indica } \\
\text { L.) } \\
\text { Mildew disease }\end{array}$ & Sinniah (2010) \\
\hline 275. & $\begin{array}{l}\text { Oidium mangiferae } \\
\text { Berthet Bolm. }\end{array}$ & $\begin{array}{l}\text { Oidium mangiferae } \\
\text { Berthet Bolm }\end{array}$ & $\begin{array}{l}\text { Pedilanthus tithymaloides } \\
\text { (L.) Poit. Current name: } \\
\text { Euphorbia tithymaloides L. } \\
\text { Powdery mildew }\end{array}$ & Adikaram et al. (2002) \\
\hline 276. & Oidium nephelii Hadiw. & $\begin{array}{l}\text { Pseudoidium nephelii } \\
\text { (Hadiw. ex U. Braun) U. } \\
\text { Braun \& R.T.A. Cook }\end{array}$ & $\begin{array}{l}\text { Rambutan (Nephelium } \\
\text { lappaceum L.) } \\
\text { Powdery mildew }\end{array}$ & Alahakoon et al. (2010) \\
\hline 277. & $\begin{array}{l}\text { Ophiobolus oryzinus } \\
\text { Sacc. }\end{array}$ & $\begin{array}{l}\text { Gaeumannomyces } \\
\text { graminis (Sacc.) Arx \& } \\
\text { D.L. Olivier }\end{array}$ & $\begin{array}{l}\text { Rice (Oryza sativa L.) } \\
\text { Crown sheath rot. }\end{array}$ & Walker (1972) \\
\hline 278. & $\begin{array}{l}\text { Penicillium digitatum } \\
\text { (Pers.) Sacc. }\end{array}$ & $\begin{array}{l}\text { Penicillium digitatum } \\
\text { (Pers.) Sacc. }\end{array}$ & $\begin{array}{l}\text { Orange (Citrus sinensis (L.) } \\
\text { Osbeck). Green mould }\end{array}$ & $\begin{array}{l}\text { Adikaram (Unpublished } \\
\text { work) }\end{array}$ \\
\hline 279. & $\begin{array}{l}\text { Penicillium digitatum } \\
\text { (Pers.) Sacc. }\end{array}$ & $\begin{array}{l}\text { Penicillium digitatum } \\
\text { (Pers.) Sacc. }\end{array}$ & $\begin{array}{l}\text { Grape fruit (Citrus grandis } \\
\text { var. racemosa (M. Roem.) } \\
\text { B.C. Stone). Current name: } \\
\text { Citrus decumana var. } \\
\text { racemosa M. Roem. Green } \\
\text { mould }\end{array}$ & $\begin{array}{l}\text { Adikaram (Unpublished } \\
\text { work) }\end{array}$ \\
\hline 280. & $\begin{array}{l}\text { Penicillium } \\
\text { funiculosum Thom. }\end{array}$ & $\begin{array}{l}\text { Talaromyces funiculosus } \\
\text { (Thom) Samson, N. } \\
\text { Yilmaz, Frisvad \& Seifert, }\end{array}$ & $\begin{array}{l}\text { Pineapple (Ananas comosus } \\
\text { (L.) Merril) Fruitlet core rot }\end{array}$ & Adikaram et al. (2019) \\
\hline 281. & $\begin{array}{l}\text { Penicillium italicum } \\
\text { Wehmer. }\end{array}$ & $\begin{array}{l}\text { Penicillium italicum } \\
\text { Wehmer }\end{array}$ & $\begin{array}{l}\text { Grapefruit (Citrus grandis } \\
\text { var. racemosa (M. Roem.) } \\
\text { B.C. Stone). Blue mould }\end{array}$ & $\begin{array}{l}\text { Adikaram, Unpublished } \\
\text { work }\end{array}$ \\
\hline 282. & $\begin{array}{l}\text { Penicillium } \\
\text { purpurogenum Stoll }\end{array}$ & $\begin{array}{l}\text { Penicillium } \\
\text { purpureogenum Stoll }\end{array}$ & Averrhoa bilimbi Red spot & $\begin{array}{l}\text { Dahanayake and } \\
\text { Wijesundera (1994) }\end{array}$ \\
\hline
\end{tabular}




\begin{tabular}{|c|c|c|c|c|}
\hline 283. & $\begin{array}{l}\text { Pestalotia theae } \\
\text { Sawada }\end{array}$ & $\begin{array}{l}\text { Pseudopestalotiopsis } \\
\text { theae (Sawada) } \\
\text { Maharachch., K.D. Hyde } \\
\text { \& Crous }\end{array}$ & $\begin{array}{l}\text { Tea (Camellia sinensis (L.) } \\
\text { Kuntze). Die-back }\end{array}$ & Arulpragasam (1990) \\
\hline 284. & $\begin{array}{l}\text { Pestalotia parmarum } \\
\text { (Cooke) Steyaert }\end{array}$ & $\begin{array}{l}\text { Pestalotiopsis palmarum } \\
\text { (Cooke) Steyaert }\end{array}$ & $\begin{array}{l}\text { Coconut palm (Cocos } \\
\text { nucifera L.). Grey blight }\end{array}$ & Mahindpala (1978) \\
\hline 285. & Pestalotia sp. & Pestalotiopsis sp. & $\begin{array}{l}\text { Cinnamon (Cinnamomum } \\
\text { verum Presl. Syn. } \\
\text { Cinnamomum zeylanicum } \\
\text { Blume) Grey blight }\end{array}$ & $\begin{array}{l}\text { Rajapakse and } \\
\text { Wasantha Kumara } \\
(2007)\end{array}$ \\
\hline 286. & $\begin{array}{l}\text { Pestalotiopsis longiseta } \\
\text { (Speg.) K. Dai \& Ts. } \\
\text { Kobay. }\end{array}$ & $\begin{array}{l}\text { Pestalotiopsis longiseta } \\
\text { (Speg.) K. Dai \& Tak. } \\
\text { Kobay. }\end{array}$ & $\begin{array}{l}\text { Tea (Camellia sinensis (L.) } \\
\text { Kuntze) Grey blight }\end{array}$ & $\begin{array}{l}\text { Maharachchikumbura et } \\
\text { al. }(2013)\end{array}$ \\
\hline 287. & $\begin{array}{l}\text { Pestalotiopsis psidii } \\
\text { (Pat.) Mordue }\end{array}$ & $\begin{array}{l}\text { Pestalotiopsis psidii (Pat.) } \\
\text { Mordue }\end{array}$ & $\begin{array}{l}\text { Guava (Psidium guava } \\
\text { Griseb. Current name: } \\
\text { Psidium guajava L.) } \\
\text { Canker }\end{array}$ & Alahakoon et al. (2008) \\
\hline 288. & $\begin{array}{l}\text { Pestalotiopsis } \\
\text { versicolor (Speg.) } \\
\text { Steyaert }\end{array}$ & $\begin{array}{l}\text { Pestalotiopsis versicolor } \\
\text { (Speg.) Steyaert }\end{array}$ & $\begin{array}{l}\text { Avocado (Persea } \\
\text { americana Mill.) }\end{array}$ & $\begin{array}{l}\text { Adikaram and } \\
\text { Karunaratne (1998) }\end{array}$ \\
\hline 289. & $\begin{array}{l}\text { Phaeotrichoconis } \\
\text { crotalariae M.A.Salam } \\
\text { \& P.N. Rao }\end{array}$ & $\begin{array}{l}\text { Phaeotrichoconis } \\
\text { crotalariae (M.A. Salam } \\
\text { \& P.N. Rao) Subram }\end{array}$ & $\begin{array}{l}\text { Water hyacinth (Eichhornia } \\
\text { crassipes Mart. Solms.) } \\
\text { Leaf spot }\end{array}$ & $\begin{array}{l}\text { Hettiarachchi et al. } \\
\text { (1983) }\end{array}$ \\
\hline 290. & $\begin{array}{l}\text { Phaeophleospora } \\
\text { elaeocarpi sp.nov. } \\
\text { Rangel }\end{array}$ & $\begin{array}{l}\text { Phaeophleospora } \\
\text { elaeocarpi T.E.T. Bond }\end{array}$ & $\begin{array}{l}\text { Elaeocarpus amoenus } \\
\text { Thwaites Thw. Bird's eye } \\
\text { spot }\end{array}$ & Bond (1947) \\
\hline 291. & $\begin{array}{l}\text { Phellinus lamaensis } \\
\text { (Murrill) Pat. }\end{array}$ & $\begin{array}{l}\text { Phellinus lamaensis } \\
\text { (Murrill) Pat. }\end{array}$ & $\begin{array}{l}\text { Cinnomum (Cinnamomum } \\
\text { verum Presl. Syn. } \\
\text { Cinnamomum zeylanicum } \\
\text { Blume) Brown root rot }\end{array}$ & $\begin{array}{l}\text { Rajapakse and } \\
\text { Wasantha Kumara } \\
\text { (2007) }\end{array}$ \\
\hline 292. & $\begin{array}{l}\text { Phellinus noxius } \\
\text { (Corner) G.H. Cunn. }\end{array}$ & $\begin{array}{l}\text { Pyrrhoderma noxium } \\
\text { (Corner) L.W. Zhou \& } \\
\text { Y.C. Dai }\end{array}$ & $\begin{array}{l}\text { Tea (Camellia sinensis (L.) } \\
\text { Kuntze). Brown root rot }\end{array}$ & Arulpragasam (1989) \\
\hline 293. & $\begin{array}{l}\text { Phoma macdonaldii } \\
\text { Boerema }\end{array}$ & $\begin{array}{l}\text { Plenodomus lindquistii } \\
\text { (Frezzi) Gruyter, } \\
\text { Aveskamp \& Verkley }\end{array}$ & $\begin{array}{l}\text { Sunflower (Helianthus } \\
\text { annuus L.) Phoma black } \\
\text { stem }\end{array}$ & $\begin{array}{l}\text { Weeraratne and } \\
\text { Priyantha (2003) }\end{array}$ \\
\hline 294. & $\begin{array}{l}\text { Phomopsis caricae } \\
\text { papayae Petr. \& Cif. }\end{array}$ & $\begin{array}{l}\text { Diaporthe caricae- } \\
\text { papayae (Petr. \& Cif.) } \\
\text { Rossman \& Udayanga }\end{array}$ & $\begin{array}{l}\text { Papaya (Carica papaya L.) } \\
\text { fruit. Phomopsis rot }\end{array}$ & $\begin{array}{l}\text { Abeywickrema et al. } \\
(2012)\end{array}$ \\
\hline 295. & Phomopsis sp. & Phomopsis sp. & $\begin{array}{l}\text { Cinnomum (Cinnamomum } \\
\text { verum Presl. Syn. } \\
\text { Cinnamomum zeylanicum } \\
\text { Blume) Rough bark } \\
\text { disease }\end{array}$ & Jayasinghe et al. (2017) \\
\hline 296. & Phomopsis sp & Phomopsis sp. & $\begin{array}{l}\text { Avocado (Persea } \\
\text { americana Mill.) }\end{array}$ & Adikaram (1986/87) \\
\hline 297. & $\begin{array}{l}\text { Phomopsis psidii Nag } \\
\text { Raj \& Ponnappa }\end{array}$ & $\begin{array}{l}\text { Phomopsis psidii Nag Raj } \\
\text { \& Ponnappa }\end{array}$ & $\begin{array}{l}\text { Guava (Psidium guava } \\
\text { Griseb.. Current name: } \\
\text { Psidium guajava L.) } \\
\text { Styler-end rot }\end{array}$ & Alahakoon et al. (2008) \\
\hline 298. & $\begin{array}{l}\text { Phomopsis theae Petch. } \\
\text { T. }\end{array}$ & $\begin{array}{l}\text { Diaporthe theae (Petch) } \\
\text { Rossman \& Udayanga }\end{array}$ & $\begin{array}{l}\text { Cinchona (Cinchona } \\
\text { officinalis) } \\
\text { Lethal stem canker }\end{array}$ & Arulpragasm (1980) \\
\hline 299. & $\begin{array}{l}\text { Phomopsis theae Petch. } \\
\text { T. }\end{array}$ & $\begin{array}{l}\text { Diaporthe theae (Petch) } \\
\text { Rossman \& Udayanga }\end{array}$ & $\begin{array}{l}\text { Tea (Camellia sinensis (L.) } \\
\text { Kuntze) } \\
\text { Collar and branch canker }\end{array}$ & $\begin{array}{l}\text { Shanmuganathan } \\
(1965) ; \\
\text { Shanmuganathan and } \\
\text { Rodrigo (1966) }\end{array}$ \\
\hline 300. & $\begin{array}{l}\text { Phomopsis theae Petch. } \\
\text { T. }\end{array}$ & $\begin{array}{l}\text { Diaporthe theae (Petch) } \\
\text { Rossman \& Udayanga }\end{array}$ & $\begin{array}{l}\text { Tea (Camellia sinensis (.) } \\
\text { Kuntze). Ring barking }\end{array}$ & Arulpragasm (1984) \\
\hline
\end{tabular}




\begin{tabular}{|c|c|c|c|c|}
\hline 301. & $\begin{array}{l}\text { Phomopsis vexans } \\
\text { (Sacc. \& P. Syd.) Harter }\end{array}$ & $\begin{array}{l}\text { Phomopsis vexans (Sacc. } \\
\& \text { P. Syd.) Harter }\end{array}$ & $\begin{array}{l}\text { Brinjal (Solanum } \\
\text { melongena L.) Phomopsis } \\
\text { blight }\end{array}$ & $\begin{array}{l}\text { Mahendranathan et al. } \\
(2010)\end{array}$ \\
\hline 302. & $\begin{array}{l}\text { Phomopsis viticola } \\
\text { (Sacc.) Sacc. }\end{array}$ & $\begin{array}{l}\text { Diaporthe neoviticola } \\
\text { Udayanga, Crous \& K.D. } \\
\text { Hyde }\end{array}$ & $\begin{array}{l}\text { Grape (Vitis vinifera L.) } \\
\text { Cane and leaf spot }\end{array}$ & Priyantha et al. (2009) \\
\hline 303. & $\begin{array}{l}\text { Phyllosticta antirrhini } \\
\text { P. Syd. }\end{array}$ & $\begin{array}{l}\text { Heterophoma poolensis } \\
\text { (Taubenh.) Qian Chen \& } \\
\text { L. Cai }\end{array}$ & $\begin{array}{l}\text { Antirrhinum majus L. } \\
\text { Leaf spot }\end{array}$ & Bond (1947) \\
\hline 304. & $\begin{array}{l}\text { Phyllosticta musarum } \\
\text { (Cooke) Vander }\end{array}$ & $\begin{array}{l}\text { Phyllosticta musarum } \\
\text { (Cooke) Aa }\end{array}$ & $\begin{array}{l}\text { Banana (Musa acuminata } \\
\text { Colla.) Freckle disease }\end{array}$ & $\begin{array}{l}\text { Abayasekara et al. } \\
(2013)\end{array}$ \\
\hline 305. & $\begin{array}{l}\text { Phyllosticta } \\
\text { capitalensis } \\
\text { Henn. }\end{array}$ & $\begin{array}{l}\text { Phyllosticta capitalensis } \\
\text { Henn. }\end{array}$ & $\begin{array}{l}\text { Rubber (Hevea brasiliensis) } \\
\text { Leaf disease }\end{array}$ & Herath et al. (2019) \\
\hline 306. & $\begin{array}{l}\text { Phyllosticta grevilleae } \\
\text { Gadd }\end{array}$ & $\begin{array}{l}\text { Phyllosticta grevilleae } \\
\text { Gadd }\end{array}$ & $\begin{array}{l}\text { Grevelleas (Grevillea } \\
\text { robusta A. Cunn. ex R. Br. } \\
\text { A. Cunn.). Leaf fall disease }\end{array}$ & Herbarium IMI 674 \\
\hline 307. & $\begin{array}{l}\text { Physoderma maydis } \\
\text { (Miyabe) Miyabe }\end{array}$ & $\begin{array}{l}\text { Physoderma maydis } \\
\text { (Miyabe) Miyabe }\end{array}$ & $\begin{array}{l}\text { Corn (Zea mays L.) } \\
\text { Brown spot }\end{array}$ & $\begin{array}{l}\text { Weeraratne and } \\
\text { Jayasinghe (2006). }\end{array}$ \\
\hline 308. & $\begin{array}{l}\text { Pleurostomophora } \\
\text { richardsiae (Nannf.) L. }\end{array}$ & $\begin{array}{l}\text { Pleurostoma richardsiae } \\
\text { (Nannf.) Réblová \& } \\
\text { Jaklitsch }\end{array}$ & $\begin{array}{l}\text { Weera (S) (Drypetes } \\
\text { sapierea (Wight \& Arn.) } \\
\text { Pax \& K.Hoffm.) Wood } \\
\text { decay }\end{array}$ & Bandara et al. (2016) \\
\hline 309. & $\begin{array}{l}\text { Pleurostomophora } \\
\text { richardsiae (Nannf.) L. }\end{array}$ & $\begin{array}{l}\text { Pleurostoma richardsiae } \\
\text { (Nannf.) Réblová \& } \\
\text { Jaklitsch }\end{array}$ & $\begin{array}{l}\text { Kaluwara (S) Ebony } \\
\text { (Diospyros ebenu J.Koenig } \\
\text { ex Retz. Wood decay }\end{array}$ & Bandara et al. (2016) \\
\hline 310. & $\begin{array}{l}\text { Pleurostomophora } \\
\text { richardsiae (Nannf.) L. }\end{array}$ & $\begin{array}{l}\text { Pleurostoma richardsiae } \\
\text { (Nannf.) Réblová \& } \\
\text { Jaklitsch }\end{array}$ & $\begin{array}{l}\text { Palu (S) (Manilkara } \\
\text { hexandra (Roxb.) Dubard) } \\
\text { Wood decay }\end{array}$ & Bandara et al. (2016) \\
\hline 311. & $\begin{array}{l}\text { Poria hypolateritia } \\
\text { Berk. ex Cooke. } \\
\text { Syn. Ceriporiopsis } \\
\text { hypolateritius (Berk. ex } \\
\text { Cooke) }\end{array}$ & $\begin{array}{l}\text { Ceriporiopsis } \\
\text { hypolateritia (Berk. ex } \\
\text { Cooke) Ryvarden }\end{array}$ & $\begin{array}{l}\text { Tea (Camellia sinensis (L.) } \\
\text { Kuntze). } \\
\text { Poria root disease }\end{array}$ & $\begin{array}{l}\text { Wijesundera and } \\
\text { Kulatunga (1993) }\end{array}$ \\
\hline 312. & $\begin{array}{l}\text { Poria hypolateritia } \\
\text { Berk. ex Cooke. } \\
\text { Syn. Ceriporiopsis } \\
\text { hypolateritius (Berk. ex } \\
\text { Cooke) }\end{array}$ & $\begin{array}{l}\text { Ceriporiopsis } \\
\text { hypolateritia (Berk. ex } \\
\text { Cooke) Ryvarden }\end{array}$ & $\begin{array}{l}\text { Tea (Camellia sinensis (L.) } \\
\text { Kuntze) } \\
\text { General wood rot }\end{array}$ & $\begin{array}{l}\text { Mulder and Redlich } \\
\text { (1962) }\end{array}$ \\
\hline 313. & $\begin{array}{l}\text { Poria hypolateritia } \\
\text { Berk. ex Cooke }\end{array}$ & $\begin{array}{l}\text { Ceriporiopsis } \\
\text { hypolateritia (Berk. ex } \\
\text { Cooke) Ryvarden }\end{array}$ & $\begin{array}{l}\text { Tea (Camellia sinensis (L.) } \\
\text { Kuntze) } \\
\text { Red root rot }\end{array}$ & $\begin{array}{l}\text { Mulder and Redlich } \\
\text { (1962) }\end{array}$ \\
\hline 314. & $\begin{array}{l}\text { Puccinia droogensis } \\
\text { Butler }\end{array}$ & $\begin{array}{l}\text { Puccinia droogensis E.J. } \\
\text { Butler }\end{array}$ & $\begin{array}{l}\text { Berberis sp. } \\
\text { Rust disease }\end{array}$ & $\begin{array}{l}\text { N.K.B. Adikaram, } \\
\text { unpublished work CMI } \\
\text { H1319/82/YS18 }\end{array}$ \\
\hline 315. & $\begin{array}{l}\text { Puccinia pelargonii- } \\
\text { zonalis Doidge }\end{array}$ & $\begin{array}{l}\text { Puccinia pelargonii- } \\
\text { zonalis Doidge }\end{array}$ & $\begin{array}{l}\text { Geranium nepalense Sweet } \\
\text { Leaf rust }\end{array}$ & Adikaram et al. (2013) \\
\hline 316. & Pyricularia sp. & Pyricularia sp. & $\begin{array}{l}\text { Kurakkan (Eleusine } \\
\text { coracana (L.) Gaertn) Leaf } \\
\text { blast }\end{array}$ & Rajapakse et al. (2003) \\
\hline 317. & $\begin{array}{l}\text { Rhizoctonia bataticola } \\
\text { Taubenh }\end{array}$ & $\begin{array}{l}\text { Macrophomina } \\
\text { phaseolina (Tassi) Goid }\end{array}$ & $\begin{array}{l}\text { Tea (Camellia sinensis (L.) } \\
\text { Kuntze). General wood rot }\end{array}$ & Norris (1930) \\
\hline 318. & $\begin{array}{l}\text { Rhizoctonia solani } \\
\text { Kühn }\end{array}$ & $\begin{array}{l}\text { Rhizoctonia solani J.G. } \\
\text { Kühn }\end{array}$ & $\begin{array}{l}\text { Beet (Beta vulgaris) } \\
\text { Black rot/Damping off }\end{array}$ & $\begin{array}{l}\text { Abeygunawardhane } \\
\text { (1969) }\end{array}$ \\
\hline 319. & $\begin{array}{l}\text { Rhizoctonia solani } \\
\text { Kühn }\end{array}$ & $\begin{array}{l}\text { Rhizoctonia solani J.G. } \\
\text { Kühn }\end{array}$ & Codiaeum variegatum (L.) & $\begin{array}{l}\text { Kelaniyangoda et al. } \\
(2002)\end{array}$ \\
\hline
\end{tabular}




\begin{tabular}{|c|c|c|c|c|}
\hline 320. & $\begin{array}{l}\text { Rhizoctonia solani } \\
\text { Kühn }\end{array}$ & $\begin{array}{l}\text { Rhizoctonia solani J.G. } \\
\text { Kühn }\end{array}$ & $\begin{array}{l}\text { Kiriala (S) (Xanthosoma } \\
\text { sagittifolium (L) schott) } \\
\text { Corm rot }\end{array}$ & Rajapakse et al. (2006) \\
\hline 321. & $\begin{array}{l}\text { Rhizoctonia solani } \\
\text { Kühn }\end{array}$ & $\begin{array}{l}\text { Rhizoctonia solani J.G. } \\
\text { Kühn }\end{array}$ & $\begin{array}{l}\text { Turfgrass (Zoysia matrella } \\
\text { (L.) Merr.)Brown patch } \\
\text { disease }\end{array}$ & $\begin{array}{l}\text { Adikaram and } \\
\text { Yakandawala (2017) }\end{array}$ \\
\hline 322. & $\begin{array}{l}\text { Rhizoctonia solani } \\
\text { Kuhn }\end{array}$ & $\begin{array}{l}\text { Rhizoctonia solani J.G. } \\
\text { Kühn }\end{array}$ & $\begin{array}{l}\text { Rice (Oryza sativa L.) } \\
\text { Sheath blight }\end{array}$ & $\begin{array}{l}\text { Kekulandara et al. } \\
(2016)\end{array}$ \\
\hline 323. & $\begin{array}{l}\text { Rhizoctonia solani } \\
\text { Kuhn }\end{array}$ & $\begin{array}{l}\text { Rhizoctonia solani J.G. } \\
\text { Kühn }\end{array}$ & $\begin{array}{l}\text { Tea (Camellia sinensis (L.) } \\
\text { Kuntze) Rhizoctonia leaf } \\
\text { disease }\end{array}$ & Gadd (1929) \\
\hline 324. & $\begin{array}{l}\text { Rhizopus oryzae Went } \\
\text { \& Prins. }\end{array}$ & $\begin{array}{l}\text { Rhizopus arrhizus A. } \\
\text { Fisch }\end{array}$ & $\begin{array}{l}\text { Avocado (Persea } \\
\text { americana Mill.) fruit } \\
\text { Rhizopus rot }\end{array}$ & $\begin{array}{l}\text { Adikaram and } \\
\text { Theivendirarajah (1981) }\end{array}$ \\
\hline 325. & $\begin{array}{l}\text { Rhizopus oryzae Went } \\
\text { \& Prins }\end{array}$ & $\begin{array}{l}\text { Rhizopus arrhizus A. } \\
\text { Fisch }\end{array}$ & $\begin{array}{l}\text { Avocado (Persea } \\
\text { americana Mill.) Fruit rot }\end{array}$ & $\begin{array}{l}\text { Adikaram and } \\
\text { Theivendirarajah (1981) }\end{array}$ \\
\hline 326. & $\begin{array}{l}\text { Rhizopus stolonifer } \\
\text { (Ehrheb.) Vuill. }\end{array}$ & $\begin{array}{l}\text { Rhizopus stolonifer } \\
\text { (Ehrenb.) Vuill. }\end{array}$ & $\begin{array}{l}\text { Avocado (Persea } \\
\text { americana Mill.) fruit } \\
\text { Rhizopus rot }\end{array}$ & $\begin{array}{l}\text { Adikaram and } \\
\text { Theivendirarajah (1981) }\end{array}$ \\
\hline 327. & $\begin{array}{l}\text { Rhizopus stolonifer } \\
\text { (Ehrheb.) Vuill. }\end{array}$ & $\begin{array}{l}\text { Rhizopus stolonifer } \\
\text { (Ehrenb.) Vuill. }\end{array}$ & $\begin{array}{l}\text { Papaya (Carica papaya L.) } \\
\text { fruit. Rhizopus rot }\end{array}$ & $\begin{array}{l}\text { Abeywickrema et al. } \\
(2012)\end{array}$ \\
\hline 328. & $\begin{array}{l}\text { Rigidoporus lignosus } \\
\text { (Klotzsch) Imazeki }\end{array}$ & $\begin{array}{l}\text { Rigidoporus microporus } \\
\text { (Sw.) Overeem }\end{array}$ & $\begin{array}{l}\text { Rubber (Hevea brasiliensis } \\
\text { (Willd. ex A. Juss.) Müll. } \\
\text { Arg.). White root rot }\end{array}$ & $\begin{array}{l}\text { Liyanage and Peries } \\
\text { (1983) }\end{array}$ \\
\hline 329. & $\begin{array}{l}\text { Rigidoporus } \\
\text { microporus (Sw.) } \\
\text { Overeem }\end{array}$ & $\begin{array}{l}\text { Rigidoporus microporus } \\
\text { (Sw.) Overeem }\end{array}$ & $\begin{array}{l}\text { Bedi-del (S) Artocarpus } \\
\text { nobilis Thw.) White root } \\
\text { disease }\end{array}$ & $\begin{array}{l}\text { Madushani et al. (2014) } \\
\text { Kuruppu et al. (2019) }\end{array}$ \\
\hline 330. & $\begin{array}{l}\text { Rigidoporus } \\
\text { microporus (Sw.) } \\
\text { Overeem }\end{array}$ & $\begin{array}{l}\text { Rigidoporus microporus } \\
\text { (Sw.) Overeem }\end{array}$ & $\begin{array}{l}\text { Rubber (Hevea brasiliensis } \\
\text { (Willd. ex A.Juss.) Müll. } \\
\text { Arg.). White root disease }\end{array}$ & $\begin{array}{l}\text { Jayasuriya and } \\
\text { Thennakoon (2007) }\end{array}$ \\
\hline 331. & $\begin{array}{l}\text { Rigidoporus } \\
\text { microporus (Sw.) } \\
\text { Overeem }\end{array}$ & $\begin{array}{l}\text { Rigidoporus microporus } \\
\text { (Sw.) Overeem }\end{array}$ & $\begin{array}{l}\text { Curry leaf (Murraya } \\
\text { koenigii (L.) Spreng.) } \\
\text { White root disease }\end{array}$ & Fernando et al. (2016) \\
\hline 332. & $\begin{array}{l}\text { Rosellinia arcuata } \\
\text { Petch }\end{array}$ & Rosellinia arcuata Petch & $\begin{array}{l}\text { Tea (Camellia sinensis (L.) } \\
\text { Kuntze). Ring barking }\end{array}$ & Arulpragasm (1984) \\
\hline 333. & $\begin{array}{l}\text { Rosellinia arcuata } \\
\text { Petch }\end{array}$ & Rosellinia arcuata Petch & $\begin{array}{l}\text { Tea (Camellia sinensis (L.) } \\
\text { Kuntze) Black root rot }\end{array}$ & Gadd (1929) \\
\hline 334. & $\begin{array}{l}\text { Rosellinia arcuata } \\
\text { Petch }\end{array}$ & Rosellinia arcuata Petch & $\begin{array}{l}\text { Tea (Camellia sinensis (L.) } \\
\text { Kuntze). General wood rot }\end{array}$ & Gadd (1929) \\
\hline 335. & $\begin{array}{l}\text { Rosellinia bunodes (B } \\
\text { and Br.) Sacc. }\end{array}$ & $\begin{array}{l}\text { Rosellinia bunodes (Berk. } \\
\& \text { Broome) Sacc. }\end{array}$ & $\begin{array}{l}\text { Tea (Camellia sinensis (L.) } \\
\text { Kuntze). Black root rot }\end{array}$ & $\begin{array}{l}\text { Shunmuganathan and } \\
\text { Fernando (1967) }\end{array}$ \\
\hline 336. & $\begin{array}{l}\text { Sarocladium oryzae } \\
\text { (Sawada) W. Gams \& } \\
\text { D. Hawksw }\end{array}$ & $\begin{array}{l}\text { Sarocladium oryzae } \\
\text { (Sawada) W. Gams \& D. } \\
\text { Hawksw. }\end{array}$ & $\begin{array}{l}\text { Rice (Oryza sativa L.) } \\
\text { Sheath rot }\end{array}$ & $\begin{array}{l}\text { MIthrasena and } \\
\text { Wijesundera (1989) }\end{array}$ \\
\hline 337. & Sclerorium rolfsii Sacc. & $\begin{array}{l}\text { Athelia rolfsii (Curzi) } \\
\text { C.C. Tu \& Kimbr. }\end{array}$ & $\begin{array}{l}\text { Chlorophytum comosum } \\
\text { (C.P. Thunberg) H.A. } \\
\text { Jacques }\end{array}$ & $\begin{array}{l}\text { Kelaniyangoda et al. } \\
(2002)\end{array}$ \\
\hline 338. & Sclerorium rolfsii Sacc. & $\begin{array}{l}\text { Athelia rolfsii (Curzi) } \\
\text { C.C. Tu \& Kimbr. }\end{array}$ & $\begin{array}{l}\text { Cowpea (Vigna unguiculata } \\
\text { (L.) Walp. Collar rot }\end{array}$ & Wijethilke (2003) \\
\hline 339. & Sclerotium rolfsii Sacc. & $\begin{array}{l}\text { Athelia rolfsii (Curzi) } \\
\text { C.C. Tu \& Kimbr. }\end{array}$ & $\begin{array}{l}\text { Cabbage (Brassica oleracea } \\
\text { L.). White mould disease }\end{array}$ & Kularathna et al. (2018) \\
\hline 340. & Sclerotium rolfsii Sacc. & $\begin{array}{l}\text { Athelia rolfsii (Curzi) } \\
\text { C.C. Tu \& Kimbr. }\end{array}$ & $\begin{array}{l}\text { Bean (Phaseolus vulgaris } \\
\text { L.). Collar rot }\end{array}$ & $\begin{array}{l}\text { Sivasubramaniam and } \\
\text { Eriyagama (1998) }\end{array}$ \\
\hline
\end{tabular}




\begin{tabular}{|c|c|c|c|c|}
\hline 341. & $\begin{array}{l}\text { Sclerotium rolfosii } \\
\text { Sacc. }\end{array}$ & $\begin{array}{l}\text { Athelia rolfsii (Curzi) } \\
\text { C.C. Tu \& Kimbr. }\end{array}$ & $\begin{array}{l}\text { Peanut (Arachis hypogaea } \\
\text { L.) Southern blight or } \\
\text { Collar rot }\end{array}$ & $\begin{array}{l}\text { Abeygunawardhane } \\
(1969)\end{array}$ \\
\hline 342. & Sclerotium rolfsii Sacc. & $\begin{array}{l}\text { Athelia rolfsii (Curzi) } \\
\text { C.C. Tu \& Kimbr. }\end{array}$ & $\begin{array}{l}\text { Onion (Allium cepa L. } \\
\text { variety Poona red). Bulb rot }\end{array}$ & Ramanathan (1988) \\
\hline 343. & Sclerotium rolfsii Sacc. & $\begin{array}{l}\text { Athelia rolfsii (Curzi) } \\
\text { C.C. Tu \& Kimbr. }\end{array}$ & $\begin{array}{l}\text { Rubber (Hevea brasiliensis } \\
\text { (Willd. ex A.Juss.) Müll. } \\
\text { Arg.) Collar rot }\end{array}$ & Jayasinghe et al. (1988) \\
\hline 344. & Sclerotium rolfsii Sacc. & $\begin{array}{l}\text { Athelia rolfsii (Curzi) } \\
\text { C.C. Tu \& Kimbr. }\end{array}$ & $\begin{array}{l}\text { Tomato (Solanum } \\
\text { lycopersicon Mill.)) Collar } \\
\text { rot }\end{array}$ & Bopitiya et al. (2019) \\
\hline 345. & $\begin{array}{l}\text { Sclerotinia sclerotiorum } \\
\text { (Lib.) de Bary }\end{array}$ & $\begin{array}{l}\text { Sclerotinia sclerotiorum } \\
\text { (Lib.) de Bary }\end{array}$ & $\begin{array}{l}\text { Cabbage (Brassica oleracea } \\
\text { L.). White mould }\end{array}$ & $\begin{array}{l}\text { Mahalingam et al. } \\
(2018)\end{array}$ \\
\hline 346. & $\begin{array}{l}\text { Sclerotinia sclerotiorum } \\
\text { (Lib.) de Bary }\end{array}$ & $\begin{array}{l}\text { Sclerotinia sclerotiorum } \\
\text { (Lib.) de Bary }\end{array}$ & $\begin{array}{l}\text { Cabbage (Brassica oleracea } \\
\text { L.). Head rot }\end{array}$ & Guruge et al. (2015) \\
\hline 347. & $\begin{array}{l}\text { Septofusidium } \\
\text { elegantulum (Pidopl.) } \\
\text { W. Gams }\end{array}$ & $\begin{array}{l}\text { Septofusidium } \\
\text { elegantulum (Pidopl.) W. } \\
\text { Gams }\end{array}$ & $\begin{array}{l}\text { Water hyacinth (Eichhornia } \\
\text { crassipes Mart. Solms.) } \\
\text { Leaf spot }\end{array}$ & $\begin{array}{l}\text { Hettiarachchi et al. } \\
\text { (1983) }\end{array}$ \\
\hline 348. & $\begin{array}{l}\text { Septoria drummondii } \\
\text { Ellis \& Everh. }\end{array}$ & $\begin{array}{l}\text { Septoria drummondii Ellis } \\
\text { \& Everh. }\end{array}$ & Phlox drummondii Hook. & Bond (1947) \\
\hline 349. & Septoria lactucae Pass. & Septoria lactucae Pass. & $\begin{array}{l}\text { Lactuca sativa } \mathrm{L} . \\
\text { Leaf spot disease. }\end{array}$ & $\begin{array}{l}\text { P. Sivanathan, } \\
\text { Unpublished work }\end{array}$ \\
\hline 350. & $\begin{array}{l}\text { Septoria lycopersici } \\
\text { Speg. }\end{array}$ & Septoria lycopersici Speg. & $\begin{array}{l}\text { Tomato (Solanum } \\
\text { lycopersicon Mill.). Leaf } \\
\text { spot }\end{array}$ & $\begin{array}{l}\text { Abeygunawardhane } \\
(1969)\end{array}$ \\
\hline 351. & Septoria violae Westd. & $\begin{array}{l}\text { Septoria violae-palustris } \\
\text { Died }\end{array}$ & $\begin{array}{l}\text { Viola betonicifolia } \mathrm{Sm} . \\
\text { Septoria leaf spot }\end{array}$ & Bond (1947) \\
\hline 352. & $\begin{array}{l}\text { Sphaceloma fawcetti } \\
\text { var. scabiosa } \\
\text { McAlpine \& Tryon) } \\
\text { Jenkins }\end{array}$ & $\begin{array}{l}\text { Sphaceloma fawcettii var. } \\
\text { scabiosae (McAlpine \& } \\
\text { Tyron) Jenkins }\end{array}$ & $\begin{array}{l}\text { Orange (Citrus sp.) } \\
\text { Citrus scab }\end{array}$ & $\begin{array}{l}\text { N.K.B. Adikaram, } \\
\text { Unpublished work }\end{array}$ \\
\hline 353. & $\begin{array}{l}\text { Sphaerotheca pannosa } \\
\text { (Wallr.) Lév. }\end{array}$ & $\begin{array}{l}\text { Podosphaera pannosa } \\
\text { (Wallr.) de Bary }\end{array}$ & $\begin{array}{l}\text { Rose (Rosa chinensis } \\
\text { var. Ramblers). Powdery } \\
\text { mildew }\end{array}$ & $\begin{array}{l}\text { Herath, H.M.G.D. and } \\
\text { N.K.B. Adikaram, } \\
\text { Unpublished work }\end{array}$ \\
\hline 354. & $\begin{array}{l}\text { Tunstallia acueata } \\
\text { (Petch) Agni. }\end{array}$ & $\begin{array}{l}\text { Rossmania aculeata } \\
\text { (Petch) Lar.N. Vassiljeva }\end{array}$ & $\begin{array}{l}\text { Tea (Camellia sinensis } \\
\text { (L.) Kuntze) Thorny Stem } \\
\text { Blight }\end{array}$ & Agnihothrudu (1961) \\
\hline 355. & $\begin{array}{l}\text { Taphrina maculans E.J. } \\
\text { Butler }\end{array}$ & $\begin{array}{l}\text { Taphrina maculans E.J. } \\
\text { Butler }\end{array}$ & $\begin{array}{l}\text { Termeric (Curcuma longa } \\
\text { L.). Leaf spot }\end{array}$ & $\begin{array}{l}\text { Abeygunawardhane } \\
(1969)\end{array}$ \\
\hline 356. & $\begin{array}{l}\text { Thanatephorus } \\
\text { cucumeris (A.B. Frank) } \\
\text { Donk }\end{array}$ & $\begin{array}{l}\text { Rhizoctonia solani J.G. } \\
\text { Kühn }\end{array}$ & $\begin{array}{l}\text { Rubber (Hevea brasiliensis } \\
\text { (Willd. ex A. Juss.) Müll. } \\
\text { Arg.).Target leaf spot }\end{array}$ & Jayasinghe (1993) \\
\hline 357. & Tilletia ayresii Berk. & $\begin{array}{l}\text { Conidiosporomyces } \\
\text { ayresii (Berk.) Vánky \& } \\
\text { R. Bauer }\end{array}$ & $\begin{array}{l}\text { Panicum maximum Jacq. } \\
\text { Smut disease }\end{array}$ & $\begin{array}{l}\text { BPI 193202, BPI } \\
841322, \text { BPI } 870571 \\
\text { Collector Fagerlind F. }\end{array}$ \\
\hline 358. & $\begin{array}{l}\text { Thielaviopsis paradoxa } \\
\text { De Seynes) Höhn.) }\end{array}$ & $\begin{array}{l}\text { Ceratocystis paradoxa } \\
\text { (Dade) C. Moreau }\end{array}$ & $\begin{array}{l}\text { Pineapple (Ananas comosus } \\
\text { (L.) Merril) Black rot }\end{array}$ & Wijesinghe et al. (2010) \\
\hline 359. & $\begin{array}{l}\text { Trametes corrugate } \\
\text { (Pers.) Bres. }\end{array}$ & $\begin{array}{l}\text { Earliella scabrosa (Pers.) } \\
\text { Gilb. \& Ryvarden }\end{array}$ & $\begin{array}{l}\text { Tea (Camellia sinensis (L.) } \\
\text { Kuntze) Soft rot }\end{array}$ & $\begin{array}{l}\text { Senanayake et al. } \\
(2015)\end{array}$ \\
\hline 360. & $\begin{array}{l}\text { Uredo pseudocannae } \\
\text { Cummins }\end{array}$ & $\begin{array}{l}\text { Uredo pseudocannae } \\
\text { Cummins }\end{array}$ & $\begin{array}{l}\text { Canna (Canna indica L.) } \\
\text { Leaf rust disease }\end{array}$ & Adikaram et al. (2013) \\
\hline 361. & $\begin{array}{l}\text { Uromyces } \\
\text { appendiculatus (Pers.) }\end{array}$ & $\begin{array}{l}\text { Uromyces appendiculatus } \\
\text { (Pers.) Link }\end{array}$ & $\begin{array}{l}\text { Cowpea (Vigna sinensis } \\
\text { (L.) Savi ex Hausskn. } \\
\text { Current name: Vigna } \\
\text { unguiculata (L.) Walp.). } \\
\text { Rust disease }\end{array}$ & $\begin{array}{l}\text { Abeygunawardhane } \\
(1969)\end{array}$ \\
\hline
\end{tabular}




\begin{tabular}{|c|c|c|c|c|}
\hline 362. & $\begin{array}{l}\text { Uromyces } \\
\text { appendiculatus (Pers.) } \\
\text { Link }\end{array}$ & $\begin{array}{l}\text { Uromyces appendiculatus } \\
\text { (Pers.) Link }\end{array}$ & $\begin{array}{l}\text { French bean (Phaseolus } \\
\text { vulgaris L.). Rust disease }\end{array}$ & Jayasekara et al (2016) \\
\hline 363. & $\begin{array}{l}\text { Uromyces } \\
\text { appendiculatus (Pers.) } \\
\text { Link }\end{array}$ & $\begin{array}{l}\text { Uromyces appendiculatus } \\
\text { (Pers.) Link }\end{array}$ & $\begin{array}{l}\text { Dambala (S) Four-winged } \\
\text { bean, (Psophocarpus } \\
\text { tetragonolobus (L.) DC.) } \\
\text { Rust disease }\end{array}$ & $\begin{array}{l}\text { P. Sivanathan, } \\
\text { Unpublished work }\end{array}$ \\
\hline 364. & $\begin{array}{l}\text { Uromyces dianthi } \\
\text { (Pers.) Niessl }\end{array}$ & $\begin{array}{l}\text { Uromyces dianthi (Pers.) } \\
\text { Niessl }\end{array}$ & $\begin{array}{l}\text { Carnations (Dianthus } \\
\text { caryophyllus L.) Rust } \\
\text { disease }\end{array}$ & de Silva et al. (2005) \\
\hline 365. & Uromyces hobsoni Vize & Uromyces hobsonii Vize & $\begin{array}{l}\text { Jasminum multiflorum } \\
\text { (Burm.f.) Andrews Viz Leaf } \\
\text { rust }\end{array}$ & Adikaram et al. (2013) \\
\hline 366. & $\begin{array}{l}\text { Ustilago scitaminea } \\
\text { Sydow. }\end{array}$ & $\begin{array}{l}\text { Sporisorium scitamineum } \\
\text { (Syd.) M. Piepenbr., M. } \\
\text { Stoll \& Oberw. }\end{array}$ & $\begin{array}{l}\text { Sugarcane (Saccharum } \\
\text { officinarum L.) Smut } \\
\text { disease }\end{array}$ & Leelananda et al. (2000) \\
\hline 367. & $\begin{array}{l}\text { Ustulina zonata (Lév.) } \\
\text { Sacc. }\end{array}$ & $\begin{array}{l}\text { Kretzschmaria zonata } \\
\text { (Lév.) P.M.D. Martin }\end{array}$ & $\begin{array}{l}\text { Tea (Camellia sinensis (L.) } \\
\text { Kuntze). Charcoal root rot }\end{array}$ & Webster (1952) \\
\hline 368. & $\begin{array}{l}\text { Ustilaginoidea virens } \\
\text { (Cooke) Takah. }\end{array}$ & $\begin{array}{l}\text { Ustilaginoidea virens } \\
\text { (Cooke) Takah. }\end{array}$ & $\begin{array}{l}\text { Rice seeds (Oryza sativa } \\
\text { L.). } \\
\text { False smut }\end{array}$ & $\begin{array}{l}\text { N.K.B. Adikaram, } \\
\text { Unpublished work }\end{array}$ \\
\hline 369. & $\begin{array}{l}\text { Verticillium theobromae } \\
\text { (Turc.) E.W. Mason \& } \\
\text { S. Hughes }\end{array}$ & $\begin{array}{l}\text { Musicillium theobromae } \\
\text { (Turconi) Zare \& W. } \\
\text { Gams }\end{array}$ & $\begin{array}{l}\text { Banana (Musa acuminata } \\
\text { Colla). Crown rot }\end{array}$ & $\begin{array}{l}\text { Indrakeerthi and } \\
\text { Adikaram (2011) }\end{array}$ \\
\hline 370. & $\begin{array}{l}\text { Verticillium theobromae } \\
\text { (Turc.) E.W. Mason \& } \\
\text { S. Hughes }\end{array}$ & $\begin{array}{l}\text { Musicillium theobromae } \\
\text { (Turconi) Zare \& W. } \\
\text { Gams }\end{array}$ & $\begin{array}{l}\text { Banana (Musa acuminata } \\
\text { Colla). Cigar-end rot }\end{array}$ & Adikaram et al. (2019) \\
\hline 371. & Verticillium sp. Nees & Verticillium Nees & $\begin{array}{l}\text { Hyperparasite of } \\
\text { Coleosporium plumeriae } \\
\text { Pat. Temple tree (Plumeria } \\
\text { sp.) Leaf rust }\end{array}$ & $\begin{array}{l}\text { Adikaram and } \\
\text { Weeraratne (2006) }\end{array}$ \\
\hline 372. & $\begin{array}{l}\text { Xylaria thwaitesii Berk. } \\
\& \text { Cooke }\end{array}$ & $\begin{array}{l}\text { Xylaria thwaitesii Berk. \& } \\
\text { Cooke }\end{array}$ & $\begin{array}{l}\text { Rubber (Hevea brasiliensis } \\
\text { (Willd. ex A. Juss.) Müll. } \\
\text { Arg.). } \\
\text { Black root disease }\end{array}$ & Liyanage et al. (1977) \\
\hline
\end{tabular}

\section{Plant pathogenic Oomycota}

\begin{tabular}{|c|c|c|c|c|}
\hline 373. & $\begin{array}{l}\text { Albugo candida (Pers. } \\
\text { ex J.F. Gmel.) Kuntze }\end{array}$ & $\begin{array}{l}\text { Albugo candida (Pers. ex } \\
\text { J.F. Gmel.) Roussel }\end{array}$ & $\begin{array}{l}\text { Cabbage (Brassica oleracea } \\
\text { L.). White rust }\end{array}$ & $\begin{array}{l}\text { Abeygunawardhane } \\
\text { (1969) }\end{array}$ \\
\hline 374. & $\begin{array}{l}\text { Albugo candida (Pers. } \\
\text { ex J.F. Gmel.) Kuntze }\end{array}$ & $\begin{array}{l}\text { Albugo candida (Pers. } \\
\text { ex J.F. Gmel.) Roussel }\end{array}$ & $\begin{array}{l}\text { Mustard, Aba (S) } \\
\text { (Brassica juncea (L.) } \\
\text { Czern.). White rust } \\
\text { disease }\end{array}$ & $\begin{array}{l}\text { N.K.B. Adikaram, } \\
\text { Unpublished work }\end{array}$ \\
\hline 375. & $\begin{array}{l}\text { Peranospora parasitica } \\
\text { Chee }\end{array}$ & $\begin{array}{l}\text { Peronospora parasitica } \\
\text { (Pers.) Fr. }\end{array}$ & $\begin{array}{l}\text { Cabbage (Brassica oleracea } \\
\text { L.). Downy Mildew }\end{array}$ & $\begin{array}{l}\text { Abeygunawardhane } \\
\text { (1969) }\end{array}$ \\
\hline 376. & $\begin{array}{l}\text { Phytophthora botryosa } \\
\text { Chee }\end{array}$ & $\begin{array}{l}\text { Phytophthora botryose } \\
\text { Chee }\end{array}$ & $\begin{array}{l}\text { Rubber (Hevea brasiliensis } \\
\text { (Willd. ex A. Juss.) Müll. } \\
\text { Arg.) Leaf fall and pod rot. }\end{array}$ & Chee (1969) \\
\hline 377. & $\begin{array}{l}\text { Phytophthora botryosa } \\
\text { (Berk. \& M.A. Curtis) } \\
\text { Rostovzev }\end{array}$ & $\begin{array}{l}\text { Phytophthora botryose } \\
\text { Chee }\end{array}$ & $\begin{array}{l}\text { Cocoa (Theobroma cacao } \\
\text { L.). } \\
\text { Pod rot of cocoa }\end{array}$ & Chee and Wastie (1970) \\
\hline 378. & $\begin{array}{l}\text { Phytophthora capsici } \\
\text { Leonian }\end{array}$ & $\begin{array}{l}\text { Phytophthora capsici } \\
\text { Leonian }\end{array}$ & $\begin{array}{l}\text { Pepper (Piper nigrum L.) } \\
\text { Quick wilt }\end{array}$ & $\begin{array}{l}\text { Department of Export } \\
\text { Agriculture, Sri Lanka }\end{array}$ \\
\hline 379. & $\begin{array}{l}\text { Phytopthora cinnamomi } \\
\text { Rands }\end{array}$ & $\begin{array}{l}\text { Phytopthora cinnamomi } \\
\text { Rands }\end{array}$ & $\begin{array}{l}\text { Cinnomum (Cinnamomum } \\
\text { verum Presl.) Syn. } \\
\text { Cinnamomum zeylanicum } \\
\text { Blume.) Stripe canker }\end{array}$ & $\begin{array}{l}\text { Rajapakse and } \\
\text { Wasantha Kumara } \\
(2007)\end{array}$ \\
\hline
\end{tabular}




\begin{tabular}{ll}
\hline Phytophthora citricola & $\begin{array}{l}\text { Phytophthora citricola } \\
\text { Sawada }\end{array}$
\end{tabular}

380. Sawada

381. Phytophthora heveae A. Phytophthora palmivora
W. Thomps.
(E.J. Butler) E.J. Butler

\begin{tabular}{|c|c|c|}
\hline 382. & $\begin{array}{l}\text { Phytophthora infestans } \\
\text { (Mont.) de Bary }\end{array}$ & $\begin{array}{l}\text { Phytophthora infestans } \\
\text { (Mont.) de Bary }\end{array}$ \\
\hline
\end{tabular}

\begin{tabular}{|c|c|c|}
\hline 383. & $\begin{array}{l}\text { Phytophthora infestans } \\
\text { (Mont.) de Bary }\end{array}$ & $\begin{array}{l}\text { Phytophthora infestans } \\
\text { (Mont.) de Bary }\end{array}$ \\
\hline 384. & $\begin{array}{l}\text { Phytophthora } \\
\text { meadii McRae }\end{array}$ & $\begin{array}{l}\text { Phytophthora } \\
\text { meadii McRae }\end{array}$ \\
\hline 385. & $\begin{array}{l}\text { Phytophthora } \\
\text { meadii McRae }\end{array}$ & $\begin{array}{l}\text { Phytophthora } \\
\text { meadii McRae }\end{array}$ \\
\hline 386. & $\begin{array}{l}\text { Phytophthora } \\
\text { palmivora (E.J. Butler) } \\
\text { E.J. Butler }\end{array}$ & $\begin{array}{l}\text { Phytophthora palmivora } \\
\text { (E.J. Butler) E.J. Butler }\end{array}$ \\
\hline 387. & $\begin{array}{l}\text { Phytophthora } \\
\text { palmivora (E.J. Butler) } \\
\text { E.J. Butler }\end{array}$ & $\begin{array}{l}\text { Phytophthora palmivora } \\
\text { (E.J. Butler) E.J. Butler }\end{array}$ \\
\hline 388. & $\begin{array}{l}\text { Phytophthora } \\
\text { palmivora (E.J. Butler) } \\
\text { E.J. Butler }\end{array}$ & $\begin{array}{l}\text { Phytophthora palmivora } \\
\text { (E.J. Butler) E.J. Butler }\end{array}$ \\
\hline
\end{tabular}

\begin{tabular}{|c|c|c|c|c|}
\hline 389. & $\begin{array}{l}\text { Phytophthora } \\
\text { palmivora (E.J. } \\
\text { Butler) E.J. Butler }\end{array}$ & $\begin{array}{l}\text { Phytophthora palmivora } \\
\text { (E.J. Butler) E.J. Butler }\end{array}$ & $\begin{array}{l}\text { Rubber (Hevea brasiliensis } \\
\text { (Willd. ex A. Juss.) Müll. } \\
\text { Arg.) Black stripe or bark } \\
\text { rot }\end{array}$ & $\begin{array}{l}\text { Satchuthananthavale } \\
\text { (1971) }\end{array}$ \\
\hline 390. & $\begin{array}{l}\text { Phytophthora } \\
\text { palmivora (E.J. Butler) } \\
\text { E.J. Butler }\end{array}$ & $\begin{array}{l}\text { Phytophthora palmivora } \\
\text { (E.J. Butler) E.J. Butler }\end{array}$ & $\begin{array}{l}\text { Rubber (Hevea brasiliensis } \\
\text { (Willd. ex A. Juss.) Müll. } \\
\text { Arg.). Canker }\end{array}$ & $\begin{array}{l}\text { Seneviratne et al. (1995 } \\
\text { a \& b) }\end{array}$ \\
\hline 391. & $\begin{array}{l}\text { Phytophthora } \\
\text { palmivora (E.J. Butler) } \\
\text { E.J. Butler }\end{array}$ & $\begin{array}{l}\text { Phytophthora palmivora } \\
\text { (E.J. Butler) E.J. Butler }\end{array}$ & $\begin{array}{l}\text { Rubber (Hevea brasiliensis } \\
\text { (Willd. ex A. Juss.) Müll. } \\
\text { Arg.). } \\
\text { Phytophthora leaf fall and } \\
\text { pod disease }\end{array}$ & $\begin{array}{l}\text { Seneviratne et al. (1995 } \\
\text { a \& b) }\end{array}$ \\
\hline 392. & $\begin{array}{l}\text { Phytophthora } \\
\text { palmivora (E.J. Butler) } \\
\text { E.J. Butler }\end{array}$ & $\begin{array}{l}\text { Phytophthora palmivora } \\
\text { (E.J. Butler) E.J. Butler }\end{array}$ & $\begin{array}{l}\text { Papaya (Carica papaya L.) } \\
\text { Fruit rot }\end{array}$ & Adikaram et al. (1998) \\
\hline 393. & $\begin{array}{l}\text { Phytophthora } \\
\text { palmivora (E.J. Butler) } \\
\text { E.J. Butler }\end{array}$ & $\begin{array}{l}\text { Phytophthora palmivora } \\
\text { (E.J. Butler) E.J. Butler }\end{array}$ & $\begin{array}{l}\text { Papaya (Carica papaya L.) } \\
\text { Stem rot }\end{array}$ & Adikaram et al. (1998) \\
\hline 394. & $\begin{array}{l}\text { Phytophthora } \\
\text { palmivora (E.J. Butler) } \\
\text { E.J. Butler }\end{array}$ & $\begin{array}{l}\text { Phytophthora palmivora } \\
\text { (E.J. Butler) E.J. Butler }\end{array}$ & $\begin{array}{l}\text { Coconut palm (Cocos } \\
\text { nucifera L.). } \\
\text { Bud rot, nut fall and leaf } \\
\text { droop. }\end{array}$ & Mahindapala (1978) \\
\hline 395. & $\begin{array}{l}\text { Phytophthora } \\
\text { palmivora (E.J. Butler) } \\
\text { E.J. Butler }\end{array}$ & $\begin{array}{l}\text { Phytophthora palmivora } \\
\text { (E.J. Butler) E.J. Butler }\end{array}$ & $\begin{array}{l}\text { Cocoa (Theobroma cacao } \\
\text { L.). Black pod and canker }\end{array}$ & $\begin{array}{l}\text { Seneviratne et al. (1995 } \\
\text { a \& b) }\end{array}$ \\
\hline 396 & Phytophthora spp. & Phytophthora spp. & $\begin{array}{l}\text { Cluster onion (Allium cepa } \\
\text { L.). Bulb rot }\end{array}$ & $\begin{array}{l}\text { Araskesasry et al. } \\
(2016)\end{array}$ \\
\hline 397. & $\begin{array}{l}\text { Plasmopara viticola } \\
\text { (Berk. \& M.A. Curtis) } \\
\text { Berl. \& De Toni }\end{array}$ & $\begin{array}{l}\text { Plasmopara viticola } \\
\text { (Berk. \& M.A. Curtis) } \\
\text { Berl. \& De Toni } \\
\end{array}$ & $\begin{array}{l}\text { Grape (Vitis vinifera L.) } \\
\text { Downy mildew }\end{array}$ & $\begin{array}{l}\text { Ramanathan and } \\
\text { Sivapalan (1988). }\end{array}$ \\
\hline 398. & $\begin{array}{l}\text { Pseudoperonospora } \\
\text { cubensis (Berk. \& M.A. } \\
\text { Curtis) Rostovzev }\end{array}$ & $\begin{array}{l}\text { Pseudoperonospora } \\
\text { cubensis (Berk. \& M.A. } \\
\text { Curtis) Rostovzev }\end{array}$ & $\begin{array}{l}\text { Bitter gourd (Momordica } \\
\text { charantia L.). } \\
\text { Downy mildew }\end{array}$ & $\begin{array}{l}\text { Ratnayake et al. } \\
(2016 a)\end{array}$ \\
\hline 399. & $\begin{array}{l}\text { Pythium echinocarpum } \\
\text { S. Ito \& Tokun. }\end{array}$ & $\begin{array}{l}\text { Pythium echinocarpum S. } \\
\text { Ito \& Tokun. }\end{array}$ & $\begin{array}{l}\text { Cucurbita moschata } \\
\text { Fruit rot }\end{array}$ & $\begin{array}{l}\text { Kugathasan et al. } \\
\text { (2019) }\end{array}$ \\
\hline
\end{tabular}

Rubber (Hevea brasiliensis

(Willd. ex A.Juss.) Müll.

Arg.) Phytophthora leaf fall

Rubber (Hevea brasiliensis

(Willd. ex A.Juss.) Müll.

Arg.) Phytophthora leaf fall Black stripe

Potato (Solanum tuberosum

L.) Late blight

Babu et al. (2005)

Tomato (Solanum

lycopersicon Mill.) Late Rajapakse et al. (2007) blight

Rubber (Hevea brasiliensis

(Willd. ex A. Juss.) Müll.

Arg.). Black stripe

Anon (1994)

Rubber (Hevea brasiliensis

(Willd. ex A. Juss.) Müll.

Arg.). Leaf fall

Rubber (Hevea brasiliensis

(Willd. ex A. Juss.) Müll

Arg.). Black stripe

Dantanarayana et al.

(1984)

Durian (Durio zibethinus

L.) Phytophthora fruit rot

Atapattu et al. (2016)

Durian (Durio zibethinus

L.). Phytophthora root and

Atapattu et al. (2016)

Rubber (Hevea brasiliensis

ex A. Juss.) Mül.

Rubber (Hevea brasiliensis

(Willd. ex A. Juss.) Mül.

Phytophthora leaf fall and

Dantanarayana et al.

(1984)

Jayasuriya et al. (1999)

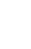




\begin{tabular}{|c|c|c|c|c|}
\hline 400. & $\begin{array}{l}\text { Pythium myriotylum de } \\
\text { Bary. }\end{array}$ & $\begin{array}{l}\text { Pythium myriotylum } \\
\text { Drechsler }\end{array}$ & $\begin{array}{l}\text { 'Kiriala' (Xanthosoma } \\
\text { sagittifolium (L.) Schott) } \\
\text { Corm rot }\end{array}$ & Tojo et al. (2005) \\
\hline 401. & $\begin{array}{l}\text { Pythium myriotylum de } \\
\text { Bary. }\end{array}$ & $\begin{array}{l}\text { Pythium myriotylum } \\
\text { Drechsler }\end{array}$ & $\begin{array}{l}\text { Ginger (Zingiber officinale } \\
\text { Roscoe). Rhizome rot }\end{array}$ & $\begin{array}{l}\text { P. Sivanathan, } \\
\text { Unpublished work }\end{array}$ \\
\hline 402. & Pythium ultimum Trow & $\begin{array}{l}\text { Globisporangium ultimum } \\
\text { (Trow) Uzuhashi, Tojo \& } \\
\text { Kakish. }\end{array}$ & $\begin{array}{l}\text { Tobacco (Nicotiana } \\
\text { tabacum L.). Damping-off }\end{array}$ & $\begin{array}{l}\text { Sumith and Bandara } \\
(2002) \text {. }\end{array}$ \\
\hline 403. & $\begin{array}{l}\text { Pythium vexans } \\
\text { Dreschl. }\end{array}$ & $\begin{array}{l}\text { Phytopythium vexans (de } \\
\text { Bary) Abad, de Cock, } \\
\text { Bala, Robideau, A.M. } \\
\text { Lodhi \& Lévesque }\end{array}$ & $\begin{array}{l}\text { Ginger (Zingiber officinale } \\
\text { Roscoe). Rhizome rot }\end{array}$ & $\begin{array}{l}\text { P. Sivanathan } \\
\text { Unpublished work }\end{array}$ \\
\hline 404. & Sclerospora sp. & Peronosclerospora sp. & $\begin{array}{l}\text { Papaya (Carica papaya } \\
\text { L.) Hyperparasite on } \\
\text { Asperisporium caricae }\end{array}$ & $\begin{array}{l}\text { Adikaram and Wijepala } \\
\text { (1995) }\end{array}$ \\
\hline
\end{tabular}

\section{DECLARATION OF CONFLICT OF INTEREST}

The authors declare that there is no conflict of interest.

\section{REFERENCES}

Abayasekara, C.L., Adikaram, N.K.B., Wanigasekara, U.W.N.P., Bandara, B.M.R. (2013). Phyllosticta musarum infection-induced defences suppress anthracnose disease caused by Colletotrichum musae in banana fruits cv 'Embul'. The Plant Pathology Journal 29 (1): 77-86.

Abeygunawardhana, D.V.W. (1969). Diseases in cultivated plants. Their diagnosis and treatment in Ceylon. The Colombo Apothecaries Co. Ltd., Colombo, 287 Pp.

Abeywickrama, K., Wijerathna, C., Rajapaksha, N., Sarananda, K. and Kannangara, S. (2012). Disease control strategies for extending storage life of papaya (Carica papaya), cultivars 'Red Lady' and 'Rathna'. Ceylon Journal of Science (Bio. Sci.) 41(1): 27-34.

Abeywickrama, K. and Bean, G.A. (1992). Cytotoxicity of Fusarium species mycotoxins and culture filtrates of Fusarium species isolated from the medicinal plant Tribulus terrestris to mammalian cells. Mycopathologia 120: 189-193.

Adikaram, N.K.B. (2004). Fungal taxonomy and current status of knowledge of fungi of Sri Lanka. National Workshop on Current Status of Lower Plants in Sri Lanka, 28 $8^{\text {th }}$ October 2004, Peradeniya (Abs).

Adikaram, N.K.B. (1986/87). A survey of postharvest losses in some fruits and vegetables and the fungi associated with them. Ceylon Journal of Science (Bio. Sci.) 19\&20: 1-10.

Adikaram, N.K.B., Jayasinghe, L. and Singh, D. (2019). Postharvest diseases and their management - Tropical fruits Part 11. Pineapple and banana. In: Dov Prusky and James Adaskaveg (Eds.), Postharvest Pathology of Fruits and Vegetables. American Phytopathological Society Press, USA (in press).

Adikaram, N.K.B. and Yakandawala, D.M.D.(2017). Brown patch disease of Zoysia turfgrass (Zoysia matrella (L.) Merr.) caused by Rhizoctonia solani Kuhn. Journal of Mycopathological Research 54(4): 523-526.

Adikaram, N.K.B., Vithanage, I.S.K. and Yakandawala D.
(2013). New rust diseases in three ornamental plant species in Sri Lanka. Tropical Agriculturist 161: 53-55. Adikaram, N.K.B., Ranawana, K.B. and Weerasuriya, A. (2007). Forest die-back in the Horton Plains National Park. Department of Wildlife Conservation, Sri Lanka, ISBN 95501580, 54 Pp.

Adikaram, N.K.B. and Weeraratne, T.P. (2006). Biology of Plumeria leaf rust disease caused by Coleosporium plumeriae. Ceylon Journal of Science (Bio. Sci.) 35(2): 157-162.

Adikaram, N.K.B., Mailewa, G. and Weerahewa, D. (2002). Changes in pigment composition, acid metabolism etc. in Pedilanthus tithimaloides leaf following powdery mildew infection. Journal of the National Science Foundation Sri Lanka 30 :1-11.

Adikaram, N.K.B., Weerasooriya, A. and Mahaliyanage, T.D. (2001). Occurrence of red thread disease in the grasses of Horton Plains National Park. Journal of the National Science Foundation Sri Lanka 29(3\&4): 117120.

Adikaram, N.K.B., Karunaratne, A.M., Indrakeerthi, S.R.P. and Menike, P.R. (1998). Resistance of immature papaya (Carica papaya L.) fruits to fungal infection: an overview. Proceedings of an International Workshop, Chiang Mai, Thailand, 18-21 May 1997, ACIAR Proceedings No. 80. Disease Resistance in Fruit, Pp.121-128.

Adikaram, N.K.B. and Karunaratne, A. (1998). Suppression of anthracnose and stem-end rot in avocado by endogenous antifungal substances and a natural inhabitant Pestalotiopsis sp. Proceedings of an International Workshop, Chiang Mai, Thailand, 18-21 May 1997, ACIAR Proceedings No. 80. Disease Resistance in Fruit, Pp. 72-77.

Adikaram, N.K.B. and Wijepala, M.(1995). Asperisporium black spot in Carica papaya: A new disease in Sri Lanka. Journal of the National Science Council Sri Lanka 23(4): 213-219.

Adikaram, N.K.B., Abhayawardhane, Y., Bandara, R., Gunathilaka, A.A.L. and Wijeratne, E.M.K. (1989). Antifungal activity, acid and sugar content in the wood apple (Limonia acidissima) and their relation to fungal development. Plant Pathology 38: 258-265.

Adikaram, N.K.B., Brown, A.E. and Swinburne, T.R. 
(1983). Observations on infection of Capsicum annuum L. fruit by Glomerella cingulata and Colletotrichum capsici. Transactions of British Mycological Society 80(3): 395-401.

Adikaram, N.K.B. and Theivendirarajah, K. (1981). Studies on the storage of avocado fruits and their spoilage organisms. Ceylon Journal of Science (Bio. Sci.) 14(1\&2): 83-87.

Agnihothrudu, Y. (1961). Note on fungi from NorthEast India VII. Tunstaliia gen. nov., causing 'Thorny Stem Blight of Tea' (Camellia sinensis O.Kuntze). Phytopathology. Z. 40: 277-282.

Alahakoon, P.W., Jayawardana, N.H., Madhushani, K.C. and Ruvini, R.H.A.W. (2010). Effectiveness of some fungicides and herbal extracts to control the powdery mildew (Oidium nephelii) in rambutan during wet and dry weather conditions. Annals of the Sri Lanka Department of Agriculture 12: 267-271.

Alahakoon, P.W., Jayawardana, N.H., Kalphashika, H.G. and Madushani, K.C. (2008). Development of environmentally friendly control method to minimize fruits rot diseases of guava (Psidium guava), using plant extracts. Annals of the Sri Lanka Department of Agriculture 10: 19-29.

Anon (1994). Identification and treatment of diseases of Hevea brasiliensis. International Rubber Research and Development Board, Hertford, U.K.

Anparasy, J., Rabeendran, N. and Raveendranath, S. (1994). Feasibility of using Trichoderma koningii and Captan in the control of onion disease caused by Fusarium solani. Proceedings of the $50^{\mathrm{st}} \mathrm{Annual}$ Sessions of the Sri Lanka Association for Advancement of Sciences 50(1): 94.

Anthony, S., Abeywickrama, K., Dayananda, R. Shanthi Wilson Wijeratnam and Arambewela, L. (2004). Fungal pathogens associated with banana fruit in Sri Lanka, and their treatment with essential oils. Mycopathologia 157(1): 91- 97.

Araskesasry, S.J., Bowleeswaran, B., P. Atputhachandran, S. Hearth and Balasooriya, B.G.R.C. (2016). A promising multiplier onion (Allium cepa) line with field resistance to major fungal diseases and possessing moderate flowering efficiency. Annals of Sri Lanka Department of Agriculture 18: 37-45.

Arulpragasam, P. V. (1990). Report on Plant Pathology Division. Technical Report. TRI Annual Report 8490.

Arulpragasam, P. V. (1989). Root diseases of tea, Tea Bulletin 8(1): 23-29.

Arulpragasam, P. V. (1989). Studies on the low country stem canker disease of tea in Sri Lanka. Ph.D. thesis, University of Kelaniya, Sri Lanka.

Arulpragasam, P. V. (1988). Report on Plant Pathology Division. Technical Report. TRI Annual Report 6879.

Arulpragasam, P. V. (1984). Ring barking of young tea plants in new clearings. Tea Quarterly 53: 4-10.

Arulpragasm, P.V. (1980). Lethal stem-canker of cinchona. Proceedings of the $36^{\text {st }}$ Annual Sessions of the Sri Lanka Association for Advancement of Sciences 36 (1), 32 (Abs.)
Atapattu, A., Mahanada, M.L.L.C., Dewage, D.S.K.P. and Rajapakse, R.P.K.C. (2016). Deaths of durian trees (Durio zibithinus) and its management in Gampaha district. DOI: 10.13140/RG.2.2.15042.22721

Babu, A.G.C., Mezeen, A.C.M., Karunasena, S. and Amarasena, B.G. (2005). Late blight resistant potato variety for cultivation in the upcountry wet zone (UCWZ) of Sri Lanka. Annals of the Sri Lanka Department of Agriculture 7:39 - 46.

Balasuriya, A. (2008). Common diseases of tea and their management. In: Handbook on Tea. Tea Research Institute of Sri Lanka, Talawakelle, Sri Lanka, pp. 173209.

Balasuriya, A. and Adikaram, N.K.B. (2009). Some spatial, temporal and spatio-temporal considerations of wood decay of tea (Camellia sinensis), caused by Nemania diffusa (Syn. Hypoxylon vestitum). Crop Protection 28(3): 273-279.

Balasuriya, A. and Adikaram, N.K.B. (2002). Extent of bush damage and resultant yield losses of a tea clone, susceptible to stem blight caused by Nemania diffusa. Sri Lanka Journal of Tea Science 67(1\&2): 21-31.

Bandara, R.H. and Attanayake, R.N. (2016). Phylogenetic complexity of Lasiodiplodia species found in Sri Lankan dry zone forests. In proceedings of the 16th Conference of the Science Council of the Asia, Colombo, Sri Lanka. 30th May - 1st June 2016. 221 (Abs).

Bandara, R.H., Deraniyagala, S.R.A.S. and Attanayake, R.N. (2016). Pleurostomophora richardsiae associated with decaying woods in a dry zone forest of Sri Lanka. In Proceedings of the International Research Symposium on Pure and Applied Sciences (IRSPAS 2016), Faculty of Science, University of Kelaniya, Sri Lanka. 16 (Abs).

Baroncelli, R., Amby, D.B., Zapparata, A., Sarrocco, S., Vannacci, G., Le Floch, G., Harrison, R.J., Holub, E. Sukno, S.A. andSreenivasaprasad, S. and Thon, M.R. (2016). Gene family expansions and contractions are associated with host range in plant pathogens of the genus Colletotrichum. BMC Genomics (2016) 17: 555 DOI 10.1186/s12864-016-2917-6

Berkeley, M. J. and Broom, C.E. (1871). The Fungi of Ceylon. Journal of Linnean Society London, xi, 494572.

Bogamuwa, S. and Karunaratne, A. (1985). The effect of four antagonists against Fusarium oxysporum causing fusarium rot of cucumber. Proceedings of the $32^{\text {nd }}$ Annual Sessions of the Sri Lanka Association for Advancement of Sciences 32(1): 53.

Bopitiya, B.D.S.S., Hewawitharana, N. and Edirisinghe, P. (2019). In vitro control of Sclerotium rolfsii causing stem rot disease in tomato using Trichoderma species and plant extracts. Proceedings of the SLAMPP Symposium on Plant Health, 30th August 2019, Oak Ray Hotel, Kandy, 17.

Bond, T.E.T. (1947). Notes on Ceylon fungi and plant diseases Part I (1 - 15). Ceylon Journal of Science (A) XII (4):171-193.

Cheanieha Q., A., Safeena, M.I.S. and Zakeel, M.C.M. (2016). Identification of suitable potential pathogens for biocontrol of water hyacinth [Eichhornia crassipes Mart. Solms]. 5th Annual Science Research Sessions 
2016, South Eastern University of Sri Lanka, Pp.231236.

Chee, K. H. (1969). Variability of Phytophthora species from Hevea brasiliensis. Transactions of the British Mycological Society 52: 425-436.

Chee, K. H. and Wastie, R. L. (1970). Black pod disease of cacao. Planter, Kuala Lumpur 46: 294-297.

Comstock, L.C. (2000). Eye spot. In: Philippe Rott. (Ed.). A Guide to Sugarcane Diseases CIRAD, 339 Pp.

Dahanayake, S. andWijesundera, R.L.C.(1994). Penicillium purpurogenum on fruits of Averrhoa bilimbi. Journal of the National Science Council Sri Lanka 22:23-24.

Damunupola, J.W., and Adikaram, N.K.B. (2000). Response of two pineapple cultivars to black rot disease caused by Thielaviopsis paradoxa. Proceedings of Annual Research Sessions, University of Peradeniya, Sri Lanka, 21 (Abs).

Dantanarayana, D. M., Peries, O. S. and Liyanage, A. de S. (1984). Taxonomy of Phytophthora species isolated from rubber in Sri Lanka. Transactions British Mycological Society 82(1): 113-126.

Department of Export Agriculture, Sri Lanka http://www. exportagridept.gov.lk/web/ index.php?option=com content\&view $=$ article \&id $=128 \&$ Itemid $=159 \&$ lang $=\overline{\text { en }}$ Accessed on 02. 05. 2019

Department of Export Agriculture, Sri Lanka http://www. exportagridept.gov.lk/weindex. php?option=com ent\&view $=$ article\&id $=137 \&$ Itemid $=159 \&$ lang $=\overline{\text { n }}$ Accessed on 02. 05. 2019.

de Silva, R.S.Y., Vithanage, K.D. and Kelaniyangoda, D.B. (2005). Import risk analysis (IRA) of Carnation. Annals of the Sri Lanka Department of Agriculture 7: 67-86.

Dharmasiri, M.A.N. (1988), Latent infection of immature papaya (Carica papaya) by Colletotrichum gloeosporioides. M.Phil. Thesis, University of Peradeniya, Sri Lanka.

Dissanayaka, D. M. S., Adikaram, N. K. B. and Yakandawala, D. M. D. (2016). Morphological and molecular characterization of Colletotrichum causing anthracnose in ripe avocado (Persea americana Mill.). Proceedings of The Peradeniya University International Research Sessions, iPURSE 2016, $4^{\text {th }}$ and $5^{\text {th }}$ November 2016. 20: 378 (Abs).

Dissanayake, N. and Wickramasinghe, D.B. (1999). Effect of N, P and K application on the occurrence and severity of narrow brown leaf spot in different rice varieties. In: Proceedings of the Annual Symposium of DOA, 267276.

Ferdinandez, H.S. Ranasinghe, C., Manamgoda, D.S., Salim, N. and Tennakoon, N.D. (2019). Molecular and phenotypic variations of Fusarium oxysporum f. sp. cubense associated with Panama disease of banana in Sri Lanka. Proceedings of the SLAMPP Symposium on Plant Health, 30th August 2019, Oak Ray Hotel, Kandy, 23.

Fernando, K.M.E.P. (2008). The host preference of a Ganoderma lucidum strain for three tree species of Fabaceae family; Cassia nodosa, Cassia fistula and Delonix regia. Journal of National Science Foundation Sri Lanka 36(4): 323-326.

Fernando, L. and Abeywickrama, L. (1996). Isolation of toxigenic fungi from commercially available medicinal plant material. Journal of National Council of Sri Lanka. 24(1): 80-88.

Fernando, T., Senaviratne, P., Siriwardane, D. and Madushani, H. (2016). White root disease of Murraya koenigii from Sri Lanka caused by Rigidoporus microporus. Journal of the National Science Foundation Sri Lanka 44(3): 347-348.

Gadd, C.H. (1936). Diseases of the tea bush - Root diseases and tea stumps. Tea Quarterly 9:102-107.

Gadd, C.H. (1929). Review of monthly reports of the Scientific Staff, Tea Research Institute. Tea Quarterly 2: 54-64.

Goonawardena, H. (1955). Stem Bleeding of Coconuts. Ceylon Coconut Quarterly VI, 89-96.

Gunawardana, A.G.K. and Bandara, J.M.R.S. (1993). Silver scurf disease of potato in Sri Lanka. Faculty of Agriculture, University of Peradeniya, Sri Lanka.

Gunawardena, Y.D.P., Qin, K.C.Y. and Nissom, P.M. (2019). Mycolytic bacteria as potential biocontrol agents against phytopathogenic fungi of Piper nigrum. Proceedings of the SLAMPP Symposium on Plant Health, 30th August 2019, Oak Ray Hotel, Kandy, 32.

Gunasekera, S. A, Liyanage, N. P. and Rice, T. V. (1985). Choanephora blight of winged bean flowers in Sri Lanka. Transactions of the British Mycological Society 85: 344-345.

Gunasekera, S.A., Shanthichandra, W.K.N and Price, T.V. (1990). Disease incidence, severity and pod yield of winged bean (Psophocarpus tetragonolobus) accessions and Psophocarus scandens. Tropical Pest Management 36(3): 207-210.

Guruge, B.M.A., Somachandra, K.P. and Attanayake, R.N. (2015). Sclerotinia sclerotiorum causing cabbage head rod in Sri Lanka. Proceedings of the 35th Annual Sessions of the Institute of Biology, 25th September 2015, 74.

Habarakada, R. and Seneviratne, S.N. de S. (1987). Alternaria brassicicola, a pathogen causing leaf diseases in crucifer vegetables. Proceedings of the $43^{\text {rd }}$ Annual Sessions of the Sri Lanka Association for Advancement of Sciences 43(1): 84.

Hawksworth, D. L. (1991). The fungal dimension of biodiversity: Magnitude, significance, and conservation. Mycological Research 95: 641- 655.

Herath, I.H.M.I.S., Manamgoda, D.S. and Udayanga, D. (2019). Morphological and molecular identification of fungal pathogens associated with cultivated rubber trees in Sri Lanka. Proceedings of the SLAMPP Symposium on Plant Health, 30th August 2019, Oak Ray Hotel, Kandy, 12.

Hettiarachchi, S., Gunasekera, S. A. and Balasooriya, I. (1983). Leaf spot diseases of water hyacinth in Sri Lanka. Journal of Aquatic Plant Management 21: 6265.

Hewage, L.C., Ekanayaka, H.M.R.K., Fernando, K.N.S., Nimalananda, N.P.H., Fernando W.M.R. and Weerasinghe, R.U. (2007). Insect, mite and diseases infestations in export foliage nurseries in Sri Lanka. Annals of the Sri Lanka Department of Agriculture 9: 227-232. 
Hunupolagama, D.M., Chandrasekharan, N., Kathriarachchi, H.S., Wijesundera, S. and Wijesundera, R.L.C. (2017). Unveiling members of the Colletotrichum acutatum Species Complex causing Colletotrichum leaf disease of Hevea brasiliensis in Sri Lanka. Current Microbiology 74(6): 747-756.

Hunupolagama, D.M., Wijesundera, R.L.C., Chandrasekharan, N.V., Wijesundera, W.S.S., Kathriarachchi, H.S., Fernando, T.H.P.S. (2015). Characterization of Colletotrichum isolates causing avocado anthracnose and first report of olletotrichum gigasporum infecting avocado in Sri Lanka. Plant Pathology \& Quarantine 5(2): 132-143.

Indrakeerthi, S.R.P. and Adikaram, N.K.B. (2011). Control of crown rot of banana using Carica papaya latex. Journal of the National Science Foundation Sri Lanka 39(2): 155-162.

Jayasekara, E.A.E.S.S., Somachandra, K.P., Gunasekara, W.M.S. Gunawardhana, K.K.N.N. and Somasiri, G A R. (2016). An action threshold and a fungicide spraying schedule for rust and angular leaf spot in bean. Annals of Sri Lanka Department of Agriculture. 18: 241-244.

Jayasinghe, C. and Fernando, T. (2009). First Report of Colletotrichum acutatum on Mangifera indica in Sri Lanka. Ceylon Journal of Science (Bio. Sci.) 38(1): 3134.

Jayasinghe, C., Silva, W. and Nishantha, N. (2009). Occurrence of Cylindrocladium quinqueseptatum Leaf Spot on Hevea brasiliensis in Sri Lanka. Ceylon Journal of Science (Bio. Sci.) 38(1): 27-30.

Jayasinghe, C.K. and Fernando, T.H. (2004). Reidentification and characterization of pathogens causing ugurassa (Flacourtia inermis) fruit anthracnose. Mycopathologia 157(1): 81-85.

Jayasinghe, C.K. (1999a). Pests and diseases of Hevea rubber and their geographical distribution. Bulletin of the Rubber Research Institute of Sri Lanka 40: 1-8.

Jayasinghe, C.K. (1999b). Rubber diseases to be cautious in the next millennium and strategies in prevention and control. Bulletin of the Rubber Research Institute of Sri Lanka 40: 32-38.

Jayasinghe, C.K. and Wijesundera, R.L.C. (1995). Invitro evaluation of fungicides against the clove isolate of Cylindrocladium quinqueseptatum. International Journal of Pest Management, 41: 219-223.

Jayasinghe, C.K. and Silva, W.P.K. (1994) Foot canker and sudden wilt of Hevea brasiliensis associated with Nattrassia mangiferae. Plant Pathology 43: 938- 940.

Jayasinghe, C.K. (1993). Natural occurrence of Thanatephorus cucumeris leaf spots on Hevea brasiliensis in Sri Lanka. Plant Pathology 42: 473-474.

Jayasinghe, C.K., Liyanage, A. de S. and Warnapura, S.S. (1988). Outbreaks and new records. Collar rot of rubber seedlings caused by Sclerotium rolfsii. FAO Plant Protection Bulletin 36: 189.

Jayasinghe, G.G., Liyanage, W. K., Wijayawardhana, M.W.G.C., Priyangika, K.M.M., Samaraweera, D. N., and Wijesinghe, K. G. G. (2017). A study of rough bark disease on cinnamon (Cinnamomum zeylanicum Blume); disease symptoms, development and the causal agent with special reference to its morphology, histopathology and nutritional statutes of affected plants. Proceedings of the symposium on minor export crops (Ed: B. Marambe) 16 - 17 March 2017, Peradeniya, Sri Lanka 63 - 72.

Jayasuriya, K. and Thennakoon, B. (2009). First report of Corynespora cassiicola on Codiaeum variegatum (croton) in Sri Lanka. Ceylon Journal of Science (Bio. Sci.) 36(2): 138-141.

Jayasuriya, K.E. and Thennakoon, B.I. (2007). Biological control of Rigidoporus microporus, the cause of white root disease in rubber. Ceylon Journal of Science (Bio. Sci.) 36: 9-16.

Jayasuriya, K.E., Wijesundera, R.L.C., Jayasinghe, C.K. and Thennakoon, B.I. (1999). A comparative study of Phytophthora meadii isolates from rubber (Hevea brasiliensis) plantations in Sri Lanka. Mycopathologia 147: $125-132$.

Jayawardana, W.A.D., Jayasekera, G.A.U., Wijesundera, R.L.C., Dissanayake, D.M.N., Sooriyapathirana, S.D.S.S., Weebadde, C.K., Perera, K.L.N.S., Gunapala, K.R.D. and Hettige, P. (2015). Evaluation of DNA markers linked to blast resistant genes, Pikh, Pit (p), and Pita, for parental selection in Sri Lankan rice breeding. Tropical Agricultural Research 26(1):82-93.

Jeyanandarajah, P. and Wijesooriya, M. (1997). Fungal infections in some foliage plants. Proceedings of the $42^{\text {rd }}$ Annual Sessions of the Sri Lanka Association for Advancement of Sciences 42(1): 53.

Jeyanandarajah, P. and Liyanage, T. (1995a). Fungi in seed crops of raddish (Ruphanus sativus L.) raised at Kandapola. Proceedings of the 51 $1^{\text {st }}$ Annual Sessions of the Sri Lanka Association for Advancement of Sciences 51(1): 48.

Jeyanandarajah, P. and Liyanage, T. (1995b). The occurrence of scurf fungus, Moniliochaetes infuscans Halst. Ex. Harter in sweet potato ((Ipomoea batatas).

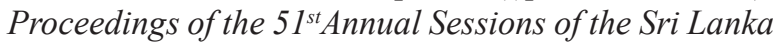
Association for Advancement of Sciences 51(1): 99.

Jeyanandarajah, P. (1990). Seed infections with Macrophoma phaseolina. Proceedings of the $37^{\text {th }}$ Annual Sessions of the Sri Lanka Association for Advancement of Sciences 37(1): 18.

Kanakaratne, N.S. and Adikaram, N.K.B. (1985). Preliminary investigations on the mango anthracnose. Proceedings of the 46th Annual Sessions of the Sri Lanka Association for Advancement of Sciences 41(1): 57.

Kariyawasam, J. (1996). Comparative efficacy of five fungicides to control charcoal rot disease in Sesame. Proceedings of the 46th Annual Sessions of the Sri Lanka Association for Advancement of Sciences 46(1): 47.

Karunanayake, K.O.L.C., Sinniah, G.D., Adikaram, N.K.B. and Abayasekara, C.L. (2015). Retention of latex at harvest enhances mango (Mangifera indica L.) fruit resistance and reduces anthracnose and stem-end rot. Australasian Plant Pathology 44(1): 113-119.

Karunanayake, L.C., Sinniah, G.D., Adikaram, N.K.B. and Abayasekara, C.L. (2014). Cultivar differences in antifungal activity and the resistance to postharvest anthracnose and stem-end rot in mango (Mangifera 
indica L.). Australasian Plant Pathology 43: 151-159.

Karunarathna, S.C., Udayanga, D., Maharachchikumbura, S.N., Pilkington, M., Manamgoda, D.S., Wijayawardene, D.N.N., Ariyawansa, H.A., Bandara, A.R., Chukeatirote, E., McKenzie, E.H.C. and Hyde, K.D. (2012). Current status of knowledge of Sri Lankan mycota. Current Research in Environmental \& Applied Mycology 2 (1): 18-29.

Kekulandara, D.S., Gunapala, K.R.D., Thilakarathne, N.S. and Deepika, K.A.G. (2016). Molecular breeding for improvement of blast and sheath blight resistance in Sri Lankan rice cultivar 'Pokuru samba'. Annals of Sri Lanka Department of Agriculture. 18: 96 - 98.

Kelaniyangoda, D.B., Nimalananda, N.P.S., Senaratne, A.C.U. and de Silva, R.S.Y (2002). Identification of plant pathogens associated with foliage nurseries. Annals of the Sri Lanka Department of Agriculture 4: 281-291.

Krishnapillai, N. and Wilson Wijeratnam, R.S. (2013). Aspergillus rot of ripe mangoes (Mangifera indica L.) var. 'Ambalavi', 'Willard' and 'Karuthakolomban'. Journal of the National Science Council Sri Lanka 41(1): 69-70.

Kugathasan, D., Sevve, P. and Jeyaseelan, E.C. (2019). Identification and management of fruit rot causing agent in Cucurbita moschata in Trincomalee district. Proceedings of the SLAMPP Symposium on Plant Health, 30th August 2019, Oak Ray Hotel, Kandy, 19.

Kularathna, K.D.M., Somachandra, K.P., Jayasekara, E.A.E.S.S. and Dissanayake, M.L.M.C. (2018). Strain Diversity and Host Range Variability of Sclerotinia sclerotiorum, the White Mould Pathogen of Cabbage. Annals of Sri Lanka Department of Agriculture 20: 4.

Kularatne, R.S (1997). Evaluation of a population of coffee Arabica cultivar Catimor for the response towards the leaf rust disease caused by Hemilleia vastatrix B \& Br. Proceedings of the $53^{\text {rd }}$ Annual Sessions of the Sri Lanka Association for Advancement of Sciences 53(1): 47.

Kuruppu, M., Jayawardhana, N.S. and Nilmini, R.A. (2019). Assessment of native Trichoderma species against Rigidoporus and Fusarium isolates pathogenic to jak trees. Annals of Sri Lanka Department of Agriculture 21: 119-123.

Leelananda, G., Dayatilake, G.A. and Sunil, H.K. (2000). Use of in vitro techniques for early screening of sugarcane lines against smut (Ustilago scitaminae) disease. Proceedings of the $56^{\text {th }}$ Annual Sessions of the Sri Lanka Association for Advancement of Sciences 56(1): 88 (Abs.)

Liyanage A. de S., Jayasinghe C.K., Liyanage N.I.S. and Jayaratne A. H. R. (1986). Corynespora leaf spot disease of rubber (Hevea brasiliensis): a new record. Journal of the Rubber Research Institute of Sri Lanka 65: 47-50.

Liyanage, N. I. S. (1989). Phytophthora citricola on rubber in Sri Lanka. Plant Pathology 38(3): 438-439.

Liyanage, N.I.S. and Peries, O.S. (1983). Distribution and spread of Rigidoporus lignosis on Hevea brasiliensis. Proceedings of the $39^{\text {th }}$ Annual Sessions of the Sri Lanka Association for Advancement of Sciences 32(1): 39.
Liyanage, A. de S. and Dantanarayana, D.M. (1983). Association of Fusarium solani with root lesions of rubber (Hevea brasiliensis) showing leaf wilt in Sri Lanka. Transactions of the British Mycological Society 80: $565-567$.

Liyanage, A. de S., Wettasinghe, S. and Dharmaratne, A. (1977). The distribution, spread and control of black root rot disease in Sri Lanka. Proceedings of the $34^{\text {th }}$ Annual Sessions of the Sri Lanka Association for Advancement of Sciences 33(1): 31.

Loos, C. A. (1951). Pathological problems. Tea Quarterly 22: $27-30$.

Loos, C. A. (1949). Technical report on blister blight situation, Ceylon II, the work in progress. Tea Quarterly 20: 105-109.

Madhupani, D.S. and Adikaram, N.K.B. (2017). Delayed incidence of stem-end rot and enhanced defenses in Aureobasidium pullulans-treated avocado (Persea americana Mill.) fruit. Journal of Plant Diseases and Protection 124(3): 227-234.

Madushani, H., Fernando, T., Wijesundara, R. and Siriwardane, D. (2014). First Report of white root disease of Artocarpus nobilis in Sri Lanka caused by Rigidoporus microporus. Journal of the National Science Foundation of Sri Lanka 42(2): 197-198.

Mahalingam, T., Guruge, B.M.A., Somachandra, K.P., Jayasekara, E.A.E.S.S., Rajapakse, C.S.K. and Attanayake, R.N. (2018). Phenotypic variation of cabbage white mold pathogen, Sclerotinia sclerotiorum in the upcountry commercial cabbage fields in Sri Lanka Journal of the National Science Foundation Sri Lanka 46(2): 159-164.

Maharachchikumbura, S. S. N., Chukeatirote, E., Guo L.D., Crous, P. W., Mckenzie, E. H.C. and Hyde, K. D. (2013). Pestalotiopsis species associated with Camellia sinensis (tea). Mycotaxon 123: 47-61.

Maharachchikumbura, S.S.N. and Adikaram, N.K.B. (2009). Occurrence of leaf blotch disease in (Botryosphaeria sp.) in Ficus religiosa in Sri Lanka. Ceylon Journal of Science (Bio. Sci.) 38(2): 51-56.

Mahendranathan, C., Wijesundera, R.L.C. and Adikaram, N.K.B. (2011). First report of Colletotrichum acutatum on anthracnose of peppers (Capsicum annum) in Sri Lanka. $18^{\text {th }}$ Australasian Plant Pathology Society Conference, Darwin, Australia, 119.

Mahendranathan, C., Terry, L.A. and Adikaram, N.K.B. (2010). Biological elicitation of resistance against anthracnose in aubergine. Acta Horticulturae 877: 1589-1595.

Mahindapala, R. (1978). Pest and diseases of coconut and their control. Ceylon Coconut Quarterly 29: 97-102.

Mithrasena, Y.J.P.K., Silva, J.N., Adikari, A.A.W.P., Weerasingha, W.M.S.K. and Sumanasingha, H.P.D. (2012a). Identification and management of brown leaf spot and grain discolouration diseases of rice (Oryza sativa L.) in Sri Lanka. Annals of the Sri Lanka Department of Agriculture 14: 77-86.

Mithrasena, Y.J.P.K., Wijesundera, W.S.S., Wijesundera, R.L.C., Wimalasiri, D.C. and Priyanthi, R.P.N. (2012b). Pathogenic and genetic diversity of Magneporthe oryzae populations from Sri Lanka. Rice Science 19: 
241-246.

Mithrasena, V.J.P.K. and Wijesundera, R.L.C. (1989). Factors affecting growth and sporulation of Sarocladium oryzae, the rice sheath blight pathogen. Proceedings of the 46th Annual Sessions of the Sri Lanka Association for Advancement of Sciences 45(1): 26.

Mulder, D. and Redlich, W. (1962). Results of a survey of red root disease (Poria hypolateritia) in Ceylon tea. Tea Quarterly 33: 141-145.

Nasla, M.F.F., Prasannath, K. and Gunapala, K. R. D. (2019). Exploring the efficacy of silicon supplementation on control of rice grain discoloration disease. Agrieast 13(1): $1-11$

Norris, R.V. (1930). Quarterly Report on the work of the Scientific Staff, Tea Research Institute. Tea Quarterly 3: 132-137.

Paranagama, P.A., Abeysekera, K.H.T., Abeywickrama, K., Nugaliyadde, L. (2003). Fungicidal and antiaflatoxigenic effects of the essential oil of Cymbopogon citratus (DC.) Stapf. (lemon grass) against Aspergillus flavus Link. isolated from stored rice. Letters in Applied Microbiology 37(1): 86-90.

Park, M. and Chandraratne, M.F. (1940). Recent research in Ceylon on the Frog Eye disease in cigarette tobacco. Tropical Agriculturist XCV, 19-21.

Pegler, D.N. (1986). Agaric flora in Sri Lanka. Kew Bulletin Additional Series XII. Kew, London: Royal Botanical Gardens.

Perera, N.A.T.T., Kelaniyangoda, D.B. and Salgadoe, A.S.A. (2013). Leaf spot diseases in banana (Musa spp.) and their control (in vitro). International Conference on Agriculture and Environment 2013, University of Ruhuna, Sri Lanka 287-290.

Peries, O.S. (1974). Ganoderma basal stem rot of coconut: A new record of the disease in Sri Lanka. Plant Disease Reporter 58(4):293-295.

Peries, O.S., Fernando, T.M. and Samaraweera, S.K. (1959). Control of white root disease of Hevea brasiliensis. Quarterly Journal of Rubber Research Institute of Ceylon 41: 81-89.

Petch, T. (1906). Descriptions of new Ceylon fungi. Annals of the Royal Botanic Gardens, Peradcniya 3:1-10.

Petch, T. (1910). Revision of Ceylon Fungi, Annals of Royal Botanic Gardens, Peradeniya, 4:299-444.

Petch, T. (1923). The Diseases of the Tea Bush. McMillan and Co. Ltd., London, 220 pp.

Petch, T. and Bisby, G.R. (1950). The fungi of Ceylon. Ceylon Government Press, Colombo, Ceylon 111Pp.

Priyantha, M.G.D.L., Jayasinghe, J.A.V.J. and Athukorala, A.R.J. (2015). Red ear rot disease - an emerging problem in maize cultivation in Sri Lanka. Annals of Sri Lanka Department of Agriculture 17: 37.

Priyantha, M.G.D.L., Piyadasa, S.G. Jayasinghe, J.V. and Kannangara, N.W.D.A.D. (2009). Occurrence of Phomopsis cane and leaf spot disease in grapes in Sri Lanka and its management. Annals of the Sri Lanka Department of Agriculture 11: 95-104.

Rajapakse, R.G.A.S. and Edirimanna, E.R.S.P. (2002). Management of bulb rot in big onion (Allium cepa L.) during storage using fungicides. Annals of the Sri Lanka Department of Agriculture 4: 319-326.
Rajapakse, R.G.A.S. and Fonseka, H. (2005). Evaluation of brinjal (Solanum melongena L.) germplasm for resistance to foot rot disease. Annals of the Sri Lanka Department of Agriculture 7: 369-374.

Rajapakse, R.G.A.S., Kahawatta, K.J.P. Wijesekara, S. and Ranathunga, R. (2007). Management of tomato leaf blight with fungicides. Annals of the Sri Lanka Department of Agriculture 9: 113-118.

Rajapakse, R.G.A.S., Ekanayake, R., Ranathunga, R. K., Perera R.N.I., Wijesekara, R.D.S.S., Ekneligoda, I.A., and Abekoon, S.A.M.R. (2006). Plant pathogens introduced to Sri Lanka through imported seed potato (Solanum tuberosum L.). Annals of the Sri Lanka Department of Agriculture 8: 371-377.

Rajapakse, R.G.A.S., Sakalasuriya, S.M.I.S.K., Kahawatta, J., Sumanapala, R.V., Edirimanna, E.R.S.P. (2005). Identification of races of Fusarium wilt pathogen of banana in Sri Lanka and selection of resistant germplasm. Annals of the Sri Lanka Department of Agriculture 7: 225-232.

Rajapakse, R.H.S. and Wasantha Kumara, K.L. (2007). A Review of Identification and management of pests and diseases of Cinnamon (Cinnamomum zeylanicum Blume). Tropical Agricultural Research \& Extension 10: $1-10$.

Rajapakse, R. G. A. S., Weerarathna, W. A. P. G. and Priyantha, M. G. D. L. (2003). In: P.B. Dharmasena, H. Samarathunge and M.S. Nijamudeen. (Eds.), Fifty Years of Research 1950-2000: Plant Pathological Research at Mahailluppallama. Field Crops Research and Development Institute, Department of Agriculture, Mahailluppallama, Sri Lanka.

Rabeendran, N. and Raveendranath, S. (1990). Testing the efficacy of some selected fungicides against Fusarium solani causing wilt in Jojoba plant (Simmondsia chinensis). Proceedings of the 46th Annual Sessions of the Sri Lanka Association for Advancement of Sciences 46(1): 122.

Ramanathan, N. and Sivapalan, A. (1988). Some observations on the downy mildew disease of grape vine caused by Plasmopara viticola in Jaffna. Journal of the National Science Foundation of Sri Lanka 16(1): 11-22.

Ramanathan, N., Sivakadacham, B. and Theivendirarajah, K. (1988). A new isolate of Sclerotium rolfsii Sacc. causing bulb rot in onion (Allium cepa L. variety Poona red). Journal of the National Science Foundation Sri Lanka 16(2): 183-194.

Ratnayake, R. M. R. N. K., Daundasekera, W. A. M., Ariyarathne, H. M., and Ganehenege, M. Y. U. (2016a). Soil application of potassium silicate reduces the intensity of downy mildew in bitter gourd (Momordica charantia L.) leaves. Ceylon Journal of Science (Bio. Sci.) 45(1): 23-31.

Ratnayake, R., Daundasekera, W.A.M., Ariyarathne, H.M., Ganehenege, M.Y.U. (2016b). Some biochemical defense responses enhanced by soluble silicon in bitter gourd-powdery mildew pathosystem. Australasian Plant Pathology 45(4):425-443.

Ravindranatha, S. and Kugathasan, S.M. (1990). Efficacy of different fungicides on purple blotch disease 
(Alternaria porri) of Red onion ((Allium ascolonicuma), Proceedings of the $46^{\text {th }}$ Annual Sessions of the Sri Lanka Association for Advancement of Sciences 46(1): 44.

Sabanayagam, J. V., Samarakoon, H.H. and Shanmuganathan, N. (1974). Susceptibility of some tea clones to stem canker caused by Macrophoma theicola Petch in the low country. Tea Quarterly 44: 74-78.

Samarajeewa, P.K. and Rathnayaka, R.M.U.S.K. (2004). Disease resistance and genetic variation of wild relatives of okra (Abelmoschus esculentum L.). Annals of the Sri Lanka Department of Agriculture 6: 167-176.

Sapumohotti, W.P. (1995). Frequency of sectoring of Fusarium oxysporum f. sp. Niveum, the causal organism of vascular wilt disease in watermelon. Proceedings of the $51^{\text {st }}$ Annual Sessions of the Sri Lanka Association for Advancement of Sciences 51(1): 102.

Satchuthananthavale, V. (1971). Black stripe or bark rot of Hevea. Quarterly Journal of the Rubber Research Institute of Ceylon 48: 125-135.

Senanayake, P.D., Mohotti, K. and Paranagama, P.A. (2015). Identification and substrate utilization of fungi associated with low country termite, Glyptotermes delatatus Bugnion \& Popoff and the host plant Camellia sinensis LO. Kuntza. Journal of the National Science Council Sri Lanka 44(2): 175-184.

Senevirathna, J.G.D.T. and Takayoki, T. (2009). Morphological and molecular identification of Fusarium verticillioides in Maize. Annals of the Sri Lanka Department of Agriculture 10:191-198.

Seneviratne, M.A.P.K., Liyanage, A, de S, and Adikaram, N.K.B. (1995a). Cultural, morphological and pathogenicity studies on some Phytophthora isolates from cocoa in Sri Lanka. Ceylon Journal of Science (Bio. Sci.) 24(2): 60-67.

Seneviratne, M.A.P.K., Liyanage, A de S. and Adikaram, N.K.B. (1995b). A model for predicting the black pod development in cacao under laboratory conditions. Ceylon Journal of Science (Bio. Sci.) 24(1): 2329.

Seneviratne, S.N. de S. and Jeyanandarajah, P. (2004). Rice diseases - problems and progress. Tropical Agricultural Research and Extension 7: 30-48.

Seneviratne S.N. de S. (1978). Rice diseases in Sri Lanka - Review. Proceedings of the $34^{\text {th }}$ Annual Sessions of the Sri Lanka Association for Advancement of Sciences 34(1): 19 (Abs.).

Shanmuganathan, N. and Rodrigo, W.R.F. (1966). Studies on collar and branch canker of young tea Phomopsis theae Petch I - Recent observations on disease incidence. Tea Quarterly 37: 221-228.

Shanmuganathan, N. (1965). Collar and branch canker in young tea caused by Phomopsis theae Petch. T. Tea Quarterly 36: 14-21.

Sinniah, G.D., Adikaram, N.K.B., Vithanage, I.S.K., Abayasekara, C.L., Maymon, M. and Freeman, S. (2013). First report of mango malformation disease caused by Fusarium mangiferae in Sri Lanka. Plant Disease 97(2): 427-429.

Sinniah, G.D., Adikaram N.K.B. and Abayasekara, C.L. (2012). First report of Cladosporium infection of mango inflorescence in the mid-country of Sri Lanka. Tropical Agriculturist 160: 139-148.
Sinniah G. (2010). Inflorescence diseases and natural disease resistance in mango in relation to anthracnose development'. Ph.D Thesis. University of Peradeniya, Sri Lanka.

Sivakumar, D., Wijeratnam, R.S.W., Wijesundera, R.L.C. and Abeyesekera, M. (1997). Postharvest diseases of rambutan (Nephelium lappaceum Linn.) in the Western Province of Sri Lanka. Journal of the National Science Council Sri Lanka 25: 225-229.

Sivanathan, S. and Adikaram, N.K.B. (1989). Biological activity of four antifungal compounds in immature avocado. Journal of Phytopathology 125(2): 97-109.

Sivanathan, S. and Adikaram, N.K.B. (1985). In vivo and in vitro toxin production by Macrophomina phaseolina. Proceedings of the 46th Annual Sessions of the Sri Lanka Association for Advancement of Sciences 41(1): 56.

Sivasubramaniam, A.S. and Eriyagama, K.T. (1998). Biological control of collar rot in beans caused by Sclerotium rolfsii using Trichoderma harzianum. Proceedings of the $54^{\text {th }}$ Annual Sessions of the Sri Lanka Association for Advancement of Sciences 54(1): 93.

Sumith, J. A. and Bandara, J. M. R. S. (2002). Effect of potassium on the development and severity of dampingoff in Tobacco (Nicotiana tabacum L.). Annals of the Sri Lanka Department of Agriculture 4: 319-326.

Thambugala, T.A.D.P. and Deshappriya, N. (2009). The role of Colletotrichum species on the Colletotrichum leaf disease of Hevea brasiliensis - a preliminary study. Journal of the National Science Foundation Sri Lanka 37(2): 135-138.

Tharangani, H.D.A., De Costa, D.M. and. Jayasinghe, G.G. (2019). Identification of fungal pathogens involved with rough bark disease of cinnamon. Proceedings of the SLAMPP Symposium on Plant Health, 30th August 2019, Oak Ray Hotel, Kandy, 14.

Tojo. M., Ono, H., Nakashima, C., Yoneyama, S. and Jayakody, J. A. S. (2005). First Report of Root Rot of Cocoyam Caused by Pythium myriotylum in Sri Lanka. Plant Disease 89(10): 1132.

Udugama, S. (2002). Septoria leaf spot disease of banana Mycosphaerella eumusae. Annals of the Sri Lanka Department of Agriculture 4: 337 - 343.

Vengadaramana, A. and Costa, D.M.D. (2015). Morphological and pathogenic variations of the causal organisms of leaf twister disease of red onion (Allium cepa L.) in Jaffna district of Sri Lanka. Tropical Agricultural Research 25(3):412-431

Vithanage, I.S., Adikaram N. an d Yakandawala D. (2014). Molecular and morphological characterization of Colletotrichum causing mango anthracnose in Sri Lanka. Proceedings of the Peradeniya University International Research Sessions, University of Peradeniya, $4^{\text {th }} \& 5^{\text {th }}$ July 2004, 18: 572.

Walker, J. (1972). Type studies on Gaeumannomyces graminis and related fungi. Transactions of the British Mycological Society 58:427-457.

Wanasinghe, U.U.T. and Damunupola, J.W. (2019). Efficacy of UV-C treatment on anthracnose disease control and postharvest quality enhancement of tomato. Proceedings of the SLAMPP Symposium on Plant Health, 30th August 
2019, Oak Ray Hotel, Kandy, 16.

Wanigasekara, U.W.N.P., Adikaram, N.K.B. and Abayasekara, C.L. (2014). Induced defences and delayed anthracnose development in banana fruits cv. 'Embul' treated at a pre-harvest stage with salicylic acid or Bion ${ }^{\circledR}$. Journal of the National Science Foundation Sri Lanka 42(2): 99-108.

Webster, B.N. (1952). Report on Pathological Division. TRI Bulletin 34: 45-49.

Weeraratne, W.A.P.G. and De Costa, D.M. (2018). Molecular identification of Fusarium spp. from wiltinfected tomato and brinjal plants in selected regions of Sri Lanka and endophytic bacteria as a potential option for disease management. Tropical Agricultural Research 30(1): 32 - 43.

Weeraratne, W.A.P.G., Nanayakkara, N.L.A.T.S., Anushika, A.D. and Darmadasa, D.D.D. (2016). Occurrence of anthracnose (Colletotrichum gloeosporioides Penz.) and rust (Goplana dioscoreae Cummins) diseases of Dioscorea in Sri Lanka. Annals of Sri Lanka Department of Agriculture. 18: 68-72.

Weeraratne, W.A.P.G., Wijerathne, W.M.S.D.K. and Dissanayake, D.M.K.K. (2019). Occurrence of Target Spot of Tomato caused by Corynespora cassiicola in Sri Lanka. Proceedings of the SLAMPP Symposium on Plant Health, 30th August 2019, Oak Ray Hotel, Kandy, 25.

Weeraratne, W.A.P.G. and Jayasinghe, J. A.V.J. (2006). Physoderma brown spot disease in hybrid Maize. Annals of the Sri Lanka Department of Agriculture 8: 273-279.

Weeraratne, W.A.P.G. and Priyantha, M. G. D. L. (2003). First report of Phoma black stem of sunflower in Sri Lanka and its management. Annals of the Sri Lanka Department of Agriculture 5: 263-270.

Wickramaarachchi, W.A.R.T. (2005). The effect of rhizobacteria on increasing plant growth and inducing systemic resistance in tomato against early blight disease. Annals of the Sri Lanka Department of Agriculture 7: 309-325.

Wickramaarachchi, W. A. R. T., Athauda A.A.T.R. and Dissanayaka, D.M.K. (2004). Evaluation of selected fungicides for controlling purple blotch disease of small onion. Annals of the Sri Lanka Department of Agriculture 6: 237-244.

Wickramasinghe, W.A.P.B., Yakandawala, D. and Adikaram, N.K.B. (2019). Morphological and molecular characterization of Colletotrichum causing anthracnose in Sri Lankan Begonia. Proceedings of the SLAMPP Symposium on Plant Health, 30th August 2019, Oak Ray Hotel, Kandy, p10 (Abs.).

Wijeratne, K.D.B.M., Adikaram, N.K.B. Yakandawala. D.M.D. and Yakandawala, K. (2016). Morphological and molecular characterization of Colletotrichum species causing anthracnose in Soursop (Annona muricata). Proceedings of $15^{\text {th }}$ Agricultural Research Symposium 1-5

Wijesekera, H.T.R., Wijesundera, R.L.C. and Rajapakse, C.N.K. (1996). Hyphal interactions between Trichoderma viridae and Ganoderma boninsense, the cause of coconut root and bole rot. Journal of the National Science Council Sri Lanka
24: 217-219.

Wijesinghe, C.J., Wilson Wijeratnam, R.S., Smarasekera, J.K.R. and Wijesundera, R.L.C. (2010). Biological control of Thielaviopsis paradoxa on pineapple by an isolate of Trichoderma asperellum. Biological Control 53: 285-290.

Wijesinghe, M.A.K and Rajapakse, P. (1997). Leaf twister disease in shallot onion Fusarium oxysporum f. sp. Cepae, Colletotrichum gloeosporioides. Proceedings of the 53 ${ }^{\text {rd }}$ Annual Sessions of the Sri Lanka Association for Advancement of Sciences 53(1): 50.

Wijesundera, R.L.C. and Kulatunge, S.M. (1993). Differences between three Poria hypolateria isolates in Sri Lanka. Journal of National Science Foundation Sri Lanka 21(2): 227-233.

Wijethilke, L.C. (2003). Biological control of collar rot of cowpea (Vigna inguiculata L.) Walp incited by Sclerotium rolfsii Sacc. Annals of the Sri Lanka Department of Agriculture 5: 299315. 